\title{
Biophysical coupling between turbulence, veliger behavior, and larval supply
}

\author{
by \\ Heidi L. Fuchs \\ B.S., University of Wisconsin - Madison (1990) \\ B.S., University of Wyoming (1999) \\ Submitted in partial fulfilment of the requirements for the degree of \\ Doctor of Philosophy in Biological Oceanography \\ at the \\ MASSACHUSETTS INSTITUTE OF TECHNOLOGY \\ and \\ WOODS HOLE OCEANOGRAPHIC INSTITUTION
}

September 2005

(C) Heidi L. Fuchs 2005. All rights reserved.

The author hereby grants to MIT and WHOI permission to reproduce and distribute publicly paper and electronic copies of this thesis document in whole or in part.

Author

MTI/WHOI Joint Program in Applied Ocean Science and Engineering 02 September 2005

Certified by .....

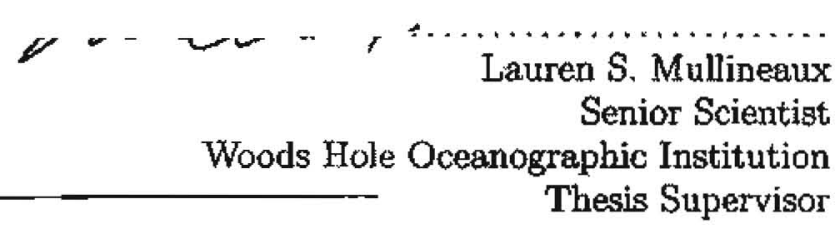

Accepted by 


\title{
Biophysical coupling between turbulence, veliger behavior, and larval supply
}

by

\author{
Heidi L. Fuchs \\ Submitted to the MIT/WHOI Joint Program in Applied Ocean Science and Engineering \\ on 02 September 2005 , in partial fulfillment of the \\ requirements for the degrees of \\ Doctor of Philosophy in Biological Oceanography
}

\begin{abstract}
The goals of this thesis were to quantify the behavior of gastropod larvae (mud snails Iyanassa obsoleta) in turbulence, and to investigate how that behavior affects larval supply in a turbulent coastal inlet. Gastropod larvae retract their velums and sink rapidly in strong turbulence. Turbulence-induced sinking would be an adaptive behavior if it resulted in increased larval supply and enhanced settlement in suitable coastal habitats.

In laboratory experiments, mud snail larvae were found to have three behavioral modes: swimming, hovering, and sinking. The proportion of sinking larvae increased exponentially with the turbulence dissipation rate over a range comparable to turbulence in a tidal inlet, and the mean larval vertical velocity shifted from upward to downward in turbulence resembling energetic nearshore areas.

The larval response to turbulence was incorporated in a vertical advection-diffusion model to characterize the effects of this behavior on larval supply and settlement in a tidal channel. Compared to passive larvae, larvae that sink in turbulence have higher near-bed concentrations throughout flood and ebb tides. This high larval supply enables behaving larvae to settle more successfully than passive larvae in strong currents characteristic of turbulent tidal inlets.

A study was conducted at Barnstable Harbor, MA to estimate the responses of larvae to turbulence in the field. Gastropod larvae from different coastal environments had genus-specific responses to turbulence, suggesting that larvae use turbulence for large-scale habitat selection. On ebb tides, mud snail larvae had a similar response to turbulence as in the laboratory, with greater sinking velocities in strong turbulence. Behavior estimates differed for flood and ebb tides, indicating that additional physical cues influence behavior. Turbulence-induced sinking behavior would enhance retention and promote settlement of mud snail larvae in habitats like Barnstable Harbor.
\end{abstract}

Thesis Supervisor: Lauren S. Mullineaux

Title: Senior Scientist

Woods Hole Oceanographic Institution 


\section{Acknowledgments}

I am grateful to my advisor Lauren Mullineaux for adopting me into her lab in my second year, for giving me the freedom to pursue this research, and for being such an excellent role model. Thanks also to my committee, Mike Neubert, Rudy Scheltema, Glenn Flierl, Danny Grünbaum, and Scott Gallager for all of their helpful suggestions. I'm grateful to Mike for his encouragement and for showing me how math should be taught. I'm grateful to Rudy for introducing me to the beautiful world of larvae, and for taking me to Antarctica. Thanks to Glenn for filling the post of MIT committee member, and for his many insightful comments. Thanks to Danny for his willingness to be on my committee and for several enlightening discussions about modeling. I'm grateful to Andy Solow for his kindness and patience; his input made my thesis better and gave me a real appreciation for statistics.

Thanks to Hal Caswell, Mike Neubert, and everyone in their labs for letting me attend lab meetings and Nantucket retreats; I learned a lot and was inspired by their great collaboration. Thanks also to John Trowbridge, Steve Elgar, Jim Lerczak, Sandy Williams, Gene Terray, and Britt Raubenheimer for their patience and willingness to explain to a biologist about turbulence and how to measure it.

My lab and field studies would have been impossible without help from many people. Jay Sisson provided technical assistance on many aspects of lab and field work, and saved the day more than once. Peter Schultz and Jim Thompson gave technical advice and did several dives to deploy/recover current meters. Stace Beaulieu and Nan Trowbridge also provided dive support. Three guest students Lynne Davies, Michael Workman, and Yuri Yamashita spent their summers laboring over my larvae. Ken Houtler, Matt Gould, Marga McElroy, Mark Dennett, Jonathan Murray, Carly Strasser, Tin Klanscek, Linda Kalnejais, and Rob Jennings drove boats and assisted with sampling on my many harbor cruises. Jim Lerczak, Rocky Geyer, Steve Elgar, Sandy Williams, Gene Terray, Lisa Levin, Wade McGillis, and Scott Gallager loaned me their instruments and equipment. Sean McKenna introduced me to the turbulence tank. Dave Kulis provided algae. Erik Anderson and Erich Horgan, and Jim Leichter gave helpful advice. Fabian Tapia, Rob Jennings, and Margaret Boettcher helped collect snaill egg capsules in the field. The Barnstable Harbormasters were helpful in selecting the field study sites, and Millway Marina provided a mooring.

Thanks to Lara, Rob, Carly, Diane, Susan, Stace, Fabian and Jim for being wonderful labmates. Thanks to Claudio DiBacco for being a great mentor. Thanks also to Ami Scheltema, Vicke Starczak, Nan Trowbridge, Gareth Lawson, and Kristin Gribble for making Redfield a friendlier place. Thanks to the WHOI Academic Program office - Julia, Marcia, 
John, and Judy - for taking such great care of us Joint Program students.

My deepest gratitude to the friends that made my time on the East Coast so enjoyable: Linda, Mea, Margaret, Joe, Sarah, Kristy, John, Jonathan, Jeff and Cara, Rose, Charlie, Rhea, Fabian, Heather and Michael, Jeff and Tetjana, Bea, Carlos and Jessica. Without them I might have run away long ago. Thanks also to my family.

Unpublished sections of this thesis hopefully will result in publications co-authored by Mike Neubert (Chapter 3) and by Andy Solow and Lauren Mullineaux (Chapter 4).

Financial support was provided by a National Science Foundation Graduate Research Fellowship, the WHOI Academic Programs Office, a WHOI Coastal Ocean Institute grant, a WHOI Mellon independent study grant to L. S. Mullineaux and M. G. Neubert, a Sea Grant New Initiative grant (Grant No. NA16RG2273, project no. R/O-38-PD), the WHOI Biology department, and the Rinehart Coastal Research Center. 


\section{Contents}

1 Introduction $\quad 9$

1.0 .1 Mud Snails . . . . . . . . . . . . . . . . 9

1.0 .2 Turbulence . . . . . . . . . . . . . . . . . . 10

1.0 .3 Thesis Overview . . . . . . . . . . . . . . 11

2 Sinking behavior of gastropod larvae (Ilyanassa obsoleta) in turbulence 15

3 Sinking in turbulence: Effects of larval behavior on larval supply and settlement in tidal currents $\quad \mathbf{2 9}$

3.1 Introduction . . . . . . . . . . . . . . . . . . 29

3.2 Model Descriptions . . . . . . . . . . . . . . . . . . . . . . 31

3.2 .1 Advection-Diffusion Model . . . . . . . . . . . . . 31

3.2 .2 Physical Parameters . . . . . . . . . . . . . . . . 32

3.2.3 Behavioral Parameters . . . . . . . . . . . . . . 35

3.2.4 Estimating Larval Supply and Settlement . . . . . . . . . . . . 35

3.2 .5 Particle-Tracking Model . . . . . . . . . . . . . . . 38

3.3 Results . . . . . . . . . . . . . . . . . . . . . . . . . 41

3.3 .1 Larval Supply . . . . . . . . . . . . . . . . . . . 41

3.3 .2 Settlement Success . . . . . . . . . . . . . . . . . 43

3.3.3 Advection-Diffusion vs. Particle Tracking model . . . . . . . . . . 48

3.4 Discussion . . . . . . . . . . . . . . . . . 48

3.4 .1 Larval Supply . . . . . . . . . . . . . . . . . . 48

3.4 .2 Settlement Success . . . . . . . . . . . . . . . . . . . 49

4 Larval behavior in turbulence: Maximum-likelihood estimates from field plankton distributions $\quad \mathbf{5 5}$

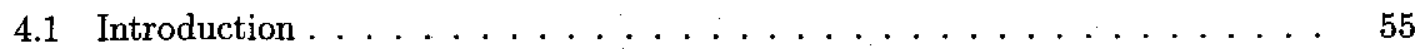


4.2 Methods . . . . . . . . . . . . . . . . . . 57

4.2 .1 Plankton Samples $\ldots \ldots \ldots \ldots \ldots \ldots$

4.2 .2 Current Measurements . . . . . . . . . . . . . . . 58

4.3 Analysis . . . . . . . . . . . . . . . . . . 59

4.3 .1 Current Measurements . . . . . . . . . . . . . . . 59

4.3.2 Advection-Diffusion Model . . . . . . . . . . . . . . . . 60

4.3.3 Maximum Likelihood Estimation of Behavior . . . . . . . . . . 61

4.3.4 Model assumptions . . . . . . . . . . . . . . . 64

4.4 Results . . . . . . . . . . . . . . . . . . 65

4.4 .1 Current Measurements . . . . . . . . . . . . . 65

4.4 .2 Plankton Profiles . . . . . . . . . . . . . . . 66

4.4.3 Maximum-Likelihood Behavior Estimates . . . . . . . . . 66

4.5 Discussion . . . . . . . . . . . . . . . . . . . 68

4.5 .1 Hydrodynamics . . . . . . . . . . . . . . . . 68

4.5 .2 Plankton Variability . . . . . . . . . . . . . . . . 69

4.5 .3 Larval Behavior . . . . . . . . . . . . . . . . . . 70

4.5 .4 Summary . . . . . . . . . . . . . . . . . 72

5 Summary and Conclusions $\quad 93$

5.1 Summary of Results . . . . . . . . . . . . . . . . . . 93

5.2 Evolutionary Context $\ldots \ldots \ldots \ldots \ldots \ldots \ldots$

5.3 Unanswered Questions and Future Work . . . . . . . . . . . . . . . 95

5.3.1 Laboratory vs. field estimates of behavior . . . . . . . . . . . . 95

5.3 .2 Omissions of the model . . . . . . . . . . . . . 96

5.3 .3 Future work . . . . . . . . . . . . . . 96

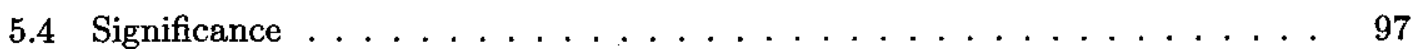

$\begin{array}{ll}\text { A Web appendix (Chapter 2) } & 101\end{array}$

B Diffusivity and Dissipation Estimates for Maximum Likelihood Analysis (Chapter 4) 


\section{Chapter 1}

\section{Introduction}

Many benthic invertebrates disperse via planktonic larvae whose behavior potentially influences large-scale settlement patterns. Larval dispersal and settlement are the result of coupled physical and biological processes. Larval behavior (swimming or sinking) allows larvae to transport themselves vertically, and vertical movement can affect the horizontal transport of larvae by positioning them in particular currents. Vertical swimming or sinking also affects the supply of competent larvae to bottom substrates prior to settlement. Larvae that respond opportunistically to environmental cues are more likely to settle in suitable coastal habitats.

Gastropod larvae sink in turbulence, and this behavior is expected to affect the supply of larvae to benthic habitats. I define larval supply as the concentration of larvae near the bottom, because near-bottom larvae are available for settlement. Larval supply is influenced not only by behavioral responses to small-scale turbulence, but also by larger scale vertical mixing. These complex biophysical interactions control the delivery of larvae to benthic habitats. My goal was to investigate the interactions between turbulence, larval behavior, and larval supply of intertidal gastropods.

\subsubsection{Mud Snails}

Mud snails (Ilyanassa obsoleta) were used as a model organism because they are significant and conspicuously abundant (Fig. 1-1) members of the intertidal community. Mud snails are benthic engineers - they rework sediments, ingest recently-settled larvae [4], and alter the distributions of other organisms through disturbance [2, 3] and competition. Mud snails are also infamous as the intermediate hosts of many duck and fish parasites [1], and as unwanted invaders of west coast habitats [5]. 


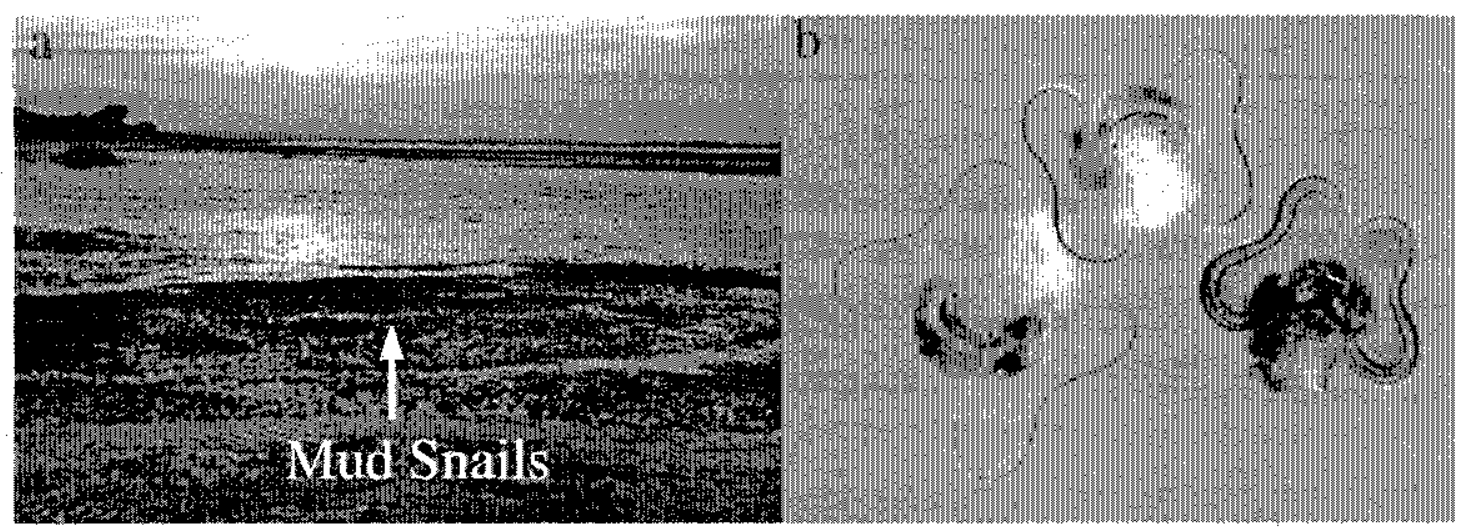

Figure 1-1: (a) Mud snail aggregations on intertidal flats of Barnstable Harbor, MA and (b) mud snail larvae that are ready to settle.

Mud snail larvae spend 1.5 to 4 weeks in the plankton before settling. When mud snail larvae are competent to metamorphose, they can select substrates for settlement over small scales [6]. Behaviors of mud snail larvae in the water column were unknown. This thesis describes the behavior of mud snail larvae in turbulence, and the potential effects of this behavior on larval supply and settlement.

\subsubsection{Turbulence}

Two aspects of turbulence are important in this thesis. The first is turbulence at the larval scale (mm's). Larvae interact with the smallest eddies, described by the Kolmogorov microscales $\eta$ (length scale), $\tau$ (time scale), and $v$ (velocity scale). These scales are related to the kinematic viscosity $\nu$ and the energy dissipation rate $\varepsilon[7]$ by

$$
\begin{aligned}
& \eta=\left(\frac{\nu^{3}}{\varepsilon}\right)^{\frac{1}{4}} \\
& \tau=\left(\frac{\nu}{\varepsilon}\right)^{\frac{1}{2}} \\
& v=(\nu \varepsilon)^{\frac{1}{4}} .
\end{aligned}
$$

The dissipation rate quantifies the transfer of turbulent kinetic energy to heat energy. Although energy is generated at large scales, it is passed to smaller scales when large eddies shed smaller eddies and so on (the energy cascade [e.g., 7]). The smallest eddies contain too little energy to overcome viscous forces, and the remaining energy is dissipated as heat. The 
dissipation rate is related to the total energy produced as well as the scales of the smallest eddies. I use $\varepsilon$ throughout this thesis to quantify the turbulence experienced by larvae.

The second important aspect of turbulence is the vertical mixing of larvae through the water column. Most larvae are able to swim or sink, but all larvae are diffused by turbulent eddies. Turbulent mixing of particles by eddies is described by the eddy diffusivity $K$. The relative strength of diffusivity vs. behavioral advection (swimming or sinking) determines the extent that behavior influences larval distributions.

\subsubsection{Thesis Overview}

The goals of this thesis were to quantify the sinking response of mud snail larvae as a function of turbulence, and to estimate the effects of this behavior on larval supply. In Chapter 2, I use a mixture model to quantify the behavior of competent larvae in laboratory-generated turbulence. In Chapter 3, I use an advection-diffusion model to characterize the effects of turbulence-induced sinking behavior on larval supply and settlement in tidal channels. In Chapter 4, I fit an advection-diffusion model to larval distributions in a tidal channel to estimate larval responses to turbulence in the field. 


\section{Bibliography}

[1] L.A. Curtis and L. E. Hurd. Age, sex, and parasites: spatial heterogeneity in a sandflat population of Ilyanassa obsoleta. Ecology, 64:819-828, 1983.

[2] T.H. DeWitt and J. S. Levinton. Disturbance, emigration, and refugia: how the mud snail, Ilyanassa obsoleta (Say), affects the habitat distribution of an epifaunal amphipod, Microdeutopus gryllotalpa (Costa). Journal of Experimental Marine Biology and Ecology, 92:97-113, 1985.

[3] R. Dunn, L. S. Mullineaux, and S. W. Mills. Resuspension of postlarval soft-shell clams Mya arenaria through disturbance by the mud snail Iyanassa obsoleta. Marine Ecology Progress Series, 180:223-232, 1999.

[4] J. H. Hunt, W. G. Jr. Ambrose, and C. H. Peterson. Effects of the gastropod, Ilyanassa obsoleta (Say), and the bivalve, Mercenaria mercenaria (L.), on larval settlement and juvenile recruitment of infauna. Journal of Experimental Marine Biology and Ecology, 108:229-240, 1987.

[5] M.S. Race. Competitive displacement and predation between introduced and native mud snails. Oecologia, 1982:337-347, 1982.

[6] R. S. Scheltema. Metamorphosis of the veliger larvae of Nassarius obsoletus (Gastropoda) in response to bottom sediment. Biological Bulletin, 120:92-109, 1961.

[7] H. Tennekes and J. L. Lumley. A First Course in Turbulence. MIT Press, 1972. 


\section{Chapter 2}

\section{Sinking behavior of gastropod larvae (Ilyanassa obsoleta) in turbulence}

by Heidi L. Fuchs, Lauren S. Mullineaux, and Andrew R. Solow

Reprinted from Limnology and Oceanography 49(6):1937-1948 


\title{
Sinking behavior of gastropod larvae (Ilyanassa obsoleta) in turbulence
}

\author{
Heidi L. Fuchs, ${ }^{1}$ Lauren S. Mullineaux, and Andrew R. Solow
}

Woods Hole Oceanographic Institution, Woods Hole, Massachusetts 02543

\begin{abstract}
Larvae of coastal gastropods sink in turbulence and may use nearshore turbulence as an initial settlement cue. Our objective was to quantify the relationship between turbulence and the proportion of sinking larvae for competent mud snail veligers (llyanassa obsoleta). We exposed larvae to a range of field-relevant turbulence conditions ( $\varepsilon=$ $8.1 \times 10^{-3}$ to $2.7 \times 10^{\circ} \mathrm{cm}^{2} \mathrm{~s}^{-3}$ ) in a grid-stirred tank, holding other factors constant. We used a video plankton reconder to record larval movements in still water and in turbulence. Larval trajectories and velocity measurements were extracted using video-image analysis. We also measured turbulent flow velocities independently, using laser Doppler velocimetry. To interpret empirical measurements in terms of larval behavior, we developed a threecomponent, normal mixture model for vertical velocity distributions of larvae in turbulence. The model was fitted to observed larval velocities by maximum likelihood, to estimate the proportions of sinking, hovering, and swimming larvae. Over the range of turbulence intensities found in typical coastal habitats, the proportion of sinking larvae increased exponentially $\left(r^{2}=0.89\right)$ with the $\log$ of the turbulence dissipation rate. The net mean behavioral velocity of the larvae shifted from positive to negative when the dissipation rate reached $\sim 10^{-1} \mathrm{~cm}^{2} \mathrm{~s}^{-3}$. By sinking when they enter turbulent, shallow water, competent larvae could improve their chances of settling in favorable coastal habitats.
\end{abstract}

Very little is known about how larval behavior in the plankton affects patterns of larval supply and settlement of benthic invertebrates. Much work has been done to describe larval behavior during the exploration of substrates, when larvae can sometimes select settlement sites over small scales (millimeters to centimeters). Less progress has been made on understanding the behavioral contribution while larvae are transported through the water column to benthic habitats. Under some hydrodynamic conditions, larvae could settle more successfully if they responded to waterbome cues by sinking toward the benthos. If the swimming velocity and gravitational sinking velocity differ by a factor of two or more, behavioral changes can significantly affect larval sink-

' Corresponding author (hfuchs@ whoi.edu).

Acknowledgments

Y. Yamashita helped collect and culture the larvae. We are grateful to J. Sisson for assistance with LDV measurements and to J. H. Trowbridge for guidance on spectral analysis. B. Raubenheimer and E. A. Terray also gave advice on flow data analysis. We thank C. DiBacco for generously sharing his culturing expertise and supplies, V. R. Starczak for advising us on the experimental design, and S. P. McKenna for introducing us to the turbulence tank. S, M. Gallager provided video equipment, software, and advice on particle tracking. M. G. Neubert, R. S. Scheltema, S. M. Gallager, G. R. Flierl, and D. Grïnbaum contributed to intellectual discussions. The tank was used by permission of W. R. McGillis. P. Alatalo, R. S. Scheltema, and M. R. Sengco loaned culturing equipment, and $M$. G. Neubert loaned a computer. D. M. Kulis supplied the algal stocks. S. E. Beaulieu, F J. Tapia, D. Grunbaum, R. Jennings, and two anonymous reviewers provided helpful comments on an earlier version of the manuscript.

The research was funded by a National Science Foundation graduate fellowship and a Woods Hole Oceanographic Institution Education fellowship to H.L.F. and a Woods Hole Oceanographic Institution Mellon Independent Study Award to L.S.M. and M. G. Neubert.

This is Woods Hole Oceanographic Institution contribution 11142 ing fluxes (Gross et al. 1992; Eckman et al. 1994) and the time it takes for larvae to reach the bottom (McNair et al. 1997). Yet, with a few exceptions (e.g., Pawlik and Butman 1993; Tamburri et al. 1996; Welch and Forward 2001), it is unknown whether larvae change their behavior in response to conditions in the water column.

Ciliated larvae are generally assumed to reach the bottom boundary layer as passive particles (Butman 1987; Abelson and Denny 1997), but passive deposition alone cannot explain some population distributions. In Barnstable Harbor, Massachusetts, mud snails (Ilyanassa obsoleta) are the most conspicuously abundant megafauna on the intertidal mud flats, yet their settlement in the harbor seems improbable, because swimming larvae have mean upward velocities $(\mathrm{H}$. L. Fuchs unpubl. data). Although swimming larvae are unlikely to be deposited on the bottom, sinking larvae bave a good chance of settling along with fine sand in the harbor, and a behavioral switch may explain the apparently successful settlement of mud snail larvae.

With heavy shells for ballast, gastropod larvae can alter their vertical flux by changing their mode of behavior from swimming to sinking. Veligers are weak, ciliary swimmers with dense shells, and their gravitational sinking velocities are greater in magnitude than their maximum swimming velocities in any direction (e.g., Hidu and Haskin 1978). When larvae switch from swimming to sinking mode, the advective component of vertical flux changes accordingly. Most settlement models assume a constant larval velocity, ignoring possible effects of behavioral changes on larval fluxes (but see Eckman et al. 1994). Yet laboratory observations (Crisp 1984; Young 1995) and field evidence (Barile et al. 1994) suggest that gastropod larvae pull in their velums and sink when disturbed, and this behavioral change may affect settlement dynamics.

Turbulence could provide an initial cue for larvae to sink and explore for settlement sites (Chia et al. 1981). Many larvae settle preferentially on particular sediments (Snel- 
Table 1. Representative dissipation rates for ocean regions.

\begin{tabular}{lll}
\hline \hline Location & $\varepsilon\left(\mathrm{cm}^{2} \mathrm{~s}^{-3}\right)$ & \multicolumn{1}{c}{ Source } \\
\hline Open ocean (mixed layer) & $10^{-7}-10^{-2}$ & Dillon and Caldwell (1980) \\
Continental shelf (mixed layer) & $10^{-5}-10^{-2}$ & Oakey and Elliott (1982) \\
Tidal channels and estuaries & $10^{-2}-10^{\circ}$ & Gross and Nowell (1985) \\
Surf zone & $10^{-1}-10^{2}$ & George et al. (1994) \\
\hline
\end{tabular}

grove et al. 1998) or in the presence of conspecifics (Scheltema et al. 1981) or chemical cues (Pawlik 1992; Tamburri et al. 1996). However, preferred settlement sites can only be detected near the bottom and over small spatial scales (tens of centimeters). In shallow nearshore areas, sinking larvae would have more contact with the bottom and more settlement opportunities than swimming larvae. There would be no settlement-related benefits for larvae that sink in deeper, offshore areas, away from suitable habitats. Turbulence dissipation rates generally increase from offshore to inshore regions (Table 1) and might indicate to larvae when they are entering potential habitat areas. We bypothesize that turbulence above some threshold level provides a primary settlement cue for mud snail larvae and that larvae respond to this cue by sinking more frequently. This is a behaviorally mediated deposition hypothesis: larvae are deposited in nearshore environments because the behavioral response to a hydrodynamic cue increases their sinking fluxes in coastal areas.

We conducted larval behavioral experiments in a gridstirred turbulence tank of the type used extensively in research on fluid turbulence (e.g., Hopfinger and Toly 1976; De Silva and Fernando 1994) and plankton feeding rates in turbulence (e.g., Saiz 1994; MacKenzie and Kiørboe 1995). Grid tanks are ideal for understanding larval behavior in

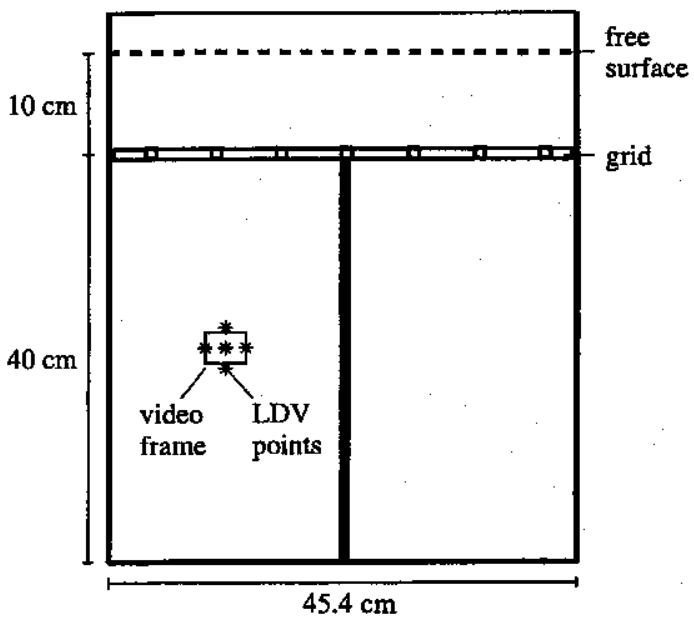

Fig. 1. Schematic of the turbulence tank as viewed from the side. The small rectangle indicates the location of video measurements, centered $19.1 \mathrm{~cm}$ from the bottom and $11 \mathrm{~cm}$ from the outer walls. Asterisks indicate the locations of LDV measurements. water-column turbulence, because they lack a developed boundary layer and substrate-related settlement cues. Larvae are not induced to explore or attach to substrates in such tanks, and their observed activities are representative of behavior in the water column.

\section{Materials and methods}

Larval cultures-Mud snail (I. obsoleta) egg capsules were collected at Barnstable Harbor on 30 June 2002 and divided into 12-liter buckets of filtered seawater in a $20^{\circ} \mathrm{C}$ culture room. Larvae hatched out over $10 \mathrm{~d}$ and were sieved daily into fresh culture buckets. Cultures were continually aerated, and seawater was changed every other day. The larvae were fed $\sim 10^{5}$ cells $\mathrm{ml}^{-1}$ of lsochrysis galbana and Thalassiosira pseudonana. Experiments were done in the culture room, so that larvae experienced consistent environmental conditions. Experiments began when larvae reached $24 \mathrm{~d}$ of age and were competent to metamorphose.

Turbulence tank-Our experiments were done in a 103liter, grid-stirred turbulence tank (Fig. 1). The grid was centered at $40 \mathrm{~cm}$ from the bottom of the tank and $10 \mathrm{~cm}$ from the free surface, and was stirred from below with an oscillation amplitude of $11.34 \mathrm{~cm}$. McKenna (2000) provides a detailed description of the tank. All measurements were made at a point far enough from the grid to be in an area of homogeneous, nearly isotropic turbulence (De Silva and Fernando 1994), and as far as possible from any boundaries. Turbulence intensity was proportional to grid oscillation frequency, which was controlled by setting the voltage. The turbulent Reynolds number $R_{e}$ Hr (see Table 2 for a description of symbols) was calculated as in Hopfinger and Toly (1976), with empirical constants given in McKenna (2000). Treatment levels were $R e_{\mathrm{HT}}=(100,200,300,400,500$, 600 ), corresponding to the turbulence dissipation range expected in tidal inlets. In our measurement volume, there was a slight $\left(<10 \mathrm{~mm} \mathrm{~s}^{-1}\right)$ downward mean flow due to the weak circulation generated by grid motion (McDougall 1979; McKenna 2000). Mean flow was accounted for in our analysis of larval behavior (see "Analysis" section).

Experimental design-Behavioral experiments were replicated six times with 24-d-old, competent larvae, and no larvae were reused. For the last replicate, only 27 -d-old larvae were available. In each replicate, the turbulence tank was filled with $0.2 \mu \mathrm{m}$ filtered seawater, at a temperature within $\pm 1^{\circ} \mathrm{C}$ of room temperature. Several thousand larvae were gently added to the tank, along with $\sim 2.5 \times 10^{4}{\text { cells } \mathrm{ml}^{-1}}^{-1}$ of food. Because of human error, no food was added in replicate 3. 
Table 2. List of symbols. All velocities are vertical, with positive upwards.

\begin{tabular}{ll}
\hline \hline Symbol & \multicolumn{1}{c}{ Description } \\
\hline$\ell$ & Eddy length scale \\
$p_{i}$ & Probability density of $w_{\mathrm{L}}$ in mode $i$ in still water \\
$P$ & Total probability density of $w_{\mathrm{L}}$ in still water \\
$p_{T^{\prime}}$ & Probability density of $w_{\mathrm{L}}$ in mode $i$ in turbulence \\
$P_{T}$ & Total probability density of $w_{\mathrm{L}}$ in turbulence \\
$R e_{\mathrm{HT}}$ & Theoretical turbulent Reynolds number \\
$W_{o}$ & Flow velocity [ $\left(\sim N\left(\mu_{o r} \sigma_{o}^{2}\right)\right]$ \\
$W_{i}$ & Larval behavioral velocity in mode $i\left[\sim N\left(\mu_{\mathrm{r}}, \sigma_{i}^{2}\right)\right]$ \\
$W_{T}$ & Larval relative velocity in mode $i\left[\left(\sim N\left(\mu_{T}, \sigma_{T}^{2}\right)\right]\right.$ \\
$w$ & Observed flow velocity \\
$\langle w\rangle$ & Mean flow velocity $\left(=\mu_{o}\right)$ \\
$w_{\mathrm{L}}$ & Observed larval velocity \\
$\left\langle w_{\mathrm{L}}\right\rangle$ & Net mean behavioral velocity \\
$\Delta w_{\mathrm{L}}$ & Behavioral velocity range \\
$w^{\prime}$ & RMS flow velocity from direct estimate \\
$\hat{w}^{\prime}$ & RMS flow velocity from spectral estimate $\left(\approx \hat{\sigma}_{o}\right)$ \\
$w_{\mathrm{HT}}^{\prime}$ & RMS flow velocity from empirical relationships \\
$w_{M \mathrm{~L}}^{\prime}$ & RMS flow velocity from maximum likelihood $\left(=\sigma_{o}\right)$ \\
$\alpha_{i}$ & Proportion of larvae in mode $i$ in still water \\
$\alpha_{T^{\prime}}$ & Proportion of larvae in mode $i$ in turbulence \\
$\varepsilon$ & Turbulence dissipation rate \\
$\eta$ & Kolmogorov length scale \\
$\nu$ & Kinematic viscosity of seawater $\left(=0.01 \mathrm{~cm}{ }^{2} \mathrm{~s}^{-1}\right)$ \\
$\sigma_{n}^{2}$ & Measurement noise variance \\
\hline &
\end{tabular}

In each replicate, the larvae were exposed to alternating periods of calm water and turbulence ( $\mathrm{Fig}, 2$ ). After an initia acclimation period, video measurements were collected with no flow in the tank. Then six turbulence treatments were administered in a randomized sequence determined by a Latin square. Rest periods between treatments allowed larvae to regain their calm-water behavior. Video measurements were collected using an analog video plankton recorder. The video frame was $3 \times 4 \mathrm{~cm}$ with an estimated $2-\mathrm{cm}$ depth of field and was illuminated by an infrared spotlight $(\lambda=800$ $\mathrm{nm})$. Larvae were already acclimated to the ambient room lighting, so no light-related behavioral changes were expected during the experiments.

Before each replicate, a subsample of larvae was removed from the culture. Larval competency was verified by putting larvae in a petri dish with Barnstable Harbor sediment (Scheltema 1961); most stopped swimming and burrowed into the sediment within $3.5 \mathrm{~h}$ and metamorphosed within $24 \mathrm{~h}(n=25)$. Other larvae were killed with a few drops of ethanol for fall-velocity measurements. Dead larvae with retracted velums were pipetted gently into the top of a 2-liter glass cylinder ( $45 \mathrm{~cm}$ tall, $7.7 \mathrm{~cm}$ diameter) filled with roomtemperature seawater. Larvae were timed $(n=20)$ as they fell through a $12.5-\mathrm{cm}$ distance near the bottom of the cylinder. We also anaesthetized larvae using $\mathrm{MgCl}_{2}$ and attempted to measure their fall velocities with velums extended, but these larvae often recovered their mobility in the seawater column. Larval shell lengths were measured $(n=$ 10) using a compound microscope with an optical micrometer.

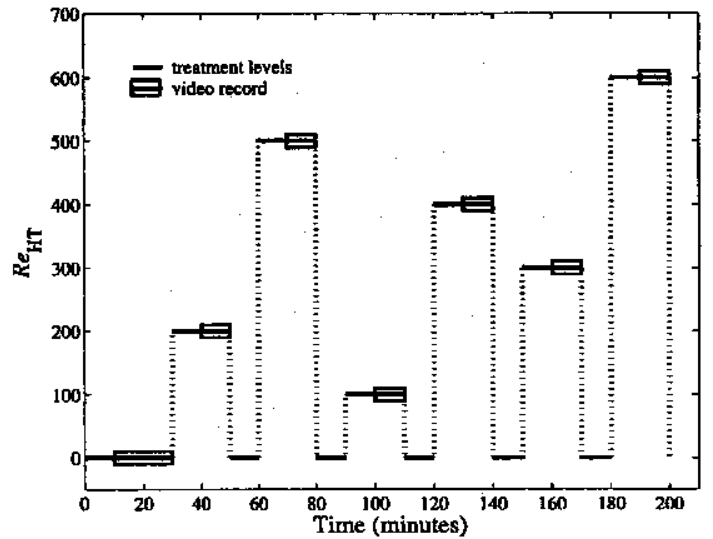

Fig. 2. Schematic of turbulent Reynolds number $R e_{\mathrm{rr}}$ vs. time in behavioral experiments. Turbulence became stationary in this tank after $\sim 5 \mathrm{~min}$ of grid oscillation. Solid lines show the duration of each turbulence treatment, and rectangles indicate when the video record was taken. Rest periods are shown between turbulence treatments. This example is from replicate 1 .

Flow velocity measurements-Flow velocities were measured with a Dantec two-axis laser Doppler velocimeter (LDV) after all larval experiments were completed, to avoid any interference of the laser or seeding particles with larval behavior. LDV is not ideal for turbulence measurements in near-zero mean flow (see "Results") but was the best instrument for measuring velocity remotely. The tank was filled with filtered seawater and heavily seeded with $10-\mu \mathrm{m}$ hollow glass spheres (density $=1.05 \mathrm{~g} \mathrm{~cm}^{-3}$ ). After 10 min of initial grid oscillation, vertical and horizontal velocities were measured ( $n=2,000-10,000$ records) by LDV at five points in the focal plane of the larval video frame (Fig. 1). Flow measurements were made at each turbulence treatment level in a randomized order and then were replicated for the center point only.

Larval velocity measurements - Larval video records were digitized using an EPIX PICXI SV5 image capture board with XCAP-Std software. Each 20-min still-water video segment was digitized into 40 50-frame sequences at 2 frames $\mathrm{s}^{-1}$ (fps). The turbulent video segments were digitized into 30 sequences per treatment replicate at 5 and 10 fps for $R e_{\mathrm{HT}}$ $\leq 200$ and $R e_{\mathrm{HT}}>200$, respectively. The sequence length was limited by image buffer size, and capture intervals were selected so that movements of individual larvae could be followed easily from frame to frame.

Image sequences were processed digitally, to measure the larval vertical velocities. Larval centroid positions were found using Matlab software (provided by S. M. Gallager) and linked into larval trajectories using a Matlab algorithm based on distance and distance/direction correlations. Travel distances were determined from a grid visible in the video frame. The grid-spacing distance was calibrated with a ruler placed in the focal plane, to account for perspective. Im- 
probable trajectory segments were removed manually. For each no-flow replicate, we obtained between 100 and 300 larval trajectories. For each turbulence treatment replicate, we obtained several hundred to 2,000 trajectories. To use only independent velocity measurements, we took the velocity for a single frame-to-frame step from each trajectory, using the step beginning closest to the center of the video frame. A few outliers ( $<2 \%$ of the samples) were removed for the statistical analysis.

The software did introduce a potential bias by splitting crossed trajectories. Hovering and swimming larvae move more slowly than sinking larvae, and slow-moving larval tracks had more steps and a greater likelihood of being split. The result was an artificial increase in the number of measurements, particularly for hoverers and swimmers. Because this bias was unlikely to add support to our hypothesis, we considered it an acceptable observation error

\section{Analysis}

Turbulence-To avoid disturbance of larvae during the experiments, we estimated turbulence characteristics from separate LDV measurements, from relationships of grid-tank dynamics, and from larval velocity measurements. LDV measurements were used to calculate the mean vertical flow velocity $\langle w\rangle$ and root-mean-square (rms) vertical velocity $w^{\prime}$ using unbiased approximations for a burst-sampled process (Buchave et al. 1979). The spectrum of the velocity time series was estimated with a block-averaged, discrete periodogram for randomly sampled data (Chan et al, 1998). We estimated the noise variance $\sigma_{n}^{2}$ and velocity variance $\hat{\sigma}_{o}^{2}$ contributions from the spectrum (Voulgaris and Trowbridge 1998). The spectral rims velocity $\hat{w}^{\prime}$ is $\sim \hat{\sigma}_{0}^{z}$. Relationships of grid-tank dynamics were used to calculate the theoretical mns vertical velocity $w_{\mathrm{HT}}^{\prime}$ using the formulation in Hopfinger and Toly (1976) with empirical constants given in McKenna (2000). This estimate of $w_{\mathrm{HT}}^{\prime}$ is a function of grid geometry and forcing conditions and is linearly related to $R e_{\mathrm{Hrr}}$. Larval velocity measurements were used to estimate statistically the fluid velocity variance ( $\left.\sigma_{a}^{2}\right)$ during each replicate of the larval experiments. Maximum-likelihood estimates (MLEs) of rms velocity $w_{\mathrm{ML}}^{\prime}\left(=\sigma_{o}\right)$ were obtained by fitting a normal mixture model to the larval velocities, as described in the following sections.

For each estimate of ms velocity, the turbulence dissipation rate $\varepsilon$ was calculated as $\varepsilon=\left(w^{\prime}\right)^{3} \ell^{-1}$, where the eddy length scale $\ell$ was taken to be $\ell=0.2 z$ and $z$ is the distance from the grid (Tennekes and Lumley 1972; McKenna 2000). The Kolmogorov length scale was estimated by $\eta=$ $\left(\nu^{3} \varepsilon^{-1}\right)^{0.25}$, where $\nu$ is the kinematic viscosity (Tennekes and Lumley 1972).

Lanval behavior-Our goal was to deternine how many larvae were sinking with retracted velums, because sinking was the only behavior that we expected to be associated with settlement. The proportion of sinkers could not be estimated simply by integrating over the proportion of observed negative (downward) velocities, however, because the observed larval velocities have both a behavioral component and a fluid transport component. A sinking larva can be carried upward by an eddy, resulting in an observed velocity in an upward (positive) direction. Even in still water, swimming and hovering larvae (swimmers that maintain a relatively constant position) move both upward and downward, making it impossible to classify larvae as sinkers on the basis of downward movement alone. Ideally, larvae with their velums retracted could be classified visually as sinkers, regardless of their velocities. At higher turbulence levels, though, motion blur in our video images prevented us from classifying larvae by visual inspection. Larvae could not be categorized individually into behavioral modes; instead, we analyzed larval behavior statistically, by fitting a normal mixture model to our larval velocity data to estimate the proportions of swimming, hovering, and sinking larvae.

In our analysis of larval behavior, several assumptions were made.

(1) Instantaneous flow velocities $W_{0}$ are normal, with mean $\mu_{o}$ and variance $\sigma_{o}^{2}$.

$$
W_{o} \sim N\left(\mu_{o}, \sigma_{v}^{2}\right)
$$

(2) In still water, the vertical velocities $W_{t}$ of larvae in a given behavioral mode are approximately normal, with means $\mu_{i}$ and variances $\sigma_{i}^{2}$.

$$
i= \begin{cases}1 \text { swimmers } & W_{i} \sim N\left(\mu_{1}, \sigma_{1}^{2}\right), \\ 2 \text { hoverers } & \left(\mu_{2} \leq 0, \sigma_{1}^{2} \geq 1\right) \\ 3 \text { sinkers } & \left(\mu_{3}<0, \sigma_{3}^{2} \geq 1\right) \\ & \end{cases}
$$

(3) Flow velocity and larval velocity are independent and additive- that is, relative larval velocity in flow $W_{T^{t}}$ equals flow velocity $W_{o}$ plus larval behavioral velocity $W_{i}$.

$$
W_{T^{\prime}}=W_{0}+W_{i}
$$

(4) Larval sinking and swimming abilities do not change significantly with flow conditions. Within a behavioral mode, $W_{1}$ is not a function of $W_{o}$.

Assumption 1 has been validated in laboratory studies of grid-generated turbulence (Mouri et al. 2002), and our LDV velocity data were normally distributed. Assumption 2 was justified by analysis of larval velocities in still water (details follow). Assumption 3 is frequently used in studies of particle transport in turbulence (e.g., Reeks 1977), because inertial forces are negligible for particles with Reynolds nurnber $\leqslant 1$. Assumption 4 could not be directly verified but was considered to be reasonable given the experimental conditions. For ciliary swimmers, the speed of movement is directly proportional to the ciliary beat frequency, which is limited by viscosity and by salinity- and temperature-dependent biochemical rates (Chia et al. 1984; Podolsky and Emlet 1993; Young 1995). These seawater properties remained constant during our experiment, and there would have been no viscosity- or biochemical rate-related effects on larval swimming or hovering abilities. Larval swimming orientations can potentially be affected by velocity shear (Jonsson et al. 1991), but such an effect was not apparent in our experiments (see "Discussion" section).

Our assumptions place no constraints on behavioral changes from one mode to another. Within a given behavioral mode, the larval velocities are drawn from a fixed, 
known distribution, but individual larvae can switch behavioral modes without restriction.

Mixture model for larval behavior in still water-We first estimated the velocity means $\mu_{i}$, variances $\sigma_{i}^{2}$, and mixing proportions $\alpha_{i}$ of swimmers, hoverers, and sinkers in no-flow conditions by fitting a three-component normal mixture model to the still-water larval velocity distributions. The probability density of observed larval vertical velocity $w_{\mathbf{L}}$ was modeled as

$$
\left.P\left(w_{\mathrm{L}} \mid \alpha_{i}, \mu_{i}, \sigma_{i}^{*}\right)=\sum_{i=1}^{3} \alpha_{i} p_{i}\left(w_{\mathrm{L}}\right\} \mu_{i}, \sigma_{i}^{2}\right)
$$

where, for $i=(1,2,3)$,

$$
p_{i}\left(w_{\mathrm{L}} \mid \mu_{i}, \sigma_{i}^{2}\right)=\frac{1}{\sqrt{2 \pi \sigma_{i}^{2}}} \exp \left[\frac{-\left(w_{\mathrm{L}}-\mu_{i}\right)^{2}}{2 \sigma_{i}^{2}}\right]
$$

Maximum-likelihood parameter estimates of $\alpha, \mu_{t}$, and $\sigma_{i}^{2}$ were calculated using the expectation-maximization (EM) algorithm (McLachlan and Peel 2000).

In still water, the proportion of sinkers $\alpha_{3}$ was too low $\left(<0.03\right.$ in all replicates) to use MLEs of $\mu_{3}$ and $\sigma_{3}^{2}$ to describe the sinking velocities. The fall velocities of dead larvae were approximately normal and were used as a proxy for the velocity distribution of live, actively sinking larvae with retracted velurns. Although larvae can sink with exfended velums by stopping ciliary motion, we observed that most larvae fully retracted their velums when sinking in turbulence. Given the predominance of velum retraction and the relatively small difference in velocities of the two types of sinkers $(<10 \% ; H$. L. Fuchs unpubl. data), we included only sinkers with retracted velums in the model.

The variables $\mu_{i}$ and $\sigma_{i}^{2}$ characterize the behavioral velocities of swimming, hovering, and sinking larvae from each culture (Fig. 3a) and were used as known values (by assumption 4) in the analysis of larval behavior in turbulence. Normality of the modes was assessed using probability plots. We also estimated the behavioral velocity range as the difference between mean swimming and sinking velocities, calculated as $\Delta w_{2}=\mu_{1}-\mu_{3}$ (Fig. 3a). Larger values of $\Delta w_{\mathrm{L}}$ indicate that larvae have more control over their vertical position in the water.

Mixture model for larval behavior in turbulence-We estimated the proportions $\alpha_{T^{i}}$ of swimmers, hoverers, and sinkers in each turbulence treaturnent by fitting a three-component, normal mixture model to the observed velocity distributions of larvae in turbulence. By assumption 3, the relative velocity of a larva in turbulence $W_{r^{i}}$ is the sum of its behavioral velocity $W_{\text {, }}$ and the fluid velocity $W_{0}$. The random variables $W_{T^{i}}$ are distributed with normal probability densities $p_{T}$, with means and variances given by

$$
\begin{aligned}
& \mu_{T^{i}}=\mu_{i}+\mu_{o} \\
& \sigma_{\tilde{T}^{\prime}}^{2}=\sigma_{i}^{2}+\sigma_{a}^{2}
\end{aligned}
$$

For each observed larval relative velocity $w_{L}$, the behavioral mode $i$ of the observed larva was unknown, and the probability density of $w_{\mathbf{L}}$ in turbulence was modeled as
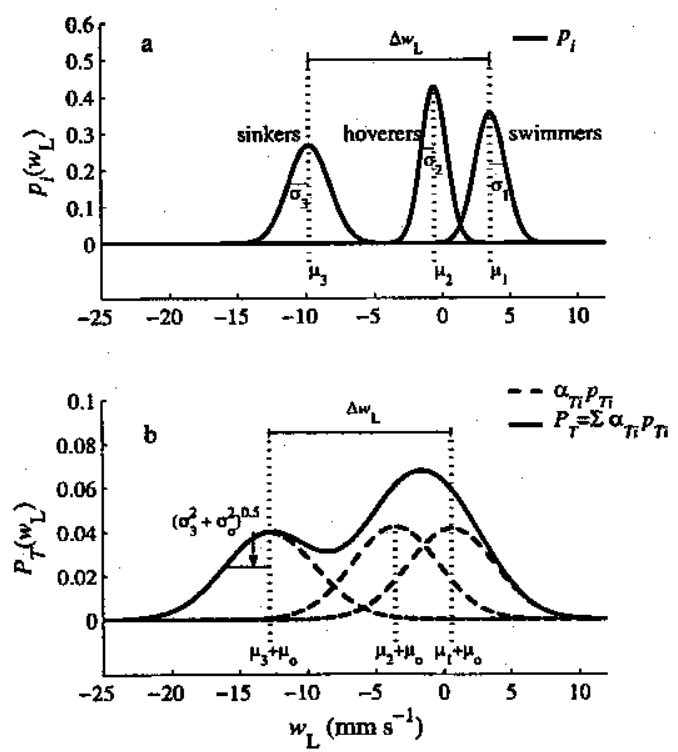

Fig. 3. Graphical representation of the three-component mixture model, showing the contribution of swimming, hovering, and sinking behaviors to the observed vertical velocity distribution of larvae in turbulence. (a) Behavioral velocity distributions of sinking, hovering, and swimming larvae were estimated for larvae in still water (dead larvae were used to determine sinking velocities) and were assumed to be independent of flow. Velocity means $\mu_{i}$ and SDs $\sigma_{i}$ are indicated for each behavioral mode. (b) The three-component mixture model for observed larval velocity distributions in turbulence has contributions from each behavioral mode, where $p_{T}$ are the probability densities of individual modes and $\alpha_{T^{\prime}}$ are the mixing proportions. Velocity means $\left(\mu_{T^{i}}=\mu_{0}+\mu_{i}\right)$ are indicated for each behavioral component, the SD $\left[\sigma_{T^{i}}=\sqrt{\left(\sigma_{0}^{2}+\sigma_{t}^{2}\right)}\right]$ is indicated only for the sinking mode, and $\mu_{o}$ and $\sigma_{\alpha}^{2}$ are the fluid velocity mean and variance. When the three-component mixture model was fitted to observed velocity data, $\alpha_{i}$ and $\sigma_{\sigma}$ were estimated by maximum likelihood. In this example, they were chosen arbitrarily for illustrative purposes $\left(\alpha_{\mathrm{T}^{\prime}}=0 . \overline{33}, \mu_{\sigma}=-3.0 \mathrm{~mm} \mathrm{~s}^{-1}, \sigma_{\sigma}=3.0 \mathrm{~mm}\right.$ $\mathrm{s}^{-1}$, and $R e_{\mathrm{Hr}}=100$ ). Note that because the mean flow velocity is negative, the model predicts that $77 \%$ of observed velocities would be $<0$ here, although the proportion of sinking larvae was only $33 \%$

$$
P_{T}\left(w_{\mathrm{L}} \mid \alpha_{T^{i},} \mu_{T^{i}}, \sigma_{T^{\prime}}^{2}\right)=\sum_{i=1}^{3} \alpha_{T^{i}} p_{T^{r}}\left(w_{\mathrm{L}} \mid \mu_{T^{i}}, \sigma_{T^{i}}^{3}\right)
$$

(Fig. 3b). The mean flow velocity $\mu_{0}(=\langle w\rangle)$ from LDV measurements was used as a known value. By assumption $4, \mu_{i}$ and $\sigma_{i}^{2}$ from still-water segments were also used as known values in eqs. 4 and 5 . The unknown parameters $\left(\alpha_{T^{i}}\right.$ and $\sigma_{o}^{2}$ ) were estimated for each treatment replicate using a modified EM algorithm (Web Appendix 1 at http://www.aslo.org/ $10 /$ toc/vol_49/issue_6/1937a l.pdf) to maximize the log-likelihood of eq. 5 over all observed velocities. Within the constraints of the model (eqs. 4,5 ), $\sigma_{T^{\prime}}$ has no statistical 

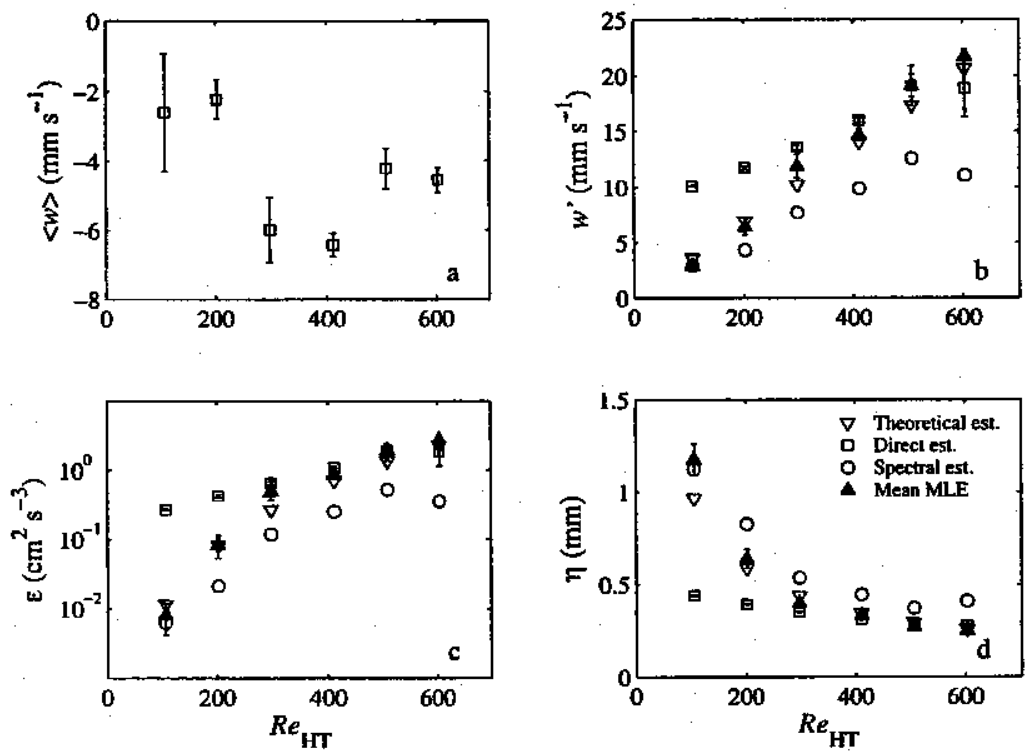

Fig. 4. Fluid velocity characteristics calculated from LDV measurements, from theory and from observed larval velocities. (a) Mean vertical velocity $\langle w\rangle$. (b) rms vertical velocity $w^{\prime}$. (c) Turbulence dissipation rate $\varepsilon$. (d) Kolmogorov length scale $\eta$. Theoretical estimates were obtained using an empirical relationship between grid-forcing conditions and rms velocities (Hopfinger and Toly 1976). Direct, unbiased estimates were calculated from raw LDV data (Buchave et al. 1979). Spectral estimates were calculated by removing the estimated noise contribution from LDV velocity spectra (Voulgaris and Trowbridge 1998). MLEs were obtained by fitting a three-component mixture model to observed velocities of larvae in turbulence and averaging estimates from six replicates. Error bars are 1 SE. Mean flow velocity (a) cannot be estimated theoretically or by spectral methods.

dependence on $\sigma_{s}^{2}$, and these parameters can be estimated simultaneously from the observed larval velocities.

Relating behavior to turbulence-We wished to determine the general relationships between turbulence characteristics and the proportion of sinking larvae. Maximum-likelihood values of $w_{\mathrm{ML}}^{\prime}\left(=\sigma_{o}\right.$ from the mixture model $)$ were our best estimates of turbulence intensity in individual replicates (see "Results" section), and these were used to calculate the dissipation rate $\varepsilon$ and the Kolmogorov length scale $\eta$ for each turbulence treatment. The parameters were averaged by treatment level, and the relationships between $\varepsilon$ or $\eta$ and the proportion of sinkers $\sigma_{T^{3}}$ were estimated by exponential regression.

Any group of larvae has a net mean behavioral velocity $\left\langle w_{\nu}\right\rangle$, and the relationship between $\left\langle w_{L}\right\rangle$ and $\varepsilon$ is of interest for addressing population-level questions about larval fiuxes. We calculated the net mean velocity of larvae in each treatment replicate as $\left\langle w_{L}\right\rangle=\Sigma \alpha_{T} \mu_{i}$. The relationship between $\left\langle w_{\mathrm{L}}\right\rangle$ and $\log _{10} \varepsilon$,

$$
\left\langle w_{\mathrm{L}}\right\rangle=\mu_{1}-a_{0} e^{\left(a_{1} \log _{10} e\right)}
$$

was estimated by exponential regression. The net velocity $\left\langle w_{L}\right\rangle$ is bounded above by the mean swimming velocity $\mu_{1}$ and falls off exponentially with $\log _{\mathrm{I}} \varepsilon$. Linear and logistic functions of $\varepsilon$ were also fitted to $\left\langle w_{L}\right\rangle$ but had poorer fits and are omitted. Because larval swimming abilities varied among cultures, the model was fitted for individual replicates and for pooled data, excluding replicates with maximum and minimum values of $\Delta w_{1}$

\section{Results}

Turbulence characteristics-A comparison of LDV measurements from five points in the video frame indicated that turbulence was generally homogeneous within our measurement area, although some inhomogeneities appeared at the highest turbulence level. At $R e_{\mathrm{rT}}=600, w^{\prime}$ values at the outer points differed from $w^{\prime}$ at the center point by $5-20 \%$. In spite of this spatial inhomogeneity, we considered it worthwhile to present results from all turbulence treatment levels. All reported LDV results refer to the average of replicate measurements taken at the center point of the video frame.

The mean vertical flow velocity $\langle w\rangle$ was generally negative but always had a magnitude $<7 \mathrm{~mm} \mathrm{~s}^{-1}$ (Fig. 4a). The relationship between $R e_{\mathrm{rr}}$ and mean flow velocity appeared to be nonlinear, presumably because the pattern of circulation in the tank has a nonlinear dependence on forcing conditions (McDougall 1979; McKenna 2000). 
Table 3. Shell size and still-water velocities for competent larvae, given as mean \pm 1 SD. Fall velocities were measured for a subsample of dead larvae $(n=20)$ from each replicate. Velocities were measured for live larvae $(100<n<300)$ during each replicate, and the velocities of swimmers and hoverers and the mixing proportions were estimated by maximum likelihood. Also given is the mean difference between swimming velocity and fall velocity $\left(\Delta w_{1}\right)$ for each culture.

\begin{tabular}{ccccccccc}
\hline \hline Replicate & $\begin{array}{c}\text { Age } \\
\text { (days) }\end{array}$ & $\begin{array}{c}\text { Shell length } \\
(\mu \mathrm{m})\end{array}$ & $\begin{array}{c}\text { Fall velocity } \\
\left(\mathrm{mm} \mathrm{s}^{-1}\right)\end{array}$ & $\begin{array}{c}\text { Hovering velocity } \\
\left(\mathrm{mm} \mathrm{s}^{-1}\right)\end{array}$ & $\begin{array}{c}\text { Swimming velocity } \\
\left(\mathrm{mm} \mathrm{s}^{-1}\right)\end{array}$ & $\begin{array}{c}\text { Proportion of } \\
\text { sinkers }\end{array}$ & $\begin{array}{c}\text { Proportion of } \\
\text { swimmers }\end{array}$ & $\begin{array}{c}\Delta w_{\mathrm{L}} \\
\left(\mathrm{mm}^{-1}\right)\end{array}$ \\
\hline 1 & 24 & $648 \pm 93$ & $-9.2 \pm 1.1$ & $-0.4 \pm 0.7$ & $4.0 \pm 1.2$ & 0.03 & 0.15 & 13.2 \\
2 & 24 & $690 \pm 43$ & $-9.2 \pm 1.0$ & $-1.3 \pm 0.2$ & $1.7 \pm 2.9$ & 0.01 & 0.47 & 10.9 \\
3 & 24 & $587 \pm 40$ & $-6.4 \pm 1.2$ & $-0.1 \pm 1.0$ & $3.0 \pm 1.6$ & 0.00 & 0.20 & 9.3 \\
4 & 24 & $662 \pm 69$ & $-8.8 \pm 1.5$ & $-0.5 \pm 0.8$ & $3.0 \pm 1.6$ & 0.00 & 0.25 & 11.8 \\
5 & 24 & $767 \pm 58$ & $-9.8 \pm 1.5$ & $-0.5 \pm 1.0$ & $3.6 \pm 1.0$ & 0.00 & 0.27 & 13.4 \\
6 & 27 & $605 \pm 46$ & $-7.0 \pm 1.2$ & $-0.9 \pm 0.3$ & $0.8 \pm 1.8$ & 0.00 & 0.61 & 7.9 \\
\hline
\end{tabular}

Direct estimates of $w^{\prime}$ increased linearly with $R e_{\mathrm{HT}}\left(r^{2}=\right.$ 0.97 ), from $10.1 \mathrm{~mm} \mathrm{~s}^{-1}$ at the lowest turbulence level to $18.9 \mathrm{~mm} \mathrm{~s}^{-1}$ at the highest level (Fig. 4b). Spectral estimates of $\hat{w}^{\prime}$ were consistently $\rightarrow 7 \mathrm{~mm} \mathrm{~s}{ }^{-1}$ less than direct estimates of $w^{\prime}$, indicating a substantial noise contribution in the measured velocity variance (Fig. $4 \mathrm{~b}$ ). The noise was assumed to have zero mean and no effect on $\langle w\rangle$. The spectral method sometimes overestimates the noise variance (Voulgaris and Trowbridge 1998), but LDV measurements are generally noisy because of Doppler noise and velocity shear in the measurement volume (Buchave et al. 1979; Voulgaris and Trowbridge 1998). Because of the high percentage of noise in the LDV measurements, the direct and spectral calculations were probably over- and underestimates of the rms velocity, but they are presented here as independent reference estimates.

When it was estimated from the three-component mixture model, the fluid velocity variance $w_{\mathrm{MI}}^{\prime}$ was always close to the theoretical values $w_{\mathrm{sT}}^{\prime}$ derived from empirical relationships of grid tank dynamics (Fig. 4b). This was also tnue for the turbulence dissipation rate $\varepsilon$ (Fig. $4 \mathrm{c}$ ) and Kolmogorov length scale $\eta$ (Fig. 4d), which were calculated directly from rms velocity estimates. The close correspondence between our average estimates of $w_{\mathrm{ML}}^{\prime}$ and $w_{\mathrm{HT}}^{\prime}$ illustrates the validity of using a mixture model to estimate turbulence intensity by maximum likelihood from the measured larval velocities.

Because of uncertainty in $w^{\prime}$ and $\hat{w}^{\prime}$ from the LDV measurements (due to the noise contribution) and because MLEs of $w_{\mathrm{Mg}}^{\prime}$ directly represent the turbulence intensity during each replicate of the larval experiments, we discuss our larval behavior results in terms of turbulence characteristics calculated from $w_{\mathrm{M} \text {. }}^{\prime}$. MLEs $w_{\mathrm{M}}^{\prime}$ closely resembled theoretical values $w_{\mathrm{Hr}}^{\prime}$, and the relationships between larval behavior and $w_{\mathrm{ML}}^{\prime}$ are qualitatively the same as those between behavior and $w_{\mathrm{HT}}^{\prime}$. As calculated from $w_{\mathrm{ML}}^{\prime}, \varepsilon$ was $8.1 \times 10^{-3}-2.7 \times$ $10^{0} \mathrm{~cm}^{2} \mathrm{~s}^{-3}$, and $\eta$ was $0.2-1.2 \mathrm{~mm}$.

Larval velocities in still water-Although all larvae were raised under identical conditions, larval size and swimming abilities varied between cultures. Mean fall velocities were $6.4-9.8 \mathrm{~mm} \mathrm{~s}^{-1}$ (Table 3), and replicates 3 and 6 had significantly slower fall velocities than other replicates (oneway analysis of variance, $F_{5,114}=24.268, p=0.001$ with post-hoc Tukey's test). The slowest-sinking larvae were atso the smallest, and larvae in replicate 6 had the slowest mean swimming velocity.

In no-flow conditions, hovering and swimming larvae formed two distinct groups in all replicates (Fig. 5a). Swimmers always had positive mean velocities and velocity variances $>1 \mathrm{~mm} \mathrm{~s}^{-1}$, whereas hoverers had negative mean velocities and velocity variances $<1.1 \mathrm{~mm} \mathrm{~s}^{-1}$ (Table 3 ). The proportion of sinking larvae was always $<0.03$ and was $\varangle 0.01$ in four of six cultures. The proportions of swimming and hovering larvae varied between cultures. The behavioral velocity range $\Delta w_{\mathrm{L}}$ was $7.9-13.4 \mathrm{~mm} \mathrm{~s}^{-1}$.

Larval behavior in turbulence-The distributions of observed larval velocities became wider at higher turbulence intensities (Fig. 5) because of the increased flow variance. The distributions also shifted toward more negative velocities at higher turbulence levels, in part because of the mean downward flow and in part because of the increasing proportion of sinking larvae. For larvae in still water, the velocity distributions were always positively skewed and bimodal, whereas in turbulence, the velocity distributions were negatively skewed.

We found a clear relationship between turbulence intensity and the proportion of larvae in each behavioral mode, as estimated from the three-component normal mixture model (Fig. 6). The proportion of sinking larvae was effectively zero at $R e_{\mathrm{HT}}=100$ and generally increased with turbulence intensity. The proportion of hovering larvae was lower in turbulence than in no-flow conditions. The proportion of swimming larvae was higher than other groups in turbulence up to $R e_{\mathrm{HT}}=\mathbf{4 0 0}$ (e.g., Fig. 7) and then decreased at higher turbulence levels as the mean proportion of sinkers increased.

Relating behavior and turbulence-When data were averaged by turbulence treatment, the mean proportion of sinking larvae $\alpha_{r^{3}}$ increased approximately exponentially with the $\log$ of the dissipation rate $\left[\alpha_{T^{3}}=0.26 \exp \left(1.1 \log _{10} \varepsilon\right), r^{2}\right.$ $=0.89 ;$ Fig. 8a $\mathrm{a}$ and decreased approximately exponentially with the Kolmogorov length scale $\left[\alpha_{T^{3}}=0.71 \exp (-3.1 \eta)\right.$, $r^{2}=0.86$; Fig. 8b].

An exponential model provided a good fit $\left(r^{2}=0.73\right.$ for pooled data) to the relationship between the net behavioral velocity $\left\langle w_{\mathrm{L}}\right\rangle$ and the dissipation rate $\varepsilon$ (Fig. 9). The net 
behavioral velocity was negative at dissipation rates greater than $\varepsilon=7.4 \times 10^{-2}-3.2 \times 10^{-1} \mathrm{~cm}^{2} \mathrm{~s}^{-3}$. When the data were pooled, this threshold was at $1.9 \times 10^{-1} \mathrm{~cm}^{2} \mathrm{~s}^{-3}$.

\section{Discussion}

Mud snail veligers in our study altered their behavior in response to turbulent flow conditions and sank more frequently in more intense turbulence. Although we cannot show conclusively that veliger sinking behavior is a precursor to settlement, the response was demonstrated in latestage, competent larvae. Moreover, the turbulence-induced response was most pronounced under turbulence conditions comparable to energetic nearshore areas where intertidal species must settle.

Our experimental turbulence treatments were specifically appropriate for questions about settlement in tidal flows at Barnstable Harbor, the natal habitat of our larvae. There are no published measurements of dissipation rates from the harbor, but Hunt and Mullineaux (2002) reported shear velocities of up to $u_{*}=3.5 \mathrm{~cm} \mathrm{~s}^{-1}$ over the inner-harbor tidal flats during flood tide. Using the relationship $\varepsilon=u_{*}^{3} / \kappa \varepsilon$, where $\kappa$ is von Karman's constant and $z$ is height above bottom (Gross and Nowell 1985), the dissipation rate can be estimated as $\varepsilon \approx 10^{\circ} \mathrm{cm}^{2} \mathrm{~s}^{-3}$ over the fiats. We measured turbulence in Barnstable Harbor during one complete tidal cycle in August 2002 and estimated dissipation rates to be $\varepsilon \approx 10^{-2}-10^{1} \mathrm{~cm}^{2} \mathrm{~s}^{-3}$ (H. L. Fuchs unpubl. data). The lowest turbulence level used in our experiments $\left(\varepsilon=8.1 \times 10^{-3}\right.$ $\mathrm{cm}^{2} \mathrm{~s}^{-3}$ ) is probably representative of slack tide, whereas the higher turbulence levels (up to $\varepsilon=2.7 \times 10^{\circ} \mathrm{cm}^{2} \mathrm{~s}^{-3}$ ) would be found during flood or ebb tides. Although laboratorygenerated turbulence is often more intense than that in relevant field conditions (Peters and Redondo 1997), our experimental turbulence levels were comparable to those in an adult mud snail habitat.

Our behavioral results (Fig. 8) suggest that veligers will exhibit sinking behavior in turbulent $\left(\varepsilon>10^{-2} \mathrm{~cm}^{2} \mathrm{~s}^{-3}\right)$, shallow areas but not in calmer $\left(\varepsilon<10^{-2} \mathrm{~cm}^{2} \mathrm{~s}^{-3}\right)$ offshore water. Our experiments were conducted at turbulence levels representative of tidal channels and partially mixed estuaries ( $\varepsilon=10^{-3}-10^{\circ} \mathrm{cm}^{2} \mathrm{~s}^{-3}$; Table 1), where behavioral changes could potentially affect larval supply to intertidal habitats. Dissipation rates are generally lower in offshore areas and are unlikely to induce a larval sinking response, even during moderate storms. In winds $\approx 15 \mathrm{~m} \mathrm{~s}^{-1}$, dissipation rates at the surface and thermocline reach $\varepsilon=10^{-3}-10^{-2} \mathrm{~cm}^{2} \mathrm{~s}^{-3}$ (Dillon and Caldwell 1980), but our larvae rarely sank at $\varepsilon$ $\leq 10^{-3} \mathrm{~cm}^{2} \mathrm{~s}^{-3}$. Although stormy conditions at sea could cause some veligers to sink (Barile et al. 1994), we expect that larvae will encounter and respond to strong turbulence primarily in nearshore areas.

Larval sinking in turbulent, coastal zones could potentially affect horizontal transport of larvae over spatial scales of tens of kilometers. Pringle and Franks (2001) described an asymmetric mixing mechanism that causes sinking particles to be transported shoreward in tidal currents. It is possible that physical mechanisms such as asymmetric mixing transport could enhance the retention of sinking larvae in coastal inlets, providing additional opportunities for settlement.
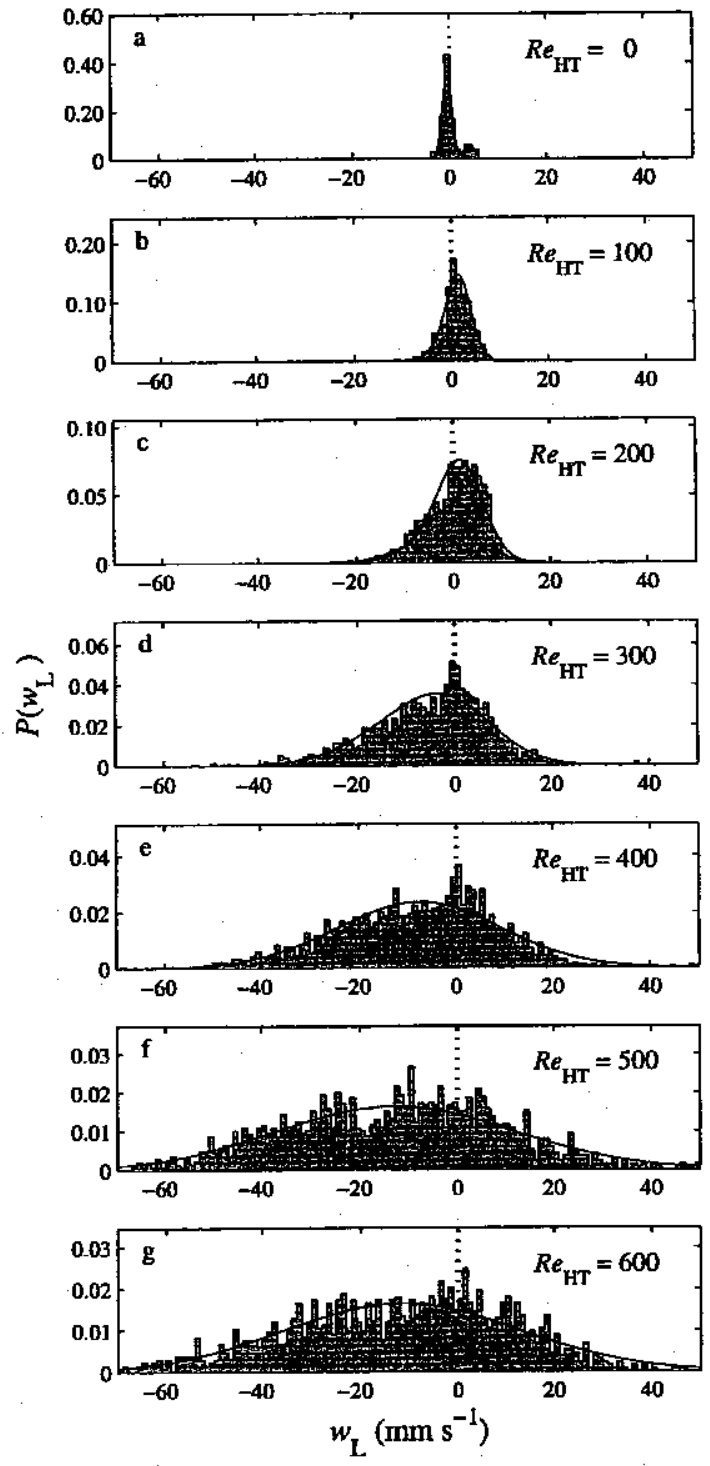

Fig. 5. Nommalized histograms of observed larval vertical velocities for all turbulence levels, from replicate 1 . Solid curves show the best fits from the three-component mixture model.

Larval behavior-We expected mud snail larvae to sink or swim, but we found that they also hover, especially in still water. Many species of mollusk larvae hover by producing mucous strings that act as natural tethers (Fenchel and Ockelmann 2002), but our larvae had no apparent mucous strings and were probably large and dense enough to 

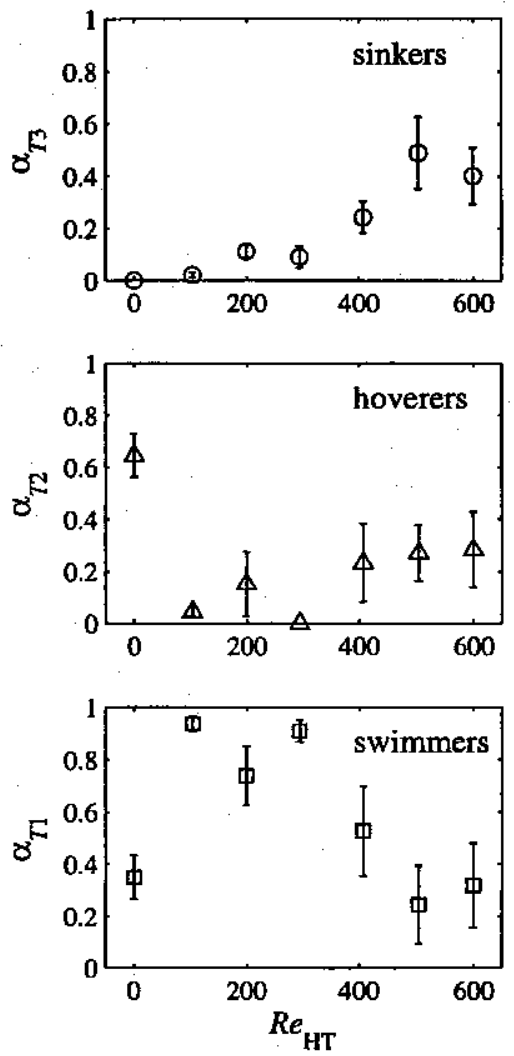

Fig. 6. Maximum-likelihood vahues of mean proportions $\alpha_{r^{\prime}}$ of sinking, hovering, and swimming larvae vs. $R e_{\mathrm{Hr}}$. Symbols show averaged estimates from all replicates for each turbulence treatment level. Error bars are 1 SE

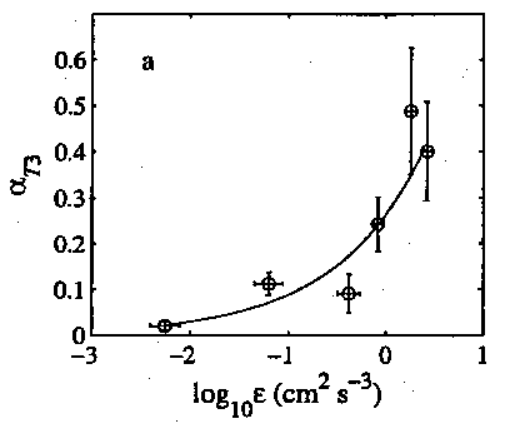

Fig. 8. Mean proportion of sinking larvae $\alpha_{T^{3}}$ vs. (a) $\log _{10}$ of the dissipation rate $\varepsilon$ and (b) Kolmogorov length scale $\eta$. All values are from MLEs. Symbols show average estimates from six replicates per treatment level (excluding $R e_{\mathrm{HT}}=0$ ), and error bars are $1 \mathrm{SE}$. Solid lines show exponential regressions.

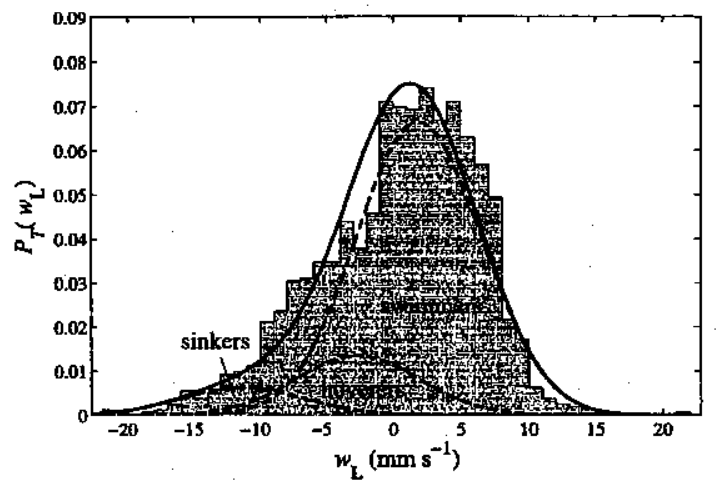

Fig. 7. Normalized histogram of observed larval velocities from replicate $1, R e_{\text {hr }}=200$, showing fitted velocity distribution for the three-component mixture model (solid curve) with contributions from each behavioral mode (dashed lines).

hover without added drag. Bivalve larvae create wider feeding currents and feed more efficiently by hovering than by swimming (Gallager 1993; Fenchel and Ockelmann 2002). In calm water, where contact rates between larvae and food particles are low, mud snail larvae also may hover more to increase feeding efficiency.

Larvae in our experiments sank more frequently at higher turbulence intensities, and this tendency could have important implications for settlement. Given constant turbulence conditions, sinking particles reach the bottom more quickly and accumulate to higher near-bottom concentrations than neutrally buoyant particles (e.g., McNair et al. 1997). Competent mud snail larvae would reach the benthos more quickly by sinking than by swimming, but there is no apparent benefit for larvae that sink in calm, deep water (e.g., offshore) over unsuitable habitats. The exponential relationship between the proportion of sinkers and $\log _{10} \varepsilon$ suggests that larvae should sink primarily in near-shore areas during en-

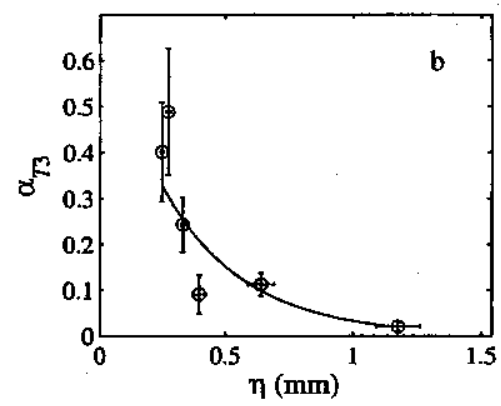




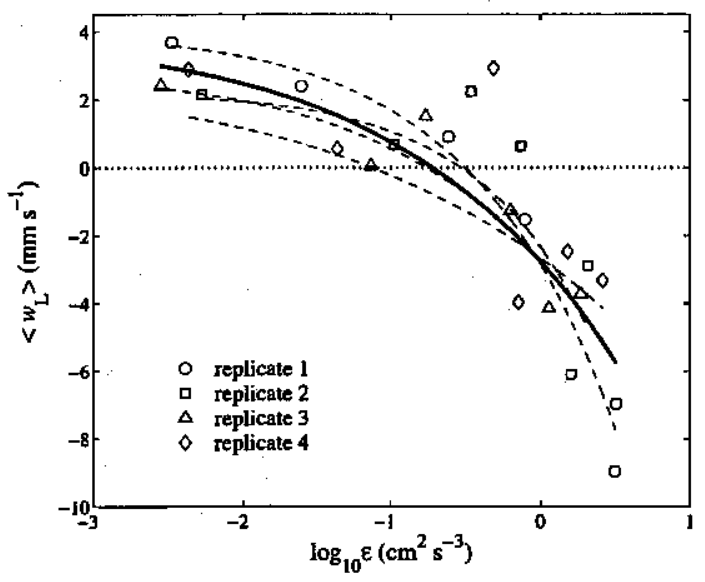

Fig. 9. Net mean behavioral velocity of larvae $\left\langle w_{L}\right\rangle$ vs. $\log _{10}$ of the dissipation rate $\varepsilon$. Symbols show velocity estimates for each treatment from replicates 1-4 (replicates with maximum and minimum values of $\Delta w_{1}$ were excluded). Dashed lines show the exponential regressions for individual replicates, and the solid line shows the regression fit to pooled data, using $\mu_{1}=4.1 \mathrm{~mm} \mathrm{~s}^{-1}$ and $\Delta w_{\mathrm{l}}=13.3 \mathrm{~mm} \mathrm{~s}^{-1}$.

ergetic tides, as might be expected if the response were related to settlement.

Veliger larvae clearly respond to turbulence, but the physiological mechanism of turbulence detection is unknown. Mud snail larvae retract their velums when the cilia are touched (Dickinson 2002), indicating the presence of mechanosensory cilia that could detect velocity shear. It has also been hypothesized that gastropod larvae sense acceleration with their statocysts (Chia et al. 1981; Crisp 1984; Young 1995). Chia et al. (1981) found a neural connection between the statocysts and cilia in nudibranch veligers (Rostanga pulchra), which suggests that these organs might have related functions. Both the velar cilia and the statocysts could potentially be used for detection of shear and acceleration in small eddies.

It is interesting to note that the sharpest increase in the proportion of sinking larvae occurred when the Kolmogorov length scale was less than the larval body length (Fig. 8b). Although Kolmogorov-scale eddies contain a very small percentage of the total turbulent kinetic energy, velocity gradients exist even at scales smaller than millimeters (Lazier and Mann 1989). Larvae may detect and respond to shear in the smallest-scale eddies, and sinking behavior could depend on interactions of larvae with eddies at the Kolmogorov scale. Alternatively, larvae may retract their velums in response to being accelerated or rotated by the flow vorticity, which increases with the dissipation rate. Regardless of the detection mechanism, descriptors of small-scale turbulence ( $\eta$ and $\varepsilon$ ) are probably the most relevant flow characteristics for understanding larval responses to turbulence.

Because vorticity increases with dissipation rate, velocity shear could potentially affect the orientation and directed- swimming abilities of larvae in strong turbulence. Larvae that normally swim in a velum-up orientation will begin to tumble if the viscous torque caused by velocity shear across the body greatly exceeds the gravitational torque, caused by an asymmetric density distribution. Tumbling is defined as rotation past $90^{\circ}$ from the normal, velum-up orientation (Jonsson et al. 1991). We calculated the critical shear (as in Kessler 1986; Jonsson et al. 1991) required to tumble our larvae as shear $\approx 10^{2} \mathrm{~s}^{-1}$. This is about an order of magnitude greater than the highest shear rate in our experiments, which we estimated as shear $\approx \varepsilon^{0.5} v^{-0.5}=1.6 \times 10^{1} \mathrm{~s}^{-1}$. For shear $<2 \times 10^{1} \mathrm{~s}^{-1}$, the gravitational torque on the larvae will always compensate the viscous torque, allowing larvae to remain within about $10^{\circ}$ of the normal upward orientation (Jonsson et al. 1991). Visual inspection of our video record confirmed that, even at the highest turbulence level, in-focus larvae were always oriented with the velums up. We conclude that velocity shear had little or no effect on larval swimming abilities in our experiment and that competent mud snail larvae probably tumble only in extremely turbulent conditions (e.g., the surf zone).

Implications of turbulence-induced sinking behaviorThere are possible ecological and evolutionary benefits for veligers that sink in turbulence. Gastropod larvae may sink in turbulence as a way of avoiding predators (Young 1995). Mud snail veligers responded to turbulence even in the absence of predators, and we infer that larval fluxes are affected by turbulence-induced sinking behavior, regardless of whether turbulence is generated by predators or by physical sources. Abelson and Denny (1997) suggested that hydrodynamic forces might alter larval behavior and even provide a settiement cue. We hypothesize that a turbulence-induced sinking response enables larvae to move toward the bottom when they reach shallower coastal waters. Near-bottom larvae contact the bottom more frequently than those in the upper water column (McNair et al. 1997) and could have more opportunities to test substrates and settle in suitable areas.

To understand biophysical coupling between turbulence and settlement, it is necessary to determine the hydrodynamic conditions where larval behavior can affect sinking fluxes (Crimaldi et al. 2002). The net behavioral velocity of our larvae shifted from positive (upward) to negative (downward) when the dissipation rate reached $\sim \varepsilon=10^{-1} \mathrm{~cm}^{2} \mathrm{~s}^{-3}$. This shift could result in significant changes in the advective component of larval vertical fluxes. On the other hand, the observed velocity distributions of our larvae grew wider as $\boldsymbol{w}^{\prime}$ increased, indicating that larval movement is dominated more by fiow as turbulence intensifies. Larvae probably detect eddies at or near the Kolmogorov scale, which is a function of $\varepsilon$, and we expect the proportion of sinking larvae $\alpha_{T}$ to increase exponentially with $\log _{10} \varepsilon$ in the field as in the lab. Behavioral changes may affect sinking fluxes less, however, when the vertical turbulence intensity $w^{\prime}$ greatly exceeds the behavioral velocity range $\Delta w_{L}$.

Although we focused on water-column processes, it is worth noting that settlement fluxes depend on both the probability of reaching the bottom and the probability of attachment to substrates (Gross et al. 1992; Crimaldi et al. 2002). 
Like the dissipation rate, Reynolds stress increases with shear velocity, and those flow conditions that induce larval sinking are also more likely to cause bed-load transport or saltation of sediments and to prevent larvae from attaching to the bottom. In energetic flows such as the strong tides at Barnstable Harbor, a large proportion of competent larvae could be sinking at a given time (Fig. 8), concentrating nearer to the bottom than nonsinking larvae do. Although the probability of larval attachment to substrates is lower in the higher shear stresses of turbulent flows (Gross et al. 1992; Pawlik and Butman 1993), near-bottom larvae could have more opportunities to test substrates and burrow into sediments during slack tides (tens of minutes) or brief lulls in turbulence (seconds to minutes; Crimaldi et al. 2002).

Turbulence varies spatially and temporally in coastal areas, and large-scale settlement patterns could be influenced by flow-mediated, active settlement processes rather than by passive deposition alone. Our motivation is to understand how biophysical coupling between turbulence and settlement behavior affects the supply of gastropod larvae to coastal populations. We have shown that turbulence alters the behavior of competent mud snail larvae in the laboratory. Field and modeling studies are in progress to determine how this biophysical coupling affects larval supply and settlement fiuxes of intertidal gastropods.

\section{References}

ABEISON, A., AND M. DENNY, 1997. Settlement of marine organisms in flow. Annu. Rev. Ecol. Syst. 28: 317-339.

Barilf, P. J., A. W. SToner, AND C. M. Young. 1994. Phototaxi and vertical migration of the queen conch (Strombus gigas linne) veliger larvae. J. Exp. Mar. Biol. Ecol. 183: 147-162.

Buchave, P., W. X. George;, JR., AND J. L. LumLeY. 1979. The measurement of turbulence with the laser-Doppler anemometer. Annu. Rev, Fluid Mech. 11: 443-503.

BUTMAN, C. A. 1987. Larval settlement of soft-sediment invertebrates: The spatial scales of pattern explained by active habitat selection and the emerging role of hydrodynamical processes. Oceanogr. Mar. Biol. Annu. Rev. 25: 113-165.

Chan, N. H., J. B. Kadane, AND T. Jiang. 1998. Time series analysis of diurnal cycles in small-scale turbulence. Environmetrics 9: 235-244.

ChIA, F-S., J. Buckland-Nicks, AND C. M. Young. 1984. Locomotion of marine invertebrate larvae: A review. Can. J. Zool. 62: 1205-1222

, R. Koss, AND L. R. BICKELL. 1981. Fine structural study of the statocysts in the veliger larva of the nudibranch, Rostanga pulchra. Cell Tissue Res. 214: 67-80.

Crmaldi, J. P., J. K. Thompson, J. H. Rosman, R. J. LOWE, AND J. R. KOSEFF. 2002. Hydrodynamics of larval settlement: The influence of turbulent stress events at potential recruitment sites. Limnol. Oceanogr. 47: 1137-1151.

CRISP, D. J. 1984. Overview of research on marine invertebrate larvae, 1940-1980, p. 103-127. In J. D. Costlow, and R. C Tipper [eds.], Marine biodeterioration: An interdisciplinary study. Naval Institute Press.

De Silva, I. P. D., and H. J. S. Fernando. 1994. Oscillating grids as a source of nearly isotropic turbulence. Phys. Fluids 6: 2455-2464.

Dickinson, A. J. G. 2002. Neural and muscular development in a gastropod larva. Ph.D. thesis, Dalhousie Univ.

Druon, T. M., AND D. R. Caldwell. 1980. The Batchelor spec- trum and dissipation in the upper ocean. J. Geophys. Res. 85: 1910-1916.

ECKMAN, J. E., F. E. WERNER, AND T. F. GROSS. 1994. Modelling some effects of behavior on larval settlement in a turbulent boundary layer. Deep-Sea Res. II 41: 185-208.

Fenchel, T., and K. W. OCKelmann. 2002. Larva on a string. Ophelia 56: 171-178.

GaLlAGER, S. M. 1993. Hydrodynamic disturbances produced by small zooplankton: Case study for the veliger larva of a bivalve mollusc. J. Plankton Res. 15: 1277-1296.

GEORGE, R., R. E. FLICK, AND R. T. GUZA. 1994. Observations of turbulence in the surf zone. J. Geophys. Res. 99: 801-810.

Gross, T. F, AND A. R. M. Nowel.. 1985. Spectral scaling in a tidal boundary layer. J. Phys. Oceanogr. 15: 496-508.

, F. E. WERNER, AND J. E. ECKMAN. 1992. Numerical modeling of larval settlement in turbulent bottom boundary layers. J. Mar. Res. 50: 611-642.

HDU, H., AND H. H. HASKIN. 1978. Swimming speeds of oyster larvae Crassostrea virginica in different salinities and temperatures. Estuaries 1: 252-255.

HOPFINGRR, E. J., AND J.-A. TOLY. 1976. Spatially decaying turbulence and its relation to mixing across density interfaces. J. Fluid Mech. 78: 155-175.

HUNT, H. L., AND L. S. MULIINEAUX. 2002. The roles of predation and postlarval transport in recruitment of the soft shell clam (Mya arenaria). Limnol. Oceanogr. 47: 151-164.

JoNsSON, P. R., C. ANDRE, AND M. LINDEGARTH. 1991. Swimming behaviour of marine bivalve larvae in a flume boundary-layer flow: Evidence for near-bottom confinement. Mar. Ecol. Progr. Ser. 79: 67-76.

KessLeR, J. O. 1986. The extemal dynamics of swimming microorganisms. Prog. Phycol. Res. 4: 257-291.

LAZJRR, J. R. N., AND K. H. MANN. 1989. Turbulence and the diffusive layers around small organisms. Deep-Sea Res. Part A 36: 1721-1733.

MACKeNZIE, B. R. AND T. KiøRBOe. 1995. Encounter rates and swimming behavior of pause-travel and cruise larval fish predators in calm and turbulent laboratory environments. Limnol. Oceanogr. 40: 1278-1289.

McDovgall, T. J. 1979. Measurements of turbulence in a zeromean-shear mixed layer. J. Fluid Mech. 94: 409-431.

MCKenNA, S. P. 2000. Free-surface turbulence and air-water gas exchange. Ph.D. thesis, MIT/WHOI Joint Program

MCl.aCHLAN, G., AND D. Peel. 2000. Finite mixture models. Wiley.

MCNAIR, J. N., J. D. NewBold, AND D. D. HART. 1997. Turbulent transport of suspended particles and dispersing benthic organisms: How long to hit bottom? J. Theor. Biol. 188: 29-52.

Mouri, H., M. TakaOKa, A. HoRI, and Y. KawashmMa. 2002. Probability density function of turbulent velocity fluctuations. Phys. Rev. E 65. [doi: 10.1103/PhysRevE.65.056304]

OAKEY, N. S., AND J. A. ElusotT, 1982. Dissipation within the surface mixed layer. J. Phys. Oceanogr. 12: 171-185.

PawLIX, J. P. 1992. Chemical ecology of the settlement of benthic marine invertebrates. Oceanogr. Mar. Biol. Annu. Rev. 30: 273-335.

, AND C. A. Butman. 1993. Settlement of a marine tube worm as a function of current velocity: Interacting effects of hydrodynamics and behavior. Limnol. Oceanogr. 38: 17301740 .

Peters, F., AND J. M. ReDondo. 1997. Turbulence generation and measurement: Application to studies on plankton. Sci. Mar. 61(Suppl. 1): 205-228.

PoDOLSKY, R. D., AND R. B. EMLET. 1993. Separating the effects of temperature and viscosity on swimming and water movement by sand dollar larvae (Dendraster excentricus). J. Exp. Biol. 176: 207-221. 
Pringle, J. M., and P. J. S. Franks. 2001. Asymmetric mixing transport: A horizontal transport mechanism for sinking plankton. Limnol. Oceanogr. 46: 381-391.

RzEKs, M. W. 1977. On the dispersion of small particles suspended in an isotropic turbulent fluid. J. Fluid Mech. 83: 529-546.

SAI, E. 1994. Observations of the free-swimming behavior of Acartia tonsa: Effects of food concentration and turbulent water motion. Limnol. Oceanogr. 39: 1566-1578.

SCHRLTEMA, R. S. 1961. Metamorphosis of the veliger larvae of Nassarius obsoletus (Gastropoda) in response to bottom sediment. Biol. Bull. 120: 92-109.

I. P. WILlizams, M. A. SHaw, AND C. Loudon, 1981. Gregarious settlement by the larvae of Hydroides dianthus (Polychaeta: Serpulidae). Mar. Ecol. Prog. Ser. 5: 69-74.

SNEIGRove, P. V. R., J. P. Grassle, AND C. A. Butman. 1998. Sediment choice by settling larvae of the bivalve, Spisula solidissima (Dillwyn), in flow and still water. J. Exp. Mar. Biol. Ecol. 231: 171-190.
TAMBURRI, M. N., C. M. FinelLI, D. S. Wethey, AND R. K. ZimMER-FAUST. 1996. Chemical induction of larval settlement behavior in flow. Biol. Bull. 191: 367-373.

Tennekes, H., AND J. L. LumIEY. 1972. A first course in turbulence. MIT Press.

Voulgaris, G., AND J. H. TROWBRIDGE. 1998. Evaluation of the acoustic Doppler velocimeter (ADV) for turbulence measurements. J. Atmos. Ocean. Technol. 15: 272-289.

WelCH, J. M., AND R. B. FORWARD, JR. 2001. Flood tide transport of blue crab, Callinectes sapidus, postlarvae: Behavioral responses to salinity and turbulence. Mar. Biol. 139: 911-918.

Young, C. M. 1995. Behavior and locomotion during the dispersal phase of larval life, p. 249-278. In L. McEdward [ed.], Ecology of marine invertebrate larvae. CRC Press.

Received: 30 January 2004 Accepted: 6 July 2004 Amended: 19 July 2004 


\section{Chapter 3}

\section{Sinking in turbulence: Effects of larval behavior on larval supply and settlement in tidal currents}

\subsection{Introduction}

Gastropod larvae retract their velums and sink in strong turbulence, and it is reasonable to hypothesize that this response is selected for because it confers some advantage to individual larvae. Mud snail larvae (Ilyanassa obsoleta) have three behaviors (swimming, hovering, and sinking), and the proportion of larvae engaged in these behaviors depends on the turbulence dissipation rate $\varepsilon[10]$. The dissipation rate is the rate of transfer of turbulent kinetic energy to heat energy at the smallest eddy scales, and is a relevant statistic for quantifying turbulence at the larval scale. Mud snail larvae sink more frequently with increasing dissipation rate, resulting in a clear shift in the average larval velocity from upwards to downwards at $\varepsilon \approx 10^{-1} \mathrm{~cm}^{2} \mathrm{~s}^{-3}[10]$. The question is how do individual larvae benefit from this behavior?

Two hypotheses have been put forth to explain why gastropod larvae sink more frequently in turbulence. The first is that larvae of coastal gastropods use turbulence as an initial settlement cue $[3,10]$. I use "cue" to mean an indicator of potentially favorable habitats $^{1}$. Turbulence dissipation rates of $\geq 10^{-1} \mathrm{~cm}^{2} \mathrm{~s}^{-3}$ are uncommon in shelf regions or open ocean $[11,6,23]$, but are typical of coastal areas and tidal inlets $[12,14,29]$. Sinking

\footnotetext{
1 "cue." Def. 2. Merriam Webster's Collegiate Dictionary. 11th ed. 2003.
} 
in strong nearshore turbulence would allow larvae to reach bottom more quickly and explore settlement sites in potentially favorable habitats. The second hypothesis is that gastropod larvae sink in turbulence to avoid predators [31]. Swimming predators of all sizes, including krill, herring, tuna, and killer whales, generate turbulence with dissipation rates estimated on the order of $10^{-1} \mathrm{~cm}^{2} \mathrm{~s}^{-3}[19]$. Sinking in turbulence at or above this level could provide an escape mechanism for larvae that have no other defense against predators. Note that predator-generated turbulence, nearshore turbulence, and the turbulence threshold for larval sinking all share an approximate lower limit of $\varepsilon \approx 10^{-1} \mathrm{~cm}^{2} \mathrm{~s}^{-3}$. Given this common turbulence threshold, neither hypothesis can be rejected based on current empirical evidence.

I use a model to explore the settlement-cue hypothesis, by evaluating the theoretical effects of turbulence-induced sinking on larval supply and settlement success in tidal currents. In this paper I define larval supply as the concentration of larvae within $1 \mathrm{~cm}$ of the bed, settlement success as the probability that a larva will settle within one tidal cycle, and settlement as permanent attachment to the bottom. Turbulence-induced sinking must affect both the spatial and temporal patterns of larval supply and settlement, but this paper addresses only temporal patterns that are due to tidal variation in turbulence. Larvae that sink rapidly in turbulence are expected to have greater sinking fluxes than larvae with near-neutral buoyancy, particularly during flood and ebb tides. Therefore the supply of larvae to the bed is expected to show different periodicity for behaving vs. passive larvae.

The timing of larval contact with the bottom could have significant effects on settlement success, particularly in strong tidal currents where slack tides are of short duration. In order to settle, larvae must attach or burrow into the substrate, and their ability to do so is affected by time-dependent near-bed hydrodynamics [5]. During flood and ebb tides when bed shear stress is above some critical value, sediment and larvae are transported as bedload. When both the bed and the larvae are mobile, larval attachment to the bottom is less probable. During slack tides larvae may settle more easily, but the period when shear stress is below a critical value can be as short as 10 minutes [1]. Temporal patterns of both larval supply and attachment probability must be considered in evaluating whether turbulence-induced sinking could be a beneficial settlement strategy.

The first goal of this chapter was to develop predictions about the supply and settlement of gastropod larvae with turbulence-induced sinking behavior in tidal inlets. A 1-dimensional, vertical advection-diffusion (AD) model was used to characterize these dynamics for passive and behaving larvae. In this model the vertical diffusion of larvae is due to turbulence as specified through a simple eddy diffusivity function, and vertical ad- 
vection is due to larval behavior as specified by a turbulence-dependent vertical velocity. The AD model has been used to describe settlement dynamics of passive larvae in steady currents over variable roughness elements [9], and of passive [15] and negatively phototactic [8] larvae in tidal currents. Although complex behaviors can be modeled only implicitly by $\mathrm{AD}$, this remains the most useful spatially-explicit model for the movement of organisms in environmental gradients [16].

The second goal of this chapter is to determine how accurately the transport and settlement dynamics of larvae with multiple individual behaviors can be captured by an $\mathrm{AD}$ model with implicit behavior. Mud snail larvae have three distinct behaviors, each with a different velocity distribution. The shapes of these distributions could affect the overall settlement dynamics in ways that cannot be captured by a mean-field $A D$ approach. To characterize any shortcomings of the AD model, an equivalent particle-tracking (PT) model [e.g., 7, 25] was used to simulate the movement of larvae with explicit individual-level behaviors. Individual-based PT models allow greater flexibility in defining rules of behavior, but require more computation time than concentration-based $\mathrm{AD}$ models.

\subsection{Model Descriptions}

The 1-dimensional vertical advection-diffusion model and particle-tracking model are outlined with details about solution methods in Sections 3.2.1 and 3.2.5. The parameters that define the hydrodynamics, larval behavior, and settlement in the models are described in more depth in Sections 3.2.2, 3.2.3, and 3.2.4.

\subsubsection{Advection-Diffusion Model}

I modeled the vertical movement and settlement of larvae in a turbulent tidal boundary layer using the 1-dimensional vertical advection-diffusion model,

$$
\frac{\partial C}{\partial t}=-\frac{\partial}{\partial z}\left(w C-K \frac{\partial C}{\partial z}\right)
$$

The solution of (3.1) predicts the concentration of larvae $C(z, t)$ at height $z$ and time $t$. In this model larvae are advected by their behavioral velocity $w(z, t)$ and diffused by the turbulent eddy diffusivity $K(z, t)$. Larvae were modeled as passive (constant $w$ ) or with turbulence-dependent behavior, where $w$ varies with the turbulence dissipation rate $\varepsilon(z, t)$ (Section 3.2.3). Both the dissipation rate and the eddy diffusivity $K$ are functions of depth and a tidally-oscillating shear velocity $u_{*}$, which is proportional to the free-stream velocity 
$U_{H}$ (Section 3.2.2).

The boundary conditions of (3.1) are

$$
\begin{array}{ll}
-w C+K \frac{\partial C}{\partial z}=0 & \text { at } z=H \\
-w C+K \frac{\partial C}{\partial z}=-\Phi_{s} & \text { at } z=0 .
\end{array}
$$

There is no flux at the surface $(z=H)$ because larvae cannot leave through the air-water interface. A settlement flux $\Phi_{s}$ is specified at the bottom $(z=0)$ as

$$
\Phi_{s}(t)=s(t) C(0, t)
$$

where $s$ is a settlement velocity. In this model the potential for substrate-selection behavior is ignored, and larvae are allowed to settle only when they contact the bottom. The settlement velocity was modeled as zero, constant, or a function of shear velocity (Section 3.2.4).

With time- and space-varying advection and diffusion coefficients, (3.1) had to be solved numerically. The partial differential equation was solved with the Matlab 6.5 PDE solver, which discretizes the spatial components of the equation to generate an ODE in time that is solved using numerical integration. The equation was solved on a linearly-spaced grid of 1-cm depth increments from 0 to $H$ for $H=[100,300,500,700] \mathrm{cm}$, using maximum current

speeds of $U_{H_{\infty}}=[10,35,65] \mathrm{cm} \mathrm{s}^{-1}$. Time intervals of $100 \mathrm{~s}$ were used over one semidiurnal tidal cycle $(12.25 \mathrm{~h}$ ), with a uniform initial distribution and a $\sim 1$ hour spin-up time. Tidal mixing quickly overcame the initial distributions, and no settlement was allowed during the spin-up time.

\subsubsection{Physical Parameters}

Mud snails live primarily in soft-substrate intertidal areas, and this model was intended to simulate larval settlement in a shallow tidal channel. I use Barnstable Harbor, MA (USA) as a reference tidal inlet because mud snails are abundant at this site. The model is run for water depths $(H=[100,300,500,700] \mathrm{cm})$ that are representative of the harbor at various locations and tidal stages. Three maximum current velocities $\left(U_{H_{\infty}}=[15,35,65] \mathrm{cm} \mathrm{s}^{-1}\right)$ were used, the fastest of which is representative of Barnstable Harbor [1, Ch. 4]; the two slower current velocities can be taken to represent calmer, more sheltered estuaries. The boundary layer is assumed to be depth-limited, as is the case at Barnstable Harbor under most conditions [1, Ch. 4]. 
Tides are modeled as symmetric, and the along-current free-stream velocity $U_{H}$ varies periodically as

$$
U_{H}(t)=0.5 U_{H_{\infty}}\left(1-\cos \frac{2 \pi t}{T}\right)
$$

where $U_{H_{\infty}}$ is the maximum free stream velocity, $H$ is the water depth, and $T$ is a tidal period of $12.25 \mathrm{~h}$. The shear velocity $u_{*}$ influences larval settlement velocity (section 3.2.4), and is related to the free-stream velocity by

$$
u_{*}(t)=\frac{U_{H}(t)}{10}
$$

This estimate is based on the drag coefficient relationship $C_{d}=u_{*}^{2} / U_{H}^{2}$ [14]. $C_{d}$ is typically on the order of $3 \times 10^{-3}$ for flow over smooth sandy substrates [13,17], but was found to be $C_{d} \approx 10^{-2}$ in Barnstable Harbor, probably due to form drag over large sandwaves (Chapter 4).

The vertical eddy diffusivity $K$ controls turbulent mixing in the model, and is related to shear velocity by

$$
K=u_{*} \kappa z
$$

where $\kappa=0.4$ is von Karman's constant and $z$ is height above the bottom [14] (Fig. 3-1a). This linear form of eddy diffusivity assumes that the mixing length is proportional to depth [e.g., 21], and is valid near the bottom (i.e. in the log layer) but less accurate than other turbulence closure schemes in the upper water column. Nevertheless, (3.6) should provide a good estimate of larval concentrations in the lower water column [15]. A minimum value of $K=1$ was used to prevent numerical instabilities in the advection-diffusion model.

The diffusivity term parameterizes large-scale turbulence in the model, but larvae must detect and respond to small-scale turbulence. The smallest eddies are characterized by the Kolmogorov length, time, and velocity scales, all of which can be expressed as functions of the turbulence dissipation rate $\varepsilon$ [28]. In this model $\varepsilon$ determines larval behavior (Section 3.2 .3 ), and is related to shear velocity by

$$
\varepsilon=\frac{u_{*}^{3}}{\kappa z}\left(1-\frac{z}{H}\right)
$$

(Fig. 3-1 b). 

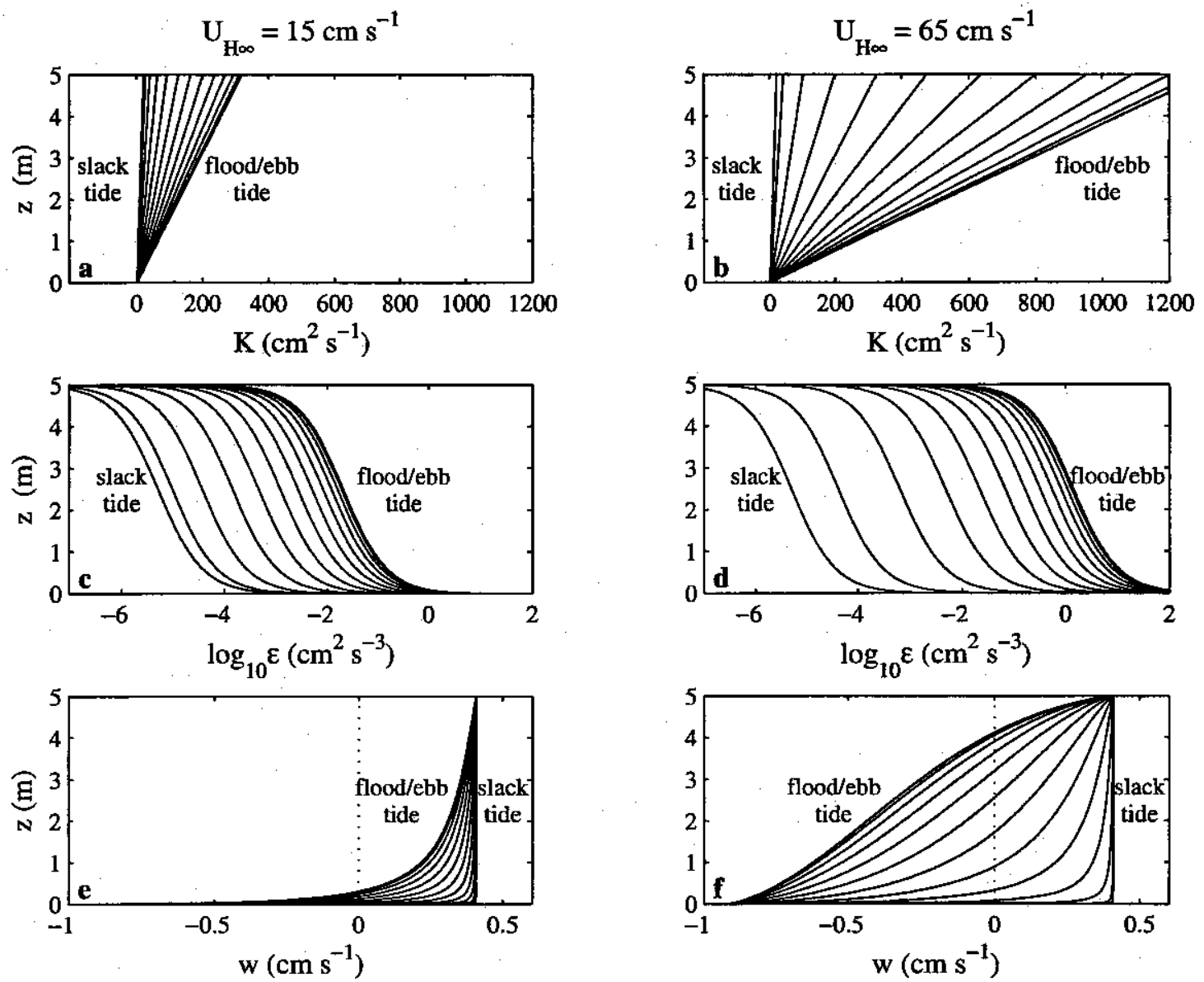

Figure 3-1: Examples of modeled (a-b) eddy diffusivity $K$, (c-d) turbulence dissipation rate $\varepsilon$, and (e-f) larval velocity $w=f(\varepsilon)$ vs. height above bottom $z$. Lines show 15-min intervals from slack tide to flood/ebb tide for $H=5 \mathrm{~m}$ and two flow speeds $U_{H_{\infty}}$ : 


\subsubsection{Behavioral Parameters}

Larvae were modeled as passive or as changing their behavior in response to turbulence. Passive larvae were modeled with a constant velocity of $w=0.05 \mathrm{~cm} \mathrm{~s}^{-1}$ or $w=-0.05$ $\mathrm{cm} \mathrm{s}^{-1}$, representing positive and negative buoyancy respectively. These values are on the order of the vertical velocities reported for some bivalve and polychaete larvae [e.g., 4, 20, 2]. These constant velocities can also be considered as subsets of mud snail larval behaviors; $w=-0.05 \mathrm{~cm} \mathrm{~s}^{-1}$ is about the average velocity of hovering larvae, and $w=0.05 \mathrm{~cm} \mathrm{~s}^{-1}$ is about the average velocity of hovering and swimming larvae combined in still water [10].

Behaving larvae were modeled as having 3 behavioral modes: 1) swimming, 2) hovering, and 3 ) sinking (e.g., Ch. 2 Fig. 3 a). The proportion $\alpha_{i}$ of larvae engaged in mode $i$ depends on the turbulence dissipation rate, as determined by fitting the following functions to laboratory data (Fig. 3-2 a-c):

$$
\begin{aligned}
& \alpha_{1}=f_{1}(\varepsilon) \\
& \alpha_{2}=1-\alpha_{1}-\alpha_{3} \\
& \alpha_{3}=f_{3}(\varepsilon)
\end{aligned}
$$

where

$$
f_{i}(\varepsilon)=\frac{1}{1+\exp \left(-b_{i 0}-b_{i 1} \log _{10} \varepsilon\right)} .
$$

The population-average vertical velocity of larvae at a point $z$ in time $t$ is

$$
w(z, t)=\sum_{i=1}^{3} \alpha_{i}(z, t) \mu_{i}
$$

Here $\mu_{i}$ is the mean vertical velocity of larvae in mode $i$ (Table 3.1). The larval velocity $w$ decreases as the dissipation rate increases (Fig. 3-2 d). As a result, larvae on average sink more near the bottom than near the surface, and sink more during flood and ebb tides than during slack tides (Fig. 3-1 e, f).

\subsubsection{Estimating Larval Supply and Settlement}

To characterize the effects of behavior on temporal patterns of larval supply, the AD model was run with no settlement. Larval supply was calculated as the concentration in the bottom 

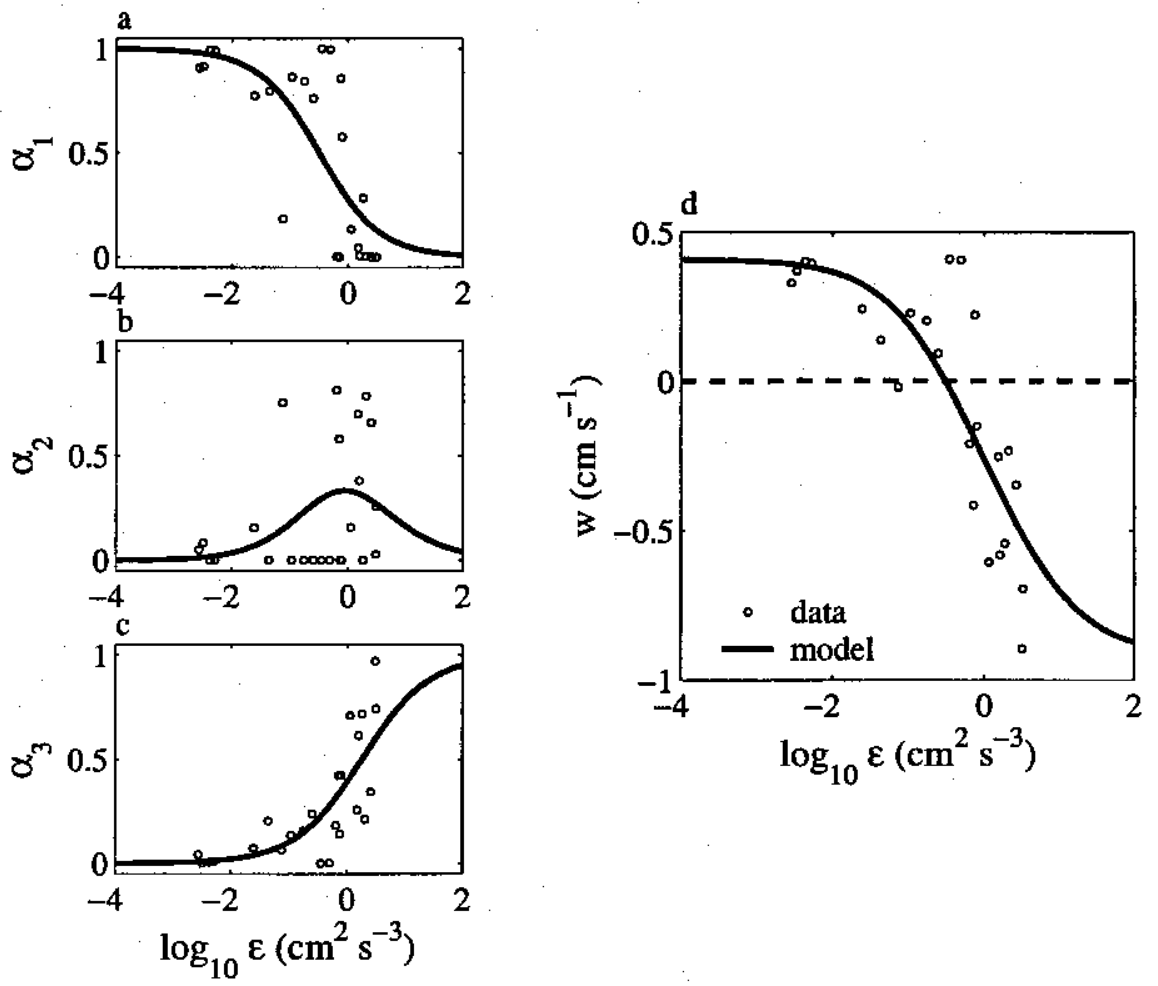

Figure 3-2: Proportions $\alpha_{i}$ of (a) swimming, (b) hovering, and (c) sinking larvae vs. dissipation rate $\log _{10} \varepsilon$ and (d) average larval vertical velocity $w$ vs. dissipation rate $\varepsilon$. Circles are estimates from laboratory experiments [10], solid lines are the form used in model. 
Table 3.1: Parameters used in the turbulence-dependent behavioral velocity functions. The vertical velocity for larvae with behavior $i$ is shown as mean $\pm 1 \mathrm{SD}$. The proportions $\alpha_{i}$ of larvae engaged in each behavior are functions of the dissipation rate, shown in Fig. 3-2 a-c.

\begin{tabular}{lc}
\hline \hline Behavior $i$ & $\begin{array}{c}\text { Velocity }\left(\mathrm{cm} \mathrm{s}^{-1}\right) \\
\mu_{i} \pm \sigma_{i}\end{array}$ \\
\hline (1) swimming & $0.41 \pm 0.16$ \\
(2) hovering & $-0.05 \pm 0.08$ \\
(3) sinking & $-0.92 \pm 0.12$ \\
\hline
\end{tabular}

$1 \mathrm{~cm}$ normalized by the total number of larvae,

$$
C_{b}(t) / C_{T}(t)=\frac{\int_{0}^{1} C(z, t) d z}{\int_{0}^{H} C(z, t) d z}
$$

To explore how the timing of larval supply affects settlement success, larvae in contact with the bottom were allowed to attach and settle with a settlement velocity $s$. Once settled, larvae were unable to re-enter the water column. Three settlement functions were used (Fig. 3-3):

$$
\begin{aligned}
& s(t)=c_{1} \quad \text { (constant) } \\
& s(t)=c_{2}\left(1-u_{*}(t) / u_{* \max }\right) \quad \text { (linear) } \\
& s(t)=\left\{\begin{array}{ll}
0.01 & \text { if } u_{*}(t)<u_{*_{c r}} \\
0 & \text { if } u_{*}(t) \geq u_{*_{c r}}
\end{array} \quad\right. \text { (step) }
\end{aligned}
$$

The linear and step cases include a dependence on the tidally-oscillating shear velocity, where $u_{* \max }=0.1 U_{H_{\infty}}$ and $u_{*_{c r}}$ is the critical shear velocity for bedload transport. The linear and step cases are more realistic than a constant settlement velocity, because larvae are expected to have more difficulty attaching to the bottom at higher shear velocities. The $u_{*_{c r}}$ for mud snail larvae was assumed to be equal to that of average Barnstable Harbor sediment (diameter $=100 \mu \mathrm{m}[26,27]$ ), estimated from a Shields diagram to be $u_{*_{c r}} \approx 1.2$ $\mathrm{cm} \mathrm{s}^{-1}$.

In the step function, larvae have a small settlement velocity $(s=0.01)$ when the shear velocity is below the critical value. In the constant and linear functions, $c_{1}$ and $c_{2}$ were selected so that the settlement velocity averaged over a tidal cycle was the same as for the 

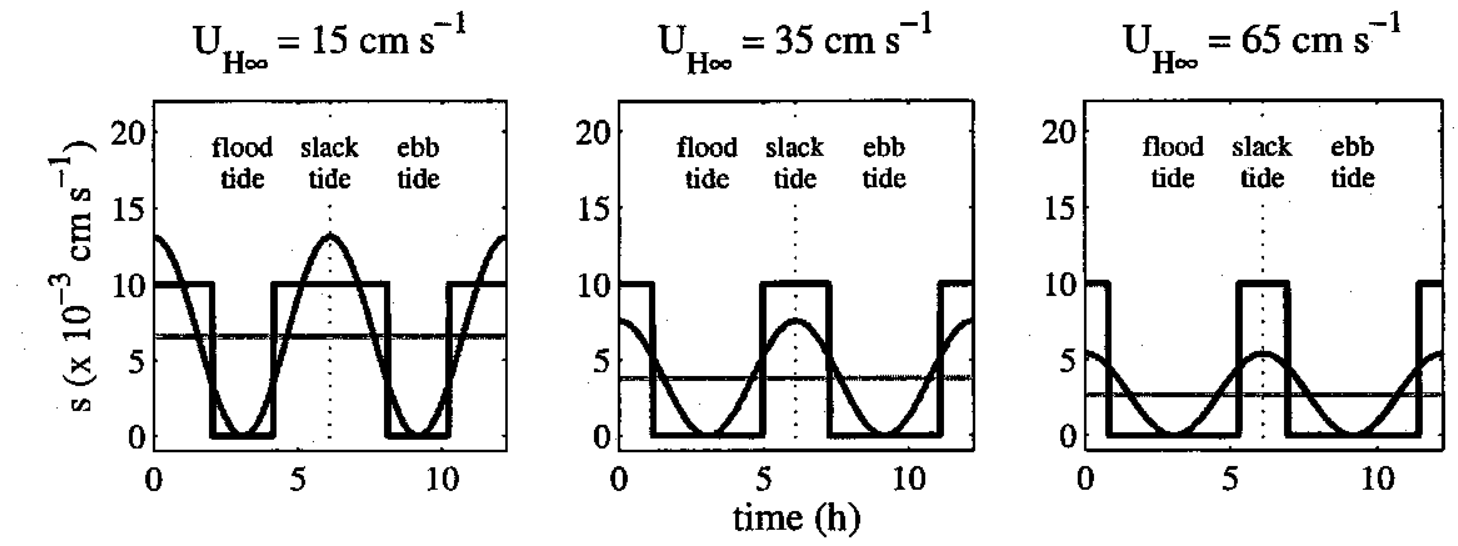

Figure 3-3: Settlement velocities $s$ (3.12) vs. time for three values of $U_{H_{\infty}}$. Line colors indicate settlement function: constant $s$, light gray; linear $s$, medium gray; step $s$, black.

step function,

$$
\bar{s}=\frac{1}{T} \int_{0}^{T} s(t) d t
$$

The time-averaged settlement velocity was greater for model runs with a smaller maximum current velocity $\left(\bar{s}=0.0066\right.$ at $U_{H_{\infty}}=15 ; \bar{s}=0.0038$ at $U_{H_{\infty}}=35 ; \bar{s}=0.0027$ at $U_{H_{\infty}}=$ $65)$, because $u_{*}(t)<u_{*_{c r}}$ for longer time periods. It is reasonable for the settlement velocity to be higher in slower flows, because slower flows are less likely to transport sediments and exert weaker drag forces on larvae as they are trying to settle.

Settlement success $Q$ was characterized by the proportion of larvae that settled within one tidal cycle,

$$
Q=1-\frac{\int_{0}^{H} C(z, T) d z}{\int_{0}^{H} C_{i}(z) d z}
$$

where $C_{i}$ is the initial concentration distribution.

\subsubsection{Particle-Tracking Model}

In the AD model, multiple larval behaviors are implicit in the dissipation-dependent larval velocity $w$ (Section 3.2.3). To determine if an implicit behavior model accurately captures the dynamics of larvae with multiple behaviors, larvae were also modeled using an individual-based particle-tracking (PT) approach. This model allowed behaviors to be mod- 
eled both implicitly, as in the AD model, and explicitly with stochastic behaviors for each individual. The position $z_{n}(t+\Delta t)$ of larva $n$ at time $t+\Delta t$ is given by

$$
z_{n}(t+\Delta t)=z_{n}(t)+\underbrace{\left[w_{n}+\frac{\partial K}{\partial z}\right] \Delta t}_{\text {deterministic }}+\underbrace{\left[2 K\left(z_{n}(t)+\frac{1}{2} \frac{\partial K}{\partial z} \Delta t, t\right) \Delta t\right]^{0.5} \xi_{t}}_{\text {random }}
$$

This is the random-walk equivalent of the 1-D advection diffusion equation, derived from the Fokker-Planck equation [7]. The PT model is corrected for spatially-varying diffusivity $[18,30,25]$, but this correction is unnecessary with linear diffusivity. The second term on the right hand side of the equation gives the larva a deterministic movement, depending on the larval velocity $w_{n}$ and the gradient in eddy diffusivity $\partial K / \partial z$ at position $z_{n}(t)$ and time $t$. The last term of the equation gives the larva an additional random-diffusive movement, where $\xi_{t} \sim N(0,1)$. In (3.15) larval behavior is implicit and deterministic, as in the AD model. When larval behavior is modeled explicitly, the behavior term is stochastic (Section 3.2.3).

Because of the random term in (3.15), larvae were sometimes transported out of the water column to $z_{n}(t+\Delta t)>H$ or $<0$. No-flux boundary conditions were enforced by reflecting the larvae back using

$$
z_{n}(t+\Delta t)= \begin{cases}-z_{n}(t+\Delta t) & \text { if } z_{n}(t+\Delta t)<0 \\ 2 H-z_{n}(t+\Delta t) & \text { if } z_{n}(t+\Delta t)>H\end{cases}
$$

For comparison against the $\mathrm{AD}$ model, the PT model was run with $H=100$ for passive larvae with three different velocities $\left(w_{n}=-0.05,-0.2\right.$, and $\left.-0.5 \mathrm{~cm} \mathrm{~s}^{-1}\right)$ and for behaving larvae with deterministic and stochastic behavior (Section 3.2.3), always with no settlement. The advection diffusion model allowed behaviors to be represented only as a populationaveraged, deterministic velocity (3.10), whereas the particle tracking model enabled the use of individual stochastic behaviors for each larva. The PT model was run with two levels of complexity. First, larval velocity was calculated as a population average (3.10) as in the AD model. Second, each larva was assigned to behavior $i$ with probability $\alpha_{i}$ at each time step, and the velocity of each larva in behavior $i$ was drawn from a normal distribution with mean $\mu_{i}$ and variance $\sigma_{i}^{2}$ (Table 3.1 ),

$$
P\left\{w_{n}\left(z_{n}(t), t\right) \sim N\left(\mu_{i}, \sigma_{i}^{2}\right)\right\}=\alpha_{i}\left(z_{n}(t), t\right)
$$

The PT model was run for a complete tidal cycle with a 1-hour spin-up time and a 
uniform initial distribution. Four different time steps $(\Delta t=0.125,0.25,0.5$, and $1.0 \mathrm{~s})$ were used to characterize the errors associated with time-step size. PT solutions were taken as the average of 10 model runs. Because the time steps differed in the AD and PT models, PT solutions were averaged over $100 \mathrm{~s}$ intervals so that solution time points corresponded to those of the AD model. For each model comparison, model outputs were judged by the similarity of larval concentration over all $z$ and $t$ grid points.

The AD and PT models include two main simplifying assumptions about behavior. First, responses of larvae to turbulence are the only behaviors included in the model, even though real mud snail larvae exhibit sediment-selection behavior [27] that probably influences the distribution of settled larvae. In the model, settlement requires contact with the bottom there is no "reaction distance" [e.g. 15] over which larvae can respond to the bottom, because there is no settlement-related behavior. Larval "tumbling" [e.g. 20, 24] is also omitted larvae that fail to settle on contact with the bed are not allowed to remain on the bottom by rolling. The second assumption is that behaviors depend only on instantaneous dissipation rates and not on the larval history of behavior. For example, in the PT model larvae can switch behavioral modes from one time-step to the next, even though real larvae probably have some minimum response time before they can switch behaviors. These behavioral simplifications make the models more tractable and make it easier to evaluate the effects of turbulence-induced sinking on larval supply and settlement. 


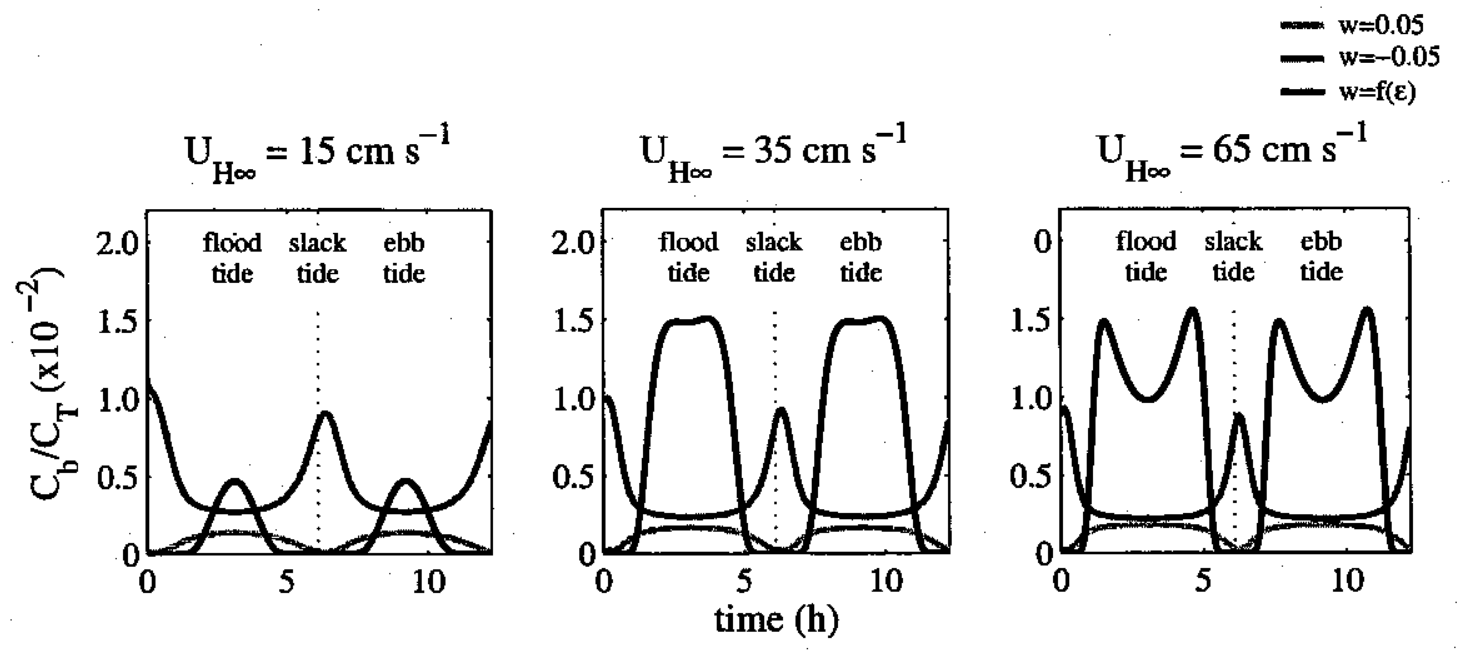

Figure 3-4: Larval supply vs. time for three values of $U_{H_{\infty}}$. Near-bed larval concentrations $C_{b}$ are normalized by the depth-integrated concentration $C_{T}$. Line colors indicate behavior: $w=0.05 \mathrm{~cm} \mathrm{~s}^{-1}$, light gray; $w=-0.05 \mathrm{~cm} \mathrm{~s}^{-1}$, medium gray; $w=f(\varepsilon)$, black. $H=5 \mathrm{~m}$.

\subsection{Results}

\subsubsection{Larval Supply}

Temporal patterns of larval supply are very different for passive larvae than for those with turbulence-dependent behavior (Fig. 3-4). For all current speeds, negatively-buoyant larvae $\left(w=-0.05 \mathrm{~cm} \mathrm{~s}^{-1}\right)$ have large peaks in near-bed concentrations at slack tides. These peaks grow slightly smaller and narrower as the maximum current velocity increases. In contrast, positively buoyant larvae $\left(w=0.05 \mathrm{~cm} \mathrm{~s}^{-1}\right)$ have elevated near-bed concentrations during flood and ebb tides. These "peaks" are actually very low near-bed concentrations however, and they change little with increases in the maximum current velocity. The supply of behaving larvae $(w=f(\varepsilon))$ to the bed is also greatest during flood and ebb tides, but is strongly dependent on the maximum current velocity. For $U_{H_{\infty}}=15 \mathrm{~cm} \mathrm{~s}^{-1}$, the dissipation rate is always low enough that the larvae are swimming upward most of the time (Fig. 3-1e); very few of these larvae concentrate near the bed. For $U_{H_{\infty}}=35 \mathrm{~cm} \mathrm{~s}^{-1}$, behaving larvae have broad peaks in near-bed concentration during flood/ebb tides. For $U_{H_{\infty}}=65 \mathrm{~cm} \mathrm{~s}^{-1}$ these peaks are even broader, but there is a slight reduction in near-bed concentration at peak flood and ebb tides because of intense turbulent mixing. For $U_{H_{\infty}}=35$ and $65 \mathrm{~cm}$ $\mathrm{s}^{-1}$, behaving larvae have higher near-bed concentrations than negatively buoyant larvae during most of the tidal cycle, excepting slack tides. 

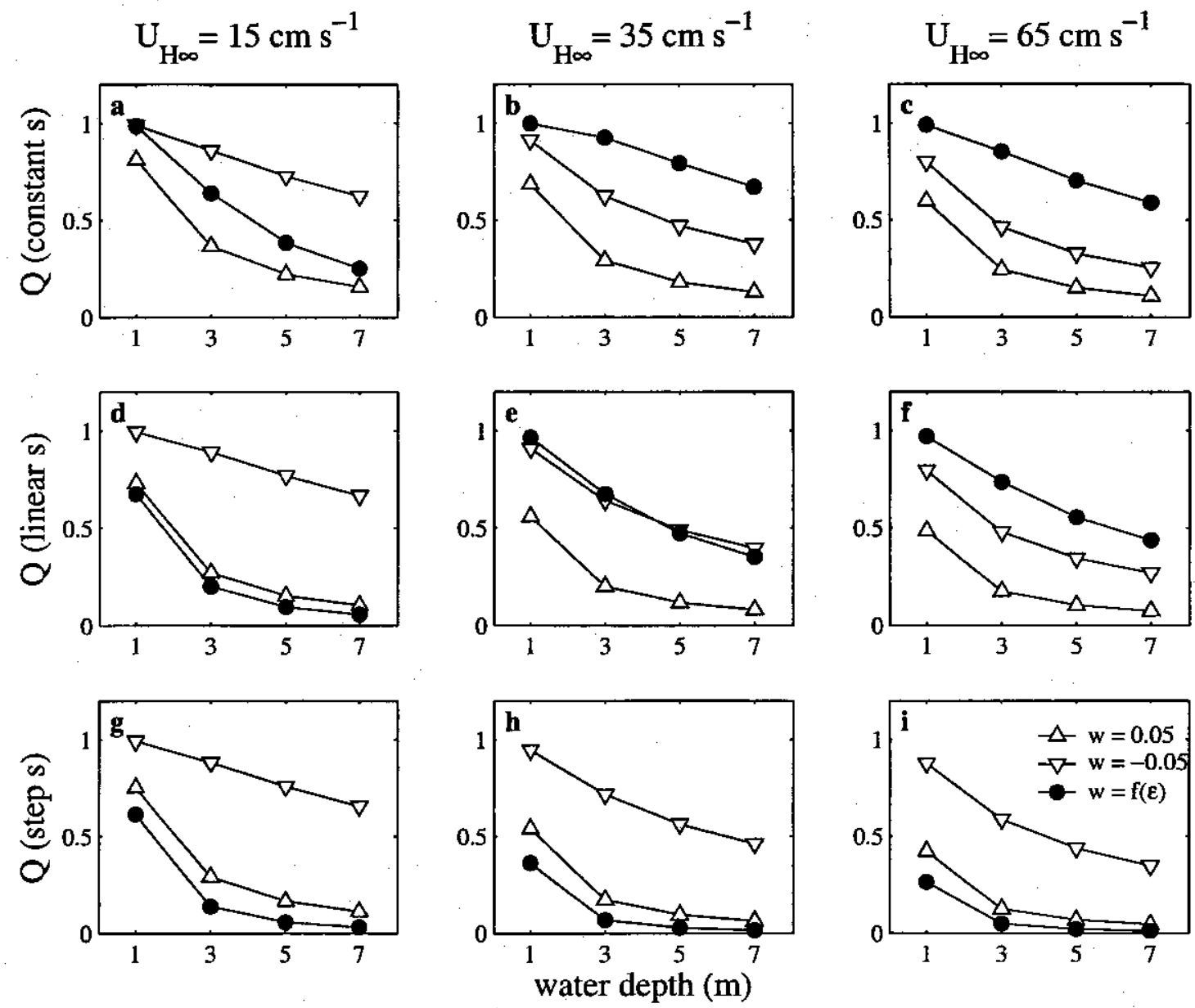

Figure 3-5: Proportion of larvae settled in 1 tidal cycle $Q$ vs. water depth $H$ for three flow velocities $U_{H_{\infty}}\left(\mathrm{a}, \mathrm{d}, \mathrm{g}, U_{H_{\infty}}=15 \mathrm{~cm} \mathrm{~s}^{-1} ; \mathrm{b}, \mathrm{e}, \mathrm{h}, U_{H_{\infty}}=35 \mathrm{~cm} \mathrm{~s}^{-1} ; \mathrm{c}, \mathrm{f}, \mathrm{i}, U_{H_{\infty}}=65\right.$ $\mathrm{cm} \mathrm{s}^{-1}$ ) and three settlement velocity functions $s$ (a, b, c, constant $s ; \mathrm{d}$, e, f, linear $s ; \mathrm{g}, \mathrm{h}$, i, step $s$ ). Symbols indicate behavior function: $w=0.05 \mathrm{~cm} \mathrm{~s}^{-1}, \Delta ; w=-0.05 \mathrm{~cm} \mathrm{~s}^{-1}, \nabla$; $w=f(\varepsilon), \bullet$. 


\subsubsection{Settlement Success}

Behavioral effects on settlement success can be considered as two separate questions: 1) Under a given set of physical conditions, which behavior is most successful for settlement? and 2) For a given behavior, which physical conditions allow larvae to settle most successfully? Results addressing these questions are discussed separately below.

\section{The most successful behavior for given conditions}

Larval settlement success depends on combined effects of behavior and the timing of larval supply and attachment probability (Fig. 3-5). Although negative buoyancy always results in more settlement than positive buoyancy, the relative benefits of turbulence-dependent behavior depend on both the current regime and the settlement function. In the slowest currents $\left(U_{H_{\infty}}=15 \mathrm{~cm} \mathrm{~s}^{-1}\right)$, behaving larvae settle less successfully than passive larvae (Fig. 3-5 d, g) because they are more positively buoyant and have lower larval supply throughout the tidal cycle (Figs. 3-1 e and 3-4 a). When settlement velocity is a step function, behaving larvae are less successful than positively-buoyant larvae at all current speeds (Fig. 3-5 g-i) because behaving larvae are swimming upward during slack tides and have very low larval supply when settlement occurs (Figs. 3-3 and 3-4). When settlement velocity is linear or constant, behaving larvae do as well as or better than negatively-buoyant ones at moderate $\left(U_{H_{\infty}}=35 \mathrm{~cm} \mathrm{~s}^{-1}\right)$ and fast $\left(U_{H_{\infty}}=65 \mathrm{~cm} \mathrm{~s}^{-1}\right)$ current speeds (Fig. 3-5 e,f). The relative benefits of different behaviors are consistent with depth (but see Fig. 3-5 e), suggesting that these results can be generalized for larvae settling in any shallow habitats.

\section{The most favorable conditions for a given behavior}

Passive larvae settle most successfully in the slowest currents $\left(U_{H_{\infty}}=15 \mathrm{~cm} \mathrm{~s}^{-1}\right)$, regardless of whether they are positively or negatively buoyant and regardless of the settlement function (Fig. 3-6a-b). It is intuitive that negatively-buoyant larvae would settle more successfully when the diffusivity is low, because diffusivity mixes larvae upward that would otherwise sink straight to the bottom. It is less obvious why positively-buoyant larvae would settle more successfully when diffusivity is low, because diffusivity mixes larvae downward that would otherwise float to the surface. This counter-intuitive result can be explained by the fact that larval supply is similar for all flow speeds, but there is a higher time-averaged settlement velocity in slower flows.

Unlike passive larvae, larvae with turbulence-dependent behavior settle most successfully 


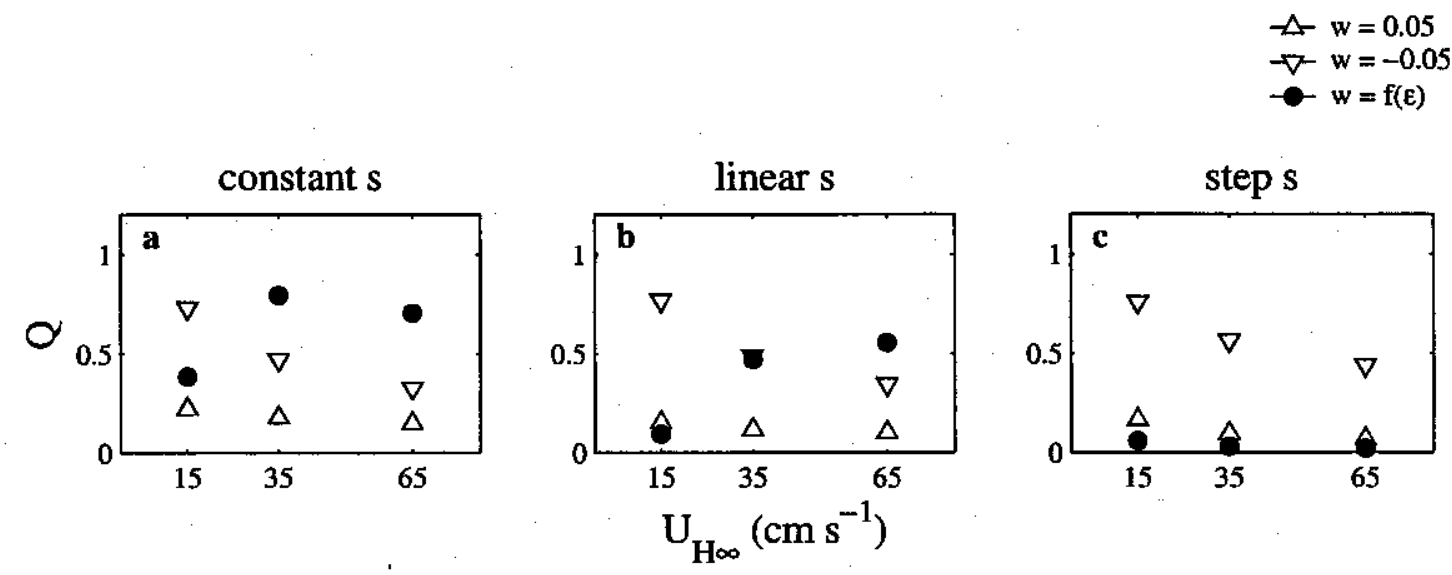

Figure 3-6: Proportion of larvae settled in 1 tidal cycle $Q$ vs. current velocity $U_{H_{\infty}}$ for three settlement velocity functions $s$. Symbols indicate behavior function: $w=0.05 \mathrm{~cm}$ $\mathrm{s}^{-1}, \triangle ; w=-0.05 \mathrm{~cm} \mathrm{~s}^{-1}, \nabla ; w=f(\varepsilon), \bullet$.

in the strongest currents $\left(U_{H_{\infty}}=65 \mathrm{~cm} \mathrm{~s}^{-1}\right)$ for the constant (not shown) and linear settlement functions (Fig. 3-6c). This result is due to the fact that larval supply is high over a longer time period as current speed increases (Fig. 3-4). The fact that behaving larvae settle more successfully in faster currents is interesting because the time-averaged settlement velocity $\bar{s}$ is actually lowest in the strongest currents. This result indicates that having high larval supply can more than compensate for the lower settlement velocities expected in more turbulent environments. 

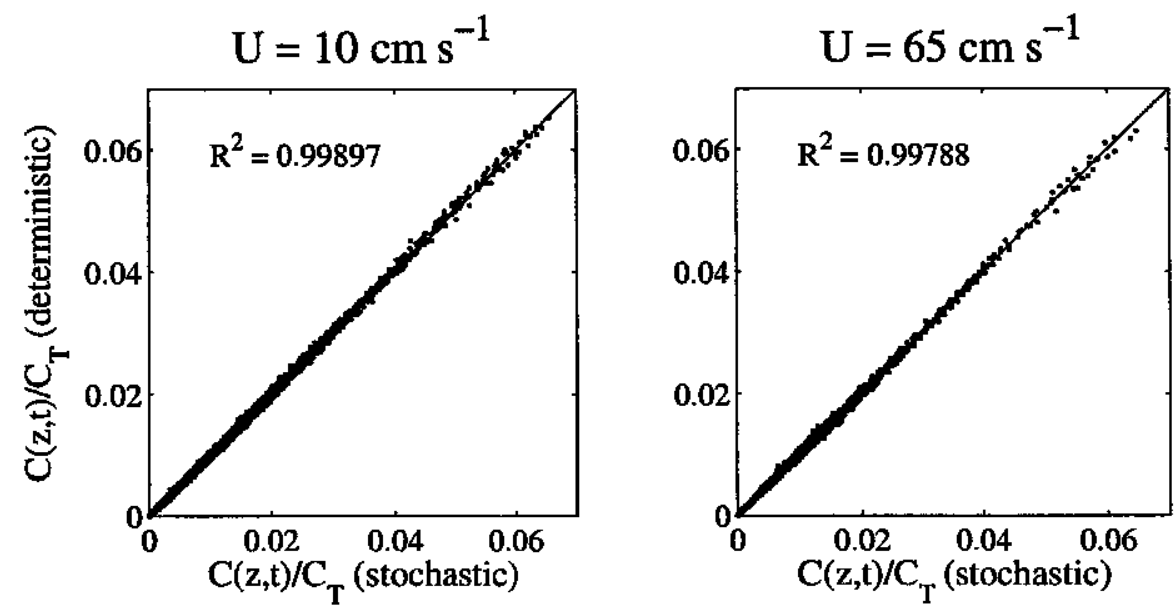

Figure 3-7: Larval concentrations from PT model with deterministic behaviors (y-axis) vs. stochastic behaviors ( $\mathrm{x}$-axis) for two flow speeds. Solutions are sampled every ten minutes and normalized by the depth-integrated concentration $C_{T}$. Solid lines are 1:1. 


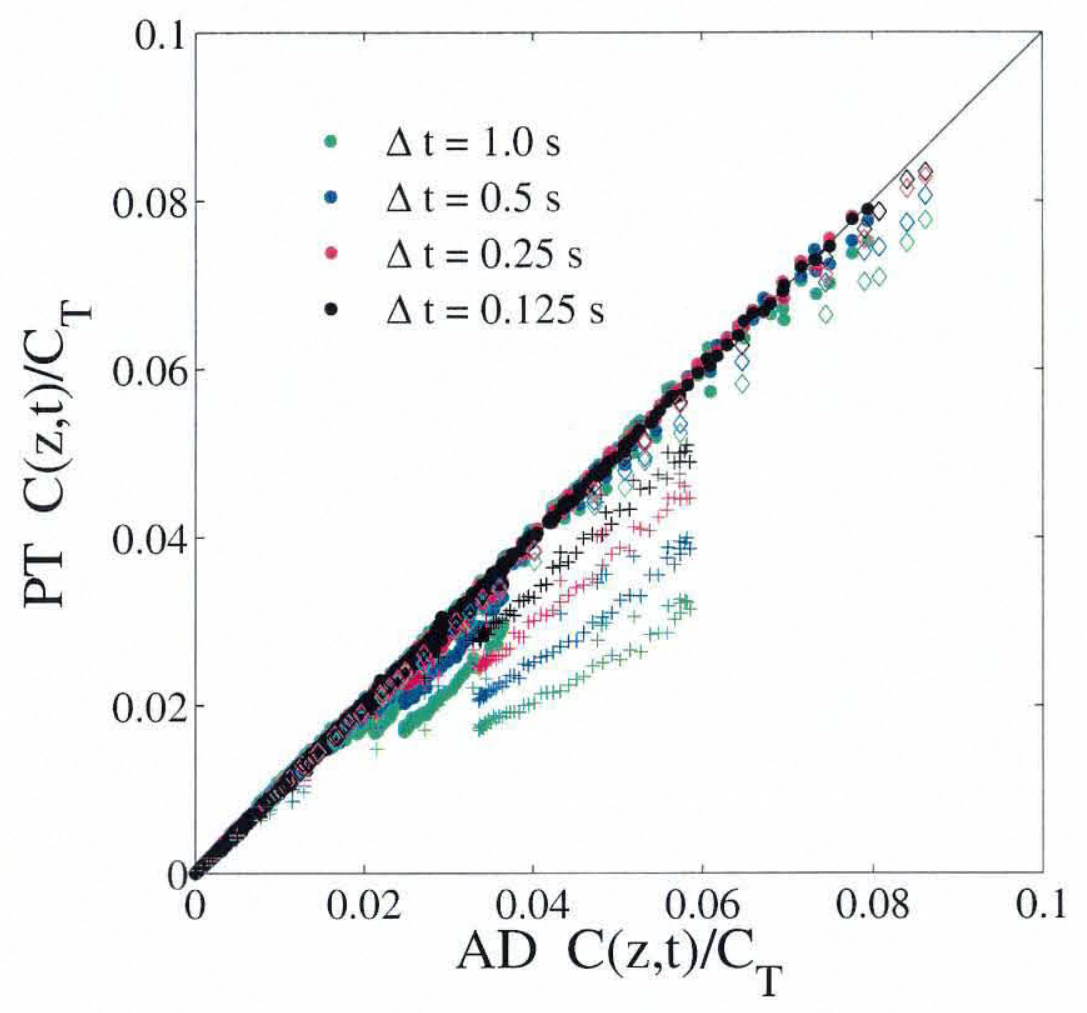

Figure 3-8: Larval concentrations from PT model (y-axis) vs. AD model (x-axis) for behaving larvae $(w=f(\varepsilon))$ for $U_{H_{\infty}}=65 \mathrm{~cm} \mathrm{~s}^{-1}$ and four different time-steps. Solutions are sampled every ten minutes and normalized by the depth-integrated concentration $C_{T}$. Crosses indicate larval concentrations in the bottom $1 \mathrm{~cm}$, diamonds indicate concentrations in the upper $1 \mathrm{~cm}$. Solid line is 1:1. 

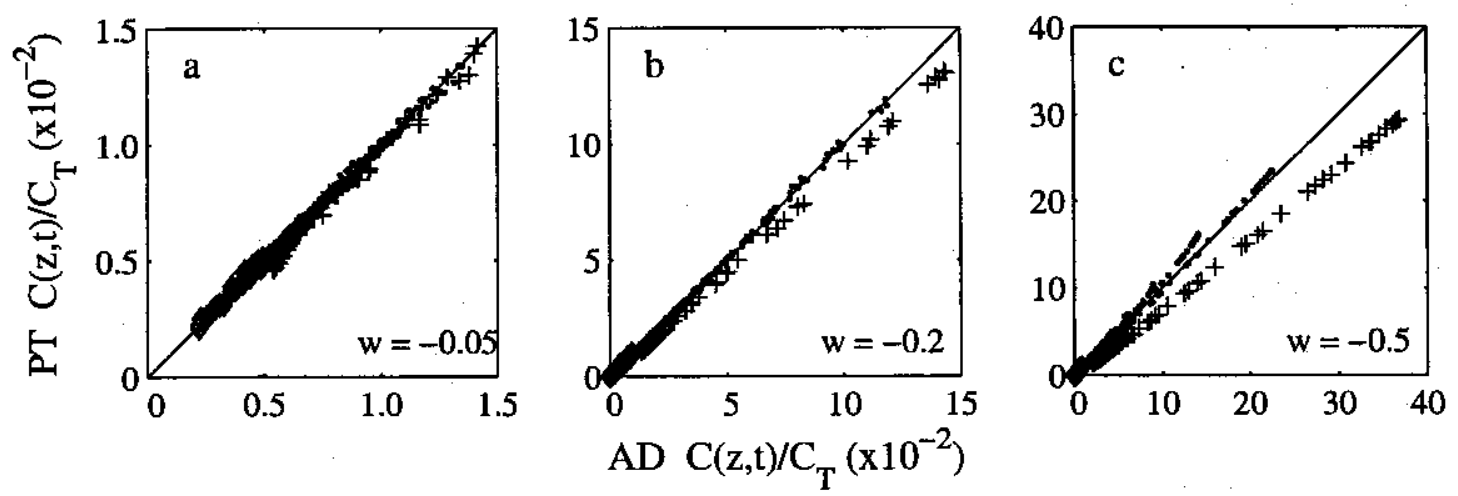

Figure 3-9: Larval concentrations from PT model (y-axis) vs. AD model ( $x$-axis) for negatively buoyant larvae with (a) $w=-0.05 \mathrm{~cm} \mathrm{~s}^{-1}$, (b) $w=-0.2 \mathrm{~cm} \mathrm{~s}^{-1}$, and (c) $w=-0.5 \mathrm{~cm} \mathrm{~s}^{-1}$ for $U_{H_{\infty}}=65 \mathrm{~cm} \mathrm{~s}^{-1}, \Delta t=1.0 \mathrm{~s}$. Solutions are are sampled every ten minutes and normalized by the depth-integrated concentration $C_{T}$. Crosses indicate larval concentrations in the bottom $1 \mathrm{~cm}$, diamonds indicate concentrations in the upper $1 \mathrm{~cm}$. Dots indicate larval concentrations at the inner grid points $(1<z<100 \mathrm{~cm})$ Solid lines are $1: 1$. 


\subsubsection{Advection-Diffusion vs. Particle Tracking model}

The particle tracking model was run for two current speeds with behaviors specified both implicitly (3.10) and explicitly (3.17), and the larval concentrations for the two model versions are very similar over all $z$ and $t$ (Fig. 3-7). Both model versions contain inaccuracies due to time-step issues (see below), but the solutions are affected equally. Given the nearly identical results for implicit and explicit behaviors, it is safe to conclude that there is no loss of accuracy when behaviors are specified implicitly as a population-average velocity.

When the PT solution for implicit behavior is compared against the AD version (Fig. 38 ), it is clear that the PT solution contains significant errors near the boundaries due to the time step. The PT solution deviates less from the AD solution as the time-step is reduced, and presumably would be accurate if the time-step were small enough. The PT model (3.15) is equivalent to the AD model (3.1) only as the number of particles $N \rightarrow \infty$ and as $\Delta t \rightarrow 0$ [7]. For $\Delta t>0$, the stochastic terms in (3.15) ensure that particles will sometimes travel a long distance and bounce off the boundaries. The result is an underestimate of concentration at the boundaries, as seen in Figure 3-8.

The underestimation of near-boundary concentration is more pronounced as the advective velocity $w$ grows larger in magnitude (Fig. 3-9). When both models were run for passive larvae with three different values of $w\left(=[-0.05,-0.2,-0.5] \mathrm{cm} \mathrm{s}^{-1}\right)$, the PT solution was reasonably accurate only when larvae were nearly neutrally-buoyant $(w=-0.05)$.

For the hydrodynamic conditions and behaviors discussed in this paper, the AD model is preferable to the PT model for two reasons. First, behavioral velocities are small enough relative to the diffusivity that multiple behaviors can be modeled implicitly as a populationaverage velocity with no loss of accuracy. Second, the PT model requires very small time steps to minimize errors, particularly for larger $w$. Although the PT model is attractive in allowing greater flexibility in modeling larval behavior, it cannot be counted on to produce accurate results near the boundaries over the short spatial scales modeled here.

\subsection{Discussion}

\subsubsection{Larval Supply}

Turbulence-induced sinking behavior significantly affects the temporal patterns of larval supply to the bed. In moderate to strong currents, negatively-buoyant larvae have large peaks in near-bed concentration during slack tides, whereas behaving larvae are highly concentrated at the bed during flood and ebb tides. These opposite patterns of larval 
supply could each be optimal for settlement under different environmental conditions.

Intuitively it might seem that larvae would benefit most from concentrating near the bottom during slack tides, when shear stress is low and sediments are stable. Yet as pointed out by Eckman et al [8], there is a cost to reaching the bottom during slack tide if the substrate is unsuitable for settlement. Larvae that reject substrates at slack tide have to wait for currents to increase again and carry them away to potentially better sites. Furthermore, larvae that contact the bottom only during slack tides might have just one settlement opportunity per tidal cycle. In contrast, larvae that reach the bottom during flood and ebb tides could benefit from being able to test substrates and still be transported rapidly away from unsuitable sites. Larvae with a high near-bed concentration during most of the tidal cycle could also have more settlement opportunities, for example during lulls in turbulence (discussed below). Negative buoyancy results in peaks of larval supply at slack tides, and might confer the optimal timing of larval supply in a world where all substrates are suitable for settlement. Turbulence-induced sinking results in high larval supply throughout flood/ebb tides, and is potentially a more successful strategy in patchy environments.

\subsubsection{Settlement Success}

In the simplified, 1-dimensional environment explored in this paper, larvae that sink in turbulence are more successful settlers than passive larvae under some conditions. In moderate to fast currents $\left(U_{H_{\infty}}=35\right.$ and $\left.65 \mathrm{~cm} \mathrm{~s}^{-1}\right)$ turbulence-induced sinking is the most successful behavior for settlement as long as the settlement velocity $s$ is non-zero during flood/ebb tides (constant and linear $s$ ). When the settlement velocity is zero during peaks of larval supply (during flood and ebb tides, step $s$ ), then almost no settlement occurs. The timing of near-bed hydrodynamics is therefore key to determining whether turbulence-induced sinking can be a more successful settlement strategy than passive transport.

The simplified settlement functions in this model ignored two important boundary layer characteristics that would probably improve the relative settlement success of behaving larvae. First, the model excluded turbulence intermittency at the bed. Even during flood and ebb tides, there are lulls between turbulent bursts at the bed. The duration of these lulls can be estimated as $\sim 6 H / U_{H_{\infty}}[5,22]$, and at peak flood/ebb tides would be on the order of $\sim 10$ to $70 \mathrm{~s}$ for the depths and current speeds used in this study. The shear stress is lower during lulls, and larvae would almost certainly be able to stick or burrow into sediments during some of these periods. Behaving larvae that have high larval supply during flood/ebb tides are probably able to exploit the intermittent stress lulls for settlement. 
The second boundary-layer simplification in this model was the absence of roughness elements. Roughness elements influence the vertical diffusivity profile near the bed as well as the horizontal distribution of shear stress along the bottom. Although the roughnesselement spacing has complex effects on larval attachment probability [5], larval settlement is generally greater over dense roughness elements than over flat beds [9]. Flat beds are rare in tidal inlets such as Barnstable Harbor, where ripples and epifauna provide smallscale bottom topography. Mud snails themselves form dense aggregations with a roughness height of 1-2 cm (Fig. 1-1), and their presence could alter the diffusivity and shear stress profiles to enhance settlement of larvae during flood/ebb tides.

Modeled larvae were allowed no behavioral responses to environmental variables other than turbulence, but this is clearly an oversimplification. Mud snail larvae settle selectively in sediment from adult habitats [27], and changes in behavior near the bed could increase both the supply of larvae and the attachment probability. Larvae within a short distance (e.g. $\leq 1 \mathrm{~cm}$ ) of the bottom probably sense biological and chemical properties of the sediments, and might have a lower probability of swimming upward when these sediments are attractive for settlement. This would result in a more negative average larval velocity near the bed, and larvae would tend to pile up near the bottom. In the laboratory, larvae settle by burrowing into sediments; this burrowing behavior could increase the settlement velocity by increasing the shear velocity at which larvae are eroded. Any additional behavioral responses would be likely to increase larval settlement success, although it remains unclear whether larvae that sink in turbulence would have greater overall settlement success than passive larvae if substrate selection were allowed.

Finally, this model does allow some general predictions about where larvae are most likely to settle, given their behavior. Although negatively buoyant larvae settle successfully under all conditions, the settlement of passive larvae is most likely to occur in slow to moderate currents. Thus for intertidal species that prefer calm or sheltered habitats, no response to turbulence is necessary. On the other hand, larvae with turbulence-dependent behavior are more likely to settle in faster currents such as those in Barnstable Harbor. Mud snails are abundant in Barnstable Harbor, and it is tempting to conclude that mud snail larvae sink in turbulence in order to settle into preferred habitats. However it is still impossible to reject the alternative hypothesis that gastropod larvae sink in turbulence to avoid predators. Regardless of the ultimate reason for sinking, it is clear that larvae with this behavior could experience enhanced settlement in turbulent coastal inlets relative to quieter inlets or calmer offshore waters. 


\section{Bibliography}

[1] J. C. Ayers. The hydrography of Barnstable Harbor, Massachusetts. Limnology and Oceanography, 4:448-462, 1959.

[2] C. A. Butman, J. P. Grassle, and E. J. Buskey. Horizontal swimming and gravitational sinking of Capitella sp. I (Annelida: Polychaeta) larvae: implications for settlement. Ophelia, 29:43-57, 1988.

[3] F. S. Chia, R. Koss, and L. R. Bickell. Fine structural study of the statocysts in the veliger larva of the nudibranch, Rostanga pulchra. Cell Tissue Research, 214:67-80, 1981.

[4] S. M. Cragg. Swimming behaviour of the larvae of Pecten maximus (L.) (Bivalvia). J. Mar. Biol. Assoc. UK, 60:551-564, 1980.

[5] J. P. Crimaldi, J. K. Thompson, J. H. Rosman, R. J. Lowe, and J. R. Koseff. Hydrodynamics of larval settlement: The influence of turbulent stress events at potential recruitment sites. Limnology and Oceanography, 47:1137-1151, 2002.

[6] T. M. Dillon and D. R. Caldwell. The Batchelor spectrum and dissipation in the upper ocean. Journal of Geophysical Research, 85:1910-1916, 1980.

[7] K. N. Dimou and E. E. Adams. A random-walk, particle tracking model for well-mixed estuaries and coastal waters. Estuarine, Coastal and Shelf Science, 37:99-110, 1993.

[8] J. E. Eckman, F. E. Werner, and T. F. Gross. Modelling some effects of behavior on larval settlement in a turbulent boundary layer. Deep-Sea Research II, 41:185-208, 1994.

[9] J.E. Eckman. A model of passive settlement by planktonic larvae onto bottoms of differing roughness. Limnology and Oceanography, 35:887-901, 1990. 
[10] H. L. Fuchs, L. S. Mullineaux, and A. R. Solow. Sinking behavior of gastropod larvae (Ilyanassa obsoleta) in turbulence. Limnology and Oceanography, 49(6):1937-1948, 2004.

[11] A. E. Gargett, T. B. Sanford, and T. R. Osborn. Surface mixing layers in the Sargasso Sea. Journal of Physical Oceanography, 9:1090-1111, 1979.

[12] R. George, R. E. Flick, and R. T. Guza. Observations of turbulence in the surf zone. Journal of Geophysical Research, 99:801-810, 1994.

[13] W. D. Grant and O. S. Madsen. The continental-shelf bottom boundary layer. Ann. Rev. Fluid Mech., 18:265-305, 1986.

[14] T. F. Gross and A. R. M. Nowell. Spectral scaling in a tidal boundary layer. Journal of Physical Oceanography, 15:496-508, 1985.

[15] T. F. Gross, F. E. Werner, and J. E. Eckman. Numerical modeling of larval settlement in turbulent bottom boundary layers. Journal of Marine Research, 50:611-642, 1992.

[16] D. Grünbaum. Advection-diffusion equations for internal state-mediated random walks. SIAM Journal on Applied Math, 61:43-73, 2000.

[17] A.D. Heathershaw. The turbulent structure of the bottom boundary layer in a tidal current. Geophys. J. R. Astr. Soc., 58:395-430, 1979.

[18] J. R. Hunter, P. D. Graig, and H. E. Phillips. On the use of random walk models with spatially variable diffusivity. Journal of Computational Physics, 106:366-376, 1993.

[19] M. E. Huntley and M. Zhou. Influence of animals on turbulence in the sea. Marine Ecology Progress Series, 273:65-79, 2004.

[20] P. R. Jonsson, C. André, and M. Lindegarth. Swimming behaviour of marine bivalve larvae in a flume boundary-layer flow: Evidence for near-bottom confinement. Marine Ecology Progress Series, 79:67-76, 1991.

[21] P. K. Kundu. Fluid Mechanics. Academic Press, 1990.

[22] I. Nezu and H. Nakagawa. Turbulence in Open-Channel Flows. A. A. Balkema, Rotterdam, 1993.

[23] N. S. Oakey and J. A. Elliott. Dissipation within the surface mixed layer. Journal of Physical Oceanography, 12:171-185, 1982. 
[24] J. P. Pawlik and C. A. Butman. Settlement of a marine tube worm as a function of current velocity: Interacting effects of hydrodynamics and behavior. Limnology and Oceanography, 38:1730-1740, 1993.

[25] O.N. Ross and J. Sharples. Recipe for 1-D Lagrangian particle tracking models in space-varying diffusivity. Limnology and Oceanography: Methods, 2:289-302, 2004.

[26] H. L. Sanders, E. M. Gousdmit, E. L. Mills, and G. E. Hampson. A study of the intertidal fauna of Barnstable Harbor, Massachusetts. Limnology and Oceanography, 7:63-79, 1962.

[27] R. S. Scheltema. Metamorphosis of the veliger larvae of Nassarius obsoletus (Gastropoda) in response to bottom sediment. Biological Bulletin, 120:92-109, 1961.

[28] H. Tennekes and J. L. Lumley. A First Course in Turbulence. MIT Press, 1972.

[29] J. H. Trowbridge, W. R. Geyer, M. M. Bowen, and A. J. Williams, III. Near-bottom turbulence measurements in a partially mixed estuary: Turbulent energy balance, velocity structure, and along-channel momentum balance. Journal of Physical Oceanography, 29:3056-3072, 1999.

[30] A. W. Visser. Using random walk models to simulate the vertical distribution of particles in a turbulent water column. Marine Ecology Progress Series, 158:275-281, 1997.

[31] C. M. Young. Behavior and locomotion during the dispersal phase of larval life. In L. McEdward, editor, Ecology of Marine Invertebrate Larvae, pages 249-278. CRC Press, 1995. 


\section{Chapter 4}

\section{Larval behavior in turbulence: Maximum-likelihood estimates from field plankton distributions}

\subsection{Introduction}

Larval behavior contributes to larval vertical distributions, which in turn influence dispersal distances and the supply of larvae to benthic habitats. Larval supply is correlated to settlement at least over $\sim$ weekly time scales [24,37], and behavioral effects on larval supply are important insofar as larval supply can be considered a proxy for settlement. Behaviors that influence the delivery of larvae to benthic habitats are still poorly understood, but are potentially very important in determining spatial and temporal settlement patterns.

Most of our knowledge about larval behavior comes from laboratory studies, but these studies provide limited insight into larval behavior under natural conditions. Turbulence $[9$, $27,45]$ and many other physical [e.g., 8, 10,39] and chemical [e.g., 17, 26, 40] cues elicit larval behaviors in the laboratory. In the natural environment however, larvae encounter multiple, simultaneous cues that change over different spatial and temporal scales. Taken together, these multiple cues could suppress or enhance behaviors. Turbulence has been identified as a potentially important, settlement-related cue for blue crabs [45] and mud snails (Ilyanassa obsoleta) [9] in the laboratory, but the effect of turbulence on larval behavior has yet to be tested in the environment. 
Estuaries are an ideal place to field-test whether larvae respond to turbulence. Turbulence in estuaries changes rapidly over tidal periods and varies over short spatial scales (m). Most other physical cues (e.g., pressure, temperature, salinity) also vary over relatively short temporal (h) and spatial scales ( $\mathrm{m}$ to $\mathrm{km}$ ), but none vary in space and time in the same way turbulence does. Therefore responses to other physical cues are unlikely to be mistaken for a response to turbulence. Larval behaviors may depend on multiple physical factors, all of which vary in estuaries. If a larval response to turbulence is detected in this dynamic environment, then turbulence could be taken as an important determinant of overall behavior.

The present study was conducted at Barnstable Harbor, MA (USA), in order to estimate larval responses to turbulence in the field. Barnstable Harbor is a well-mixed coastal inlet with low freshwater inflow. The boundary layer is fully turbulent and depth-limited, with maximum current speeds of 50 to $80 \mathrm{~cm} \mathrm{~s}^{-1}[1,20]$. The tidal range averages $\sim 3 \mathrm{~m}$, and $60 \%$ of the bottom is exposed at low tide. The intertidal flats are covered with well-sorted, fine sand and silt, with an average sediment grain diameter of $\sim 0.1 \mathrm{~mm}$ throughout the harbor $[35,33]$. Mud snails are the most conspicuously abundant megafauna on the intertidal flats, and were a focus of this study.

We formed two hypotheses about mud snail larval behavior in the field, based on our previous work on mud snail larvae. In the laboratory, competent (able to metamorphose) mud snail larvae exhibit three behaviors: swimming, hovering, and sinking with the velums withdrawn. The proportion of sinking larvae increases exponentially with the turbulence dissipation rate $\varepsilon$, and on average larvae switch from upward-swimming to sinking at dissipation rate of about $10^{-1} \mathrm{~cm}^{2} \mathrm{~s}^{-3}$. Modeling results suggest that this behavior will enhance settlement in coastal inlets like Barnstable Harbor. We hypothesize that competent larvae have a similar response to turbulence in the field, and sink more in stronger turbulence. Because sinking in turbulence is thought to be a settlement-related behavior, we hypothesize that pre-competent larvae have little or no response to turbulence.

We also used this study as an opportunity to ask the question, do larvae respond differently to turbulence on flood and ebb tides? Tidally-dependent behaviors allow larvae of some estuarine crab species to exit or enter coastal embayments at appropriate life stages $[5,45]$. Mud snail larvae might have different settlement success if they sink to the bottom during flood vs. ebb tides. Although our laboratory results allow us to predict that mud snail larvae will sink more in stronger turbulence, our experiments were conducted at constant temperature and salinity, giving us no empirical basis to predict whether this behavior depends on tidal stage. Our field study was done in a tidal environment, allowing us to test 
whether tidal stage affects the larval response to turbulence.

Larval behaviors are difficult to quantify in controlled experiments, let alone in uncontrolled natural habitats. Larval ecologists often use the vertical distributions of larvae in the field to speculate about larval behavior [e.g., 3, 5, 29]. Remote sampling techniques provide more quantitative ways to observe and estimate plankton velocities in the field $[11,12]$, but species-level analyses of remotely-sampled data are still difficult or impossible. In this study, behaviors were estimated quantitatively from the vertical distributions of larvae in a turbulent boundary layer, rather than from behavioral observations. Larval velocities were estimated as a function of the turbulence dissipation rate, using a maximum likelihood analysis of larval concentration distributions. These maximum-likelihood behavior estimates represent population-level responses to turbulence. The results suggest that other cues are also important, but turbulence does elicit a strong behavioral response for crab and gastropod larvae in the field.

\subsection{Methods}

\subsubsection{Plankton Samples}

Plankton samples and CTD data were collected from a small boat moored in the Barnstable Harbor channel (Fig. 4-1) in summer 2004 (22, 27, 29 July). Each day involved 10 hours of sampling beginning at 07:30. Hourly measurements consisted of one CTD profile and one vertical profile of plankton samples. CTD profiles were collected with an Ocean Sensors OS200. Plankton samples were collected at the surface and in 1-m increments to the bottom (Fig. 4-2), using an Ebara dominator pump with a Great Plains Industries TM200 flowmeter. A Scotty downrigger was used to set the plankton pump at precise depths. For each plankton sample, $300 \mathrm{~L}$ of water was pumped through a $200 \mu \mathrm{m}$-mesh plankton net.

Plankton samples were stored overnight at $4{ }^{\circ} \mathrm{C}$ and preserved on the following day except the 22 July samples, which were preserved 2 days later. Samples were fixed in $4 \%$ formalin with borax buffer for up to 2 weeks, and then transferred to buffered $80 \%$ ethanol. For sorting, 22 July samples were sieved into $200-500 \mu \mathrm{m}$ and $>500 \mu \mathrm{m}$ size fractions. All other samples were sieved into $200-425 \mu \mathrm{m}$ and $>425 \mu \mathrm{m}$ size fractions. These size fractions correspond to the approximate size ranges of pre-competent and competent mud snail larvae. Samples from 22 July were poorly preserved and were not identified to species.

Invertebrate larvae were sorted and identified to major taxa. Only brachyuran crab zoea and gastropod larvae were found in most samples and were counted. Because we 


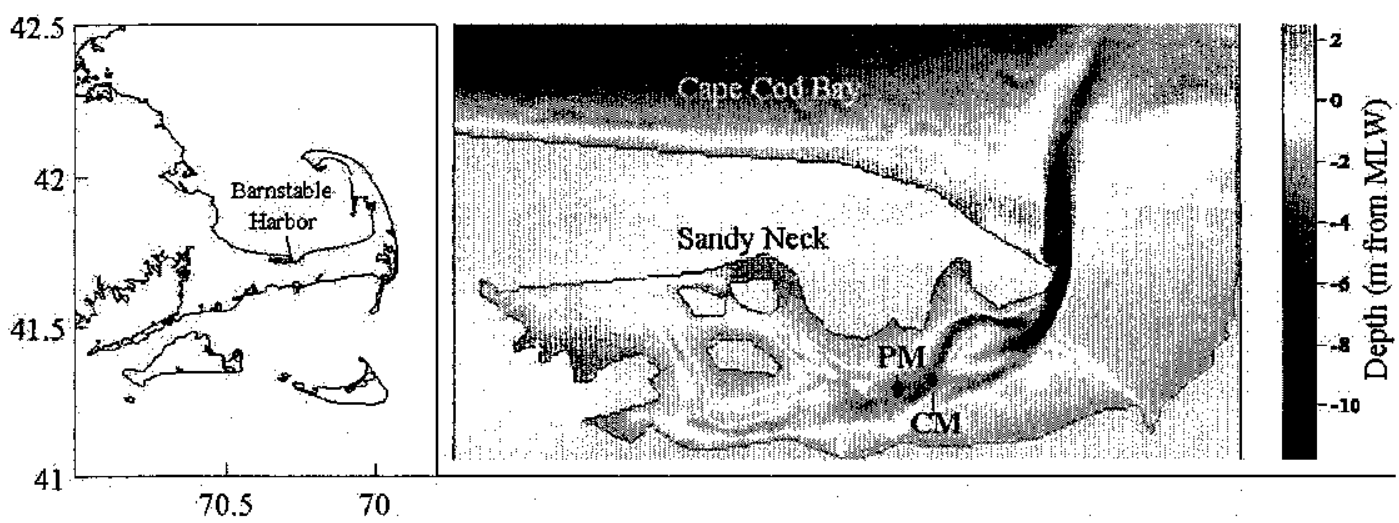

Figure 4-1: Cape Cod map showing location of Barnstable Harbor, and Barnstable Harbor bathymetry map with locations of plankton mooring (PM) and current meters (CM). Dark outlines indicate mean high water and white lines indicate mean low water (MLW).

were interested in behaviors specific to gastropod larvae, gastropods were identified to species using descriptions in the literature [34, 36, 41]. In addition to Ilyanassa obsoleta larvae, Crepidula spp. (including Crepidula plana and Crepidula fornicata) and Anachis spp. (including Anachis avara and Anachis translirata) were found in at least half the profiles and were used for a genus-level analysis. Other species of gastropods (e.g., Bittium alternatum, Lunatia heros) were too rare for a species- or genus-level behavioral analysis.

\subsubsection{Current Measurements}

Flow velocities were measured with an acoustic Doppler current profiler (ADCP) and an acoustic Doppler velocimeter (ADV), deployed in the Barnstable Harbor channel (Fig. 4-1) during the plankton sampling period. The ADCP measured current profiles but was unable to measure velocities within about $1.5 \mathrm{~m}$ of the bottom, and the ADV provided an additional measurement closer to the bottom. The instruments were deployed 20 July and recovered 17 August 2004 from the $\mathrm{R} / \mathrm{V}$ Tioga. A 1.2-MHz, RDInstruments Workhorse ADCP was mounted on a tripod, with the transducer heads looking up and located $\sim 0.75 \mathrm{~m}$ above the bed. The tripod was leveled to a $\sim 2^{\mathrm{a}}$ tilt, within the acceptable limits for Reynolds stress calculations [22]. Approximately $10 \mathrm{~m}$ south of the ADCP, a 5-MHz, Sontek ADVOcean was mounted by divers to a pipe jetted into the sand, with the transducer head pointed up and located $\sim 0.5 \mathrm{~m}$ above the bed. The channel bottom was covered with large sand 
waves (height $\sim 2 \mathrm{~m}$, wavelength $\sim 6$ to $10 \mathrm{~m}$ ) aligned perpendicular to the channel. Both instruments were deployed atop the ridge of a sand wave.

The ADCP collected data continuously from about 15:00 20 July to about 12:00 $14 \mathrm{Au}-$ gust. Using RDI's mode 12, 10-Hz sub-pings were averaged over one second and recorded every other second. Velocities were recorded in beam coordinates for Reynolds stress estimation. To resolve the shallow water column, a $25-\mathrm{cm}$ bin size was used, with the first bin centered at $1.5 \mathrm{~m}$ from the bed. The ADV collected data from 00:00 22 July until 14:00 17 August. Velocities were measured in earth coordinates $(E, N$, and $U p)$ at $8 \mathrm{~Hz}$ for $512 \mathrm{~s}$ bursts every half hour. The ADV measurement volume was located about $0.7 \mathrm{~m}$ from the bed. ADCP and ADV data are reported for 22 July to 31 July.

\subsection{Analysis}

\subsubsection{Current Measurements}

\section{ADCP}

The ADCP was used to measure current and turbulence profiles in the water column. For the calculation of mean current velocities and shear, velocities were transformed from beam to cartesian coordinates and corrected for pitch and roll $[21,38]$. Currents were rotated to coordinates where $u(z, t)$ is the along-channel velocity (positive towards Cape Cod Bay), $v(z, t)$ is the cross-channel velocity, and $w(z, t)$ is the vertical velocity (positive upwards). Velocities for each depth bin were calculated as 10-minute averages, $U, V$, and $W$. The depth-averaged shear velocity $u_{*_{d}}$ and hydraulic roughness length $z_{o}$ were calculated from the along-current velocity profiles using the Law of the Wall [e.g., 4],

$$
U(z, t)=\frac{u_{*_{d}}(t)}{\kappa} \ln \left(\frac{z}{z_{o}}\right)
$$

where $\kappa$ is von Karman's constant $(=0.4)$. A depth-averaged drag coefficient was calculated as $\overline{C_{d}}=u_{*_{d}}^{2} / \bar{U}^{2}$, where $\bar{U}$ is the depth-averaged along-current velocity [16].

Reynolds stress $\overline{u^{\prime} w^{\prime}}$ was calculated from the original ADCP beam velocities over $10-$ minute intervals using the variance method [e.g., 22, 38]. Relevant turbulence quantities were calculated as functions of the Reynolds stress and the along-current velocity shear. The vertical eddy diffusivity $K_{p}$ is defined as

$$
K_{p}=-\overline{u^{\prime} w^{\prime}} / \frac{\partial U}{\partial z}
$$


The turbulence dissipation rate $\varepsilon_{p}$ was assumed to be equal to the production of turbulent kinetic energy [e.g., 43], estimated as

$$
\varepsilon_{p}=-\overline{u^{\prime} w^{\prime}} \frac{\partial U}{\partial z}
$$

\section{ADV}

The ADV was used to measure 3-dimensional velocities near the bed. The velocity data included bad measurements due to obstruction of the sensor head by crabs or floating algae [P. Schultz, pers. comm.]. The data were pre-processed to remove low-quality measurements [e.g., 7], and $29 \%$ of recorded bursts were thrown out. Velocities were then rotated to coordinates where $u(t)$ is the along-channel velocity, $v(t)$ is the cross-channel velocity, and $w(t)$ is the vertical velocity.

The mean velocities, shear velocity, drag coefficient, and turbulence dissipation rate were calculated for each 512-s burst. Velocity time series were de-trended and de-meaned for calculation of turbulence quantities. The shear velocity $u_{*}$ was calculated directly from the Reynolds stress as $u_{*}=\left|\overline{u^{\prime} w^{\prime}}\right|^{0.5}$, where $u^{\prime}$ and $w^{\prime}$ are the along-current and vertical velocity fluctuations. A drag coefficient was calculated for each burst as $C_{d}=u_{*}^{2} / U^{2}$, where $U$ is the average velocity [16]. Dissipation rate estimates $\varepsilon_{w}$ were obtained from the one-sided wavenumber spectra $E_{w}$ of vertical velocity by fitting

$$
E_{w}=\alpha\left(\frac{24}{55}\right) \varepsilon_{w}^{2 / 3}\left(k^{-5 / 3}+\left(k_{s}-k\right)^{-5 / 3}\right)
$$

in the inertial subrange [43], where $\alpha \approx 1.5$ is an empirical constant [14], $k$ is the wavenumber (related to frequency $f$ by $k=2 \pi f /|U|$ ), and $k_{s}$ is the wavenumber corresponding to the sampling frequency. The $w$ spectra were unaffected by noise but showed some effects of aliasing at higher flow velocities, and the wavenumber term of (4.4) includes a correction for aliasing.

\subsubsection{Advection-Diffusion Model}

Larval behaviors were quantified in terms of vertical velocities; although behaviors can be characterized in other ways, it is the swimming or sinking velocities that determine vertical advection of larvae toward or away from settlement sites. Larval vertical velocities were estimated as a function of the turbulence dissipation rate by fitting a vertical advection- 
diffusion $(\mathrm{AD})$ model

$$
\frac{\partial C}{\partial t}=-\frac{\partial}{\partial z}\left(w C-K_{s} \frac{\partial C}{\partial z}\right)
$$

to the observed plankton distributions. This model predicts the concentration of larvae $C(z, t)$ at height $z$ and time $t$. Larvae are advected due to their behavioral velocity $w(z, t)$ and diffused due to turbulent eddy diffusivity $K_{s}(z, t)$. Boundary conditions are no-flux, so larvae bounce off the bottom and surface. No settlement was included in the boundary conditions because the mixing time scale was assumed to be shorter than the settlement time scale.

The larval velocity was modeled as a linear function of the turbulence dissipation rate,

$$
w=b_{0}+b_{1} \log _{10} \varepsilon_{s}
$$

In this model $b_{1}$ is the most interesting parameter, as it predicts whether larval velocity is positively or negatively related to the dissipation rate. If larvae have no response to turbulence, then $b_{1}=0 \mathrm{~s}^{2} \mathrm{~cm}^{-1}$ and $b_{0}$ indicates whether larvae are positively or negatively buoyant.

In order to fit the AD model to the plankton data, (4.5) had to be run with diffusivities $K_{s}$ and dissipation rates $\varepsilon_{s}$ that were accurate for each plankton sampling period. The numerical solution of (4.5) also required that $K_{s}$ and $\varepsilon_{s}$ be continuous in time. Therefore, high-order polynomial functions were fitted to field data to produce diffusivity and dissipation functions that were both accurate and continuous (Appx. B).

The AD model was run for a range of parameters $\left(-0.3 \leq b_{0} \leq 0.2 \mathrm{~cm} \mathrm{~s}^{-1} ;-0.3 \leq b_{1} \leq\right.$ $0.3 \mathrm{~s}^{2} \mathrm{~cm}^{-1}$ ) that were reasonable given the range of larval velocities in the literature [e.g. $2,9]$ and the expected range of dissipation rates [e.g., 13, 16, 43]. A water depth of $H=4$ $\mathrm{m}$ was used in the model, approximating the mean depth at the plankton sampling site. A constant-depth model closely approximated the depth-normalized distribution of larvae in a variable-depth water column (see Sec. 4.3.4). The model was run separately for each plankton sampling day, using the appropriate diffusivity and dissipation functions. Results were used in the maximum likelihood analysis described in the next section.

\subsubsection{Maximum Likelihood Estimation of Behavior}

Plankton data were analyzed separately for each size class and 5 groups of larvae: Ilyanassa obsoleta, Crepidula spp., Anachis spp., pooled gastropod larvae, and pooled Brachyuran crab zoea. Plankton profiles from flood and ebb tides were analyzed separately (Fig. 4-2), 
to test for a dependence of behavior on tidal stage.

The AD model (4.5) was fitted to the plankton data by maximum likelihood. The likelihood $L_{j}(\theta)$ of each observed plankton profile was calculated for each combination of parameter values $\theta=\left(b_{0}, b_{1}\right)$ using the multinomial model

$$
=\frac{N_{j} !\left[p_{j 1}(\theta)^{n_{j 1}} p_{j 2}(\theta)^{n_{j 2}} \ldots p_{j K}(\theta)^{n_{j K}}\right]}{n_{j 1} ! n_{j 2} ! \ldots n_{j K} !}
$$

where $N_{j}$ is the total number of larvae in profile $j, n_{j k}$ is the number of larvae in sample $k$ of profile $j$ of the data, and $p_{j k}(\theta)$ is the proportion of larvae in sample $k$ of profile $j$ of the model, given $\theta$. The $p_{j k}(\theta)$ were found by sampling the AD model solution at the same proportional depths $z_{k} / H$, time, and date corresponding to plankton profile $j$, and dividing by the total concentration in the model profile. Larval behavior parameters $\hat{\theta}=\left(\hat{b_{0}}, \hat{b_{1}}\right)$ were estimated as those that maximized the log likelihood $L L(\theta)$

$$
L L(\theta)=\sum_{j=1}^{J} \ln L_{j}(\theta)
$$

over all profiles in each group. A $95 \%$ confidence interval for the slope $b_{1}$ was estimated using the profile likelihood.

A likelihood ratio was used to test the hypothesis that the larval response to turbulence is different for flood and ebb tides,

$$
\begin{array}{ll}
H_{0}: & \theta_{\text {flood }}=\theta_{\text {ebb }} \\
H_{\mathrm{A}}: & \theta_{\text {flood }} \neq \theta_{\text {ebb }}
\end{array}
$$

where $\theta_{\text {flood }}$ and $\theta_{\text {ebb }}$ are the behavior parameters for flood and ebb tides. The null hypothesis was rejected if $2\left[L L\left(\hat{\theta}_{\text {flood }}\right)+L L\left(\hat{\theta}_{\text {ebb }}\right)-L L\left(\hat{\theta}_{\text {flood+ebb }}\right)\right]>\chi_{2,0.05}^{2}$, where $\hat{\theta}_{\text {flood }}$ and $\hat{\theta}_{\text {ebb }}$ are maximum-likelihood parameter estimates (MLE's) for flood-tide and ebb-tide samples, and $\hat{\theta}_{\text {flood+ebb }}$ are the MLEs for combined flood- and ebb-tide samples. This hypothesis was tested separately for the small and large size fractions of each larval group. A similar test was used for the hypothesis that large and small size-fraction larvae respond differently to turbulence. A Chi-square goodness-of-fit test was used to determine whether the linear behavior model (4.6) was correct for each larval group, tidal stage, and size fraction. 

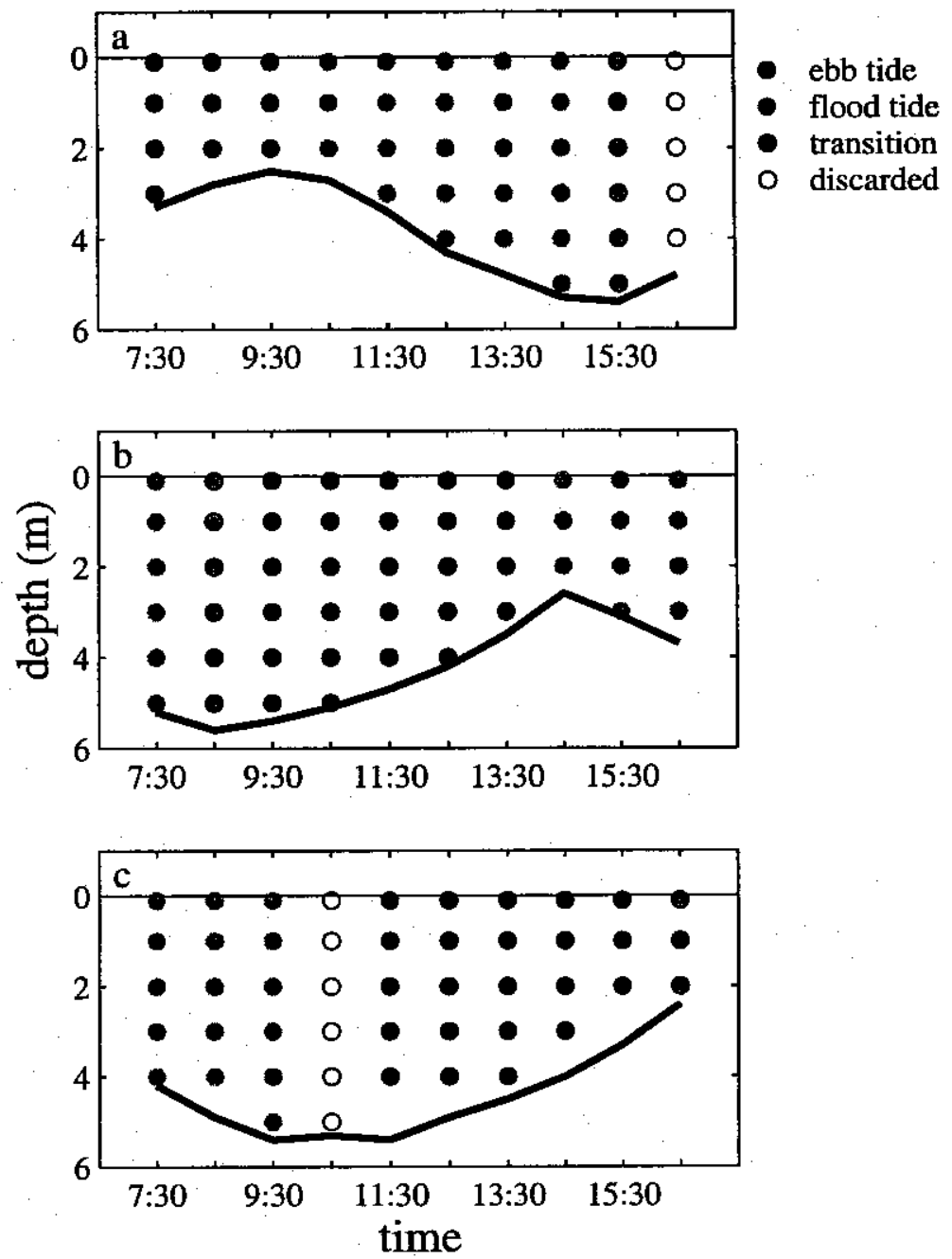

Figure 4-2: Schematic of plankton samples collected on (a) $22 \mathrm{July,} \mathrm{(b)} 27 \mathrm{July}$, and (c) 29 July. Symbols show classification of samples as flood or ebb tide profiles or transitional profiles (analysed with both flood and ebb tide samples). Two profiles were discarded from the analysis due to stratification $\left(\geq 1{ }^{\circ} \mathrm{C}\right.$ difference between surface and bottom). Thick solid line indicates water depth relative to the surface. 


\subsubsection{Model assumptions}

Behavior estimates were made from the vertical distributions of larvae in a turbulent boundary layer, rather than from behavioral observations. This analysis required several assumptions about how larvae are transported in turbulent eddies.

A key assumption of this analysis is that neutrally buoyant particles are evenly distributed, and any deviations from an even vertical distribution are due to behavior. This assumption is valid only if the water column is well mixed, as stratification could indicate the presence of separate water masses containing isolated larval patches [e.g., 10]. Plankton profiles were excluded from the analysis if the concurrent CTD profiles showed any stratification, defined as a temperature difference of $\geq 1{ }^{\circ} \mathrm{C}$ between the surface and bottom. Barnstable Harbor is very well-mixed, and by this criteria only two plankton profiles had to be excluded.

Another assumption is that larval diffusivity is equivalent to fluid diffusivity. This assumption is valid if the transport of larvae by eddies is exempt from particle inertia and crossing-trajectory effects [e.g., 44, 32]. These effects were considered negligible based on criteria reviewed in Ross and Sharples [32]. Large, dense particles have inertia that increases the response time $\tau_{p}$ or lag time between eddy motion and motion of a particle [32, Eq. 10]. The response time of a $1 \mathrm{~mm}$ larva with a density of $1.07 \mathrm{~g} \mathrm{~cm}^{-3}$ is $\tau_{p}<0.1 \mathrm{~s}$, and inertial effects are negligible. Trajectory-crossing occurs when particles have vertical velocities $w_{p}$ greater than the eddy velocity fluctuations $w^{\prime}$. Fast particles fall through eddies rather than following them, and particle motion becomes uncorrelated with the fluid motion. The correlation of particle motion and fluid motion can be quantified as the ratio of particle diffusivity $K_{p}$ to fluid diffusivity $K_{f}$ [32, Eq. 11]. For an average larva $\left(w_{p}=0.5 \mathrm{~cm} \mathrm{~s}^{-1}\right)$ in Barnstable Harbor, $K_{p} / K_{f} \geq 0.97$ and crossing-trajectory effects are negligible.

It is also assumed that the $\mathrm{AD}$ model with constant depth $H$ accurately predicts the particle distribution in a water column of variable depth. This assumption was tested using a particle-tracking equivalent of the advection diffusion model (Chapter 3 ). The model was run for three behavior functions $\left(w=-0.05 \mathrm{~cm} \mathrm{~s}^{-1}, w=0.05 \mathrm{~cm} \mathrm{~s}^{-1}, w=f(\varepsilon)\right)$ with constant depth $\left(H_{c}=4 \mathrm{~m}\right)$ and with a $1.5 \mathrm{~m}$ tidal amplitude $\left(\overline{H_{v}(t)}=4 \mathrm{~m}\right)$ over a full tidal cycle. Results were sampled at the same proportional depths. A least-squares regression confirmed that a constant-depth model accurately predicts the distribution of particles in water of variable depth $\left(R^{2}=0.99\right)$.

Finally, this analysis required the assumption that Barnstable Harbor currents are laterally homogeneous over small (100's m) spatial scales, because the plankton data and hydro- 
dynamic data were collected about $500 \mathrm{~m}$ apart. An assumption of laterally-homogeneous flow is used frequently in plankton studies [e.g., 12] because a separation between instruments is necessary to avoid flow disturbance. In this study the sites were selected in cooperation with the harbor master to avoid navigational hazards, and the distance between sites was unavoidable. A potential problem with the lateral homogeneity assumption is addressed in the discussion.

\subsection{Results}

\subsubsection{Current Measurements}

The water column at Barnstable Harbor was well mixed, as evidenced by nearly vertical temperature and salinity profiles (Fig. 4-3). Salinity varied by no more than about 1 psu over any 10-hour sampling period, indicating low freshwater inflow into the harbor. Temperature varied by 5 to $6{ }^{\circ} \mathrm{C}$ between high tide and low tide, due to rapid warming of the shallow inlet during low tides.

Maximum current velocities were about $80 \mathrm{~cm} \mathrm{~s}^{-1}$ when averaged over 10 min intervals (Fig. 4-4a), with higher velocities on flood tides than on ebb tides. Shear velocity estimates from the ADCP velocity profiles were up to $10 \mathrm{~cm} \mathrm{~s}^{-1}$ (Fig. 4-4b), whereas the maximum estimate from the ADV was only $6.6 \mathrm{~cm} \mathrm{~s}^{-1}$ (Fig. 4-5b). It is likely that the velocity profile method overestimated the shear velocity. Drag coefficients from the ADV measurements averaged $C_{d}=1.34 \times 10^{-2}$, with higher values on ebb tides than on flood tides (Fig. 4-5b).

Dissipation rates were tidally asymmetric, and high relative to values reported for other tidal inlets (Fig. 4-5d). Near the bed, dissipation rates $\varepsilon_{w}$ from ADV velocity spectra ranged from $10^{-3.2}$ to $10^{1.0} \mathrm{~cm}^{2} \mathrm{~s}^{-3}$ with higher values on ebb tides than on flood tides (Fig. 4-5d). The tidal signal was less apparent in surface estimates of dissipation rate $\varepsilon_{p}$ (Fig. 4-4d), which were about 2 orders of magnitude lower than near-bottom estimates. Tidal asymmetries were captured well by the smooth function $\varepsilon_{s}$ that was fitted to $\varepsilon_{p}$ and used in the larval behavior analysis (Fig. 4-7).

Eddy diffusivity estimates $K_{p}$ were also tidally asymmetric and generally high (Fig. 46). Flood tide diffusivity profiles had typical mid-depth maxima of a few hundred $\mathrm{cm}^{2} \mathrm{~s}^{-1}$. In contrast, ebb tide profiles had lower diffusivities at mid-depth and higher diffusivities near the surface and bottom. These asymmetries were captured well by the smooth surfaces $K_{s}$ that were fitted to $K_{p}$ and used in the advection-diffusion model. 


\subsubsection{Plankton Profiles}

The 10-hour series of plankton samples showed that larvae were temporally patchy even over short time scales. When the size classes were pooled, the depth-averaged larval concentration $\left(\# L^{-1}\right)$ usually varied by an order of magnitude or more within each 10-hour period. This was true for major taxa (Fig. 4-8) and at the genus level for gastropods (Fig. 4-9). Patches of Crepidula spp. and Anachis spp. appeared to coincide, whereas Ilyanassa were most abundant when the other 2 genera were scarce or absent (Fig. 4-9).

Larvae were rarely distributed evenly in vertical profiles (Figs. 4-10 to 4-14). Two plankton profiles were omitted because they were collected during periods of slight stratification (22 July, 16:30 and $29 \mathrm{July}, 10: 30$ ). For the remaining profiles the water column was very well-mixed, and the uneven vertical distributions of larvae can be attributed to behavior. It would be difficult, however, to interpret these vertical profiles in terms of behavior without a statistical analysis. Larval vertical distributions depend on vertical mixing profiles, behavioral responses to dissipation rate, and the dissipation rate profiles as well as the previous vertical distributions (before samples were collected). The maximum likelihood analysis (results below) allowed us to extract quantitative behavior estimates from observed larval distributions and turbulence profiles.

\subsubsection{Maximum-Likelihood Behavior Estimates}

The response of crab larvae to turbulence was significantly different $(\alpha=0.05)$ on flood and ebb tides (Fig. 4-15a-b). On flood tides, larvae had a nearly constant downward velocity of about $w=-0.1 \mathrm{~cm} \mathrm{~s}^{-1}$. On ebb tides, larval velocity was positively related to the dissipation rate, so that larvae were swimming upwards at $\varepsilon$ greater than $\sim 0.1 \mathrm{~cm}^{2} \mathrm{~s}^{-3}$.

The behavior of pooled gastropod larvae was also significantly different on flood and ebb tides. For the large size fraction, sample sizes were very small and $b_{1}$ had wide confidence intervals. As a result, behavioral estimates for the two size fractions were never significantly different. Results are shown for both size fractions combined in Fig. 4-15, with all MLE's given in Table 4.1. For pooled gastropods, larval velocity $w$ had a near-zero slope $\left(\hat{b}_{1}=\right.$ $0.0125)$ vs. $\varepsilon$ on flood tides and a more positive slope $\left(\widehat{b}_{1}=0.075\right)$ vs. $\varepsilon$ on ebb tides (Fig. 4-15c-d). The estimates of $w$ were below the neutral buoyancy line for almost all conditions.

Gastropod larvae showed genus-level differences in the response to turbulence. Ilyanassa larvae showed almost no relationship between $w$ and $\varepsilon$, with negative velocities under all conditions (flood tides $\hat{b}_{0}=-0.14 \mathrm{~cm} \mathrm{~s}^{-1}$, ebb tides $\hat{b}_{0}=-0.16 \mathrm{~cm} \mathrm{~s}^{-1}$ ). There was a strong negative relationship between $w$ and $\varepsilon$ for the large size fraction on ebb tides, but 
Table 4.1: Maximum-likelihood parameter estimates for the response of larvae to turbulence, $w=b_{0}+b_{1} \log _{10} \varepsilon$.

\begin{tabular}{|c|c|c|c|c|c|c|c|}
\hline \multirow[b]{2}{*}{ taxon } & \multirow[b]{2}{*}{ tidal stage } & \multicolumn{2}{|c|}{$\begin{array}{c}\text { small } \\
\text { fraction }\end{array}$} & \multicolumn{2}{|c|}{$\begin{array}{c}\text { large } \\
\text { fraction }\end{array}$} & \multicolumn{2}{|c|}{$\begin{array}{c}\text { both } \\
\text { fractions }\end{array}$} \\
\hline & & $\begin{array}{c}\hat{b}_{0} \\
\mathrm{~cm} \mathrm{~s}^{-1}\end{array}$ & $\begin{array}{c}\hat{b}_{1} \\
\mathrm{~s}^{2} \mathrm{~cm}^{-1}\end{array}$ & $\begin{array}{c}\hat{b}_{0} \\
\mathrm{~cm} \mathrm{~s}-1\end{array}$ & $\begin{array}{c}\hat{b}_{1} \\
\mathrm{~s}^{2} \mathrm{~cm}^{-1}\end{array}$ & $\begin{array}{c}\hat{b}_{0} \\
\mathrm{~cm} \mathrm{~s}\end{array}$ & $\begin{array}{c}\hat{b}_{1} \\
\mathrm{~s}^{2} \mathrm{~cm}^{-1}\end{array}$ \\
\hline crabs & flood & -0.14 & -0.075 & -0.1 & 0.0125 & -0.12 & 0.0 \\
\hline & ebb & 0.2 & 0.2 & 0.08 & 0.125 & 0.12 & 0.15 \\
\hline \multirow[t]{2}{*}{ gastropods } & flood & -0.08 & 0.0125 & -0.14 & 0.025 & -0.08 & 0.0125 \\
\hline & $\mathrm{ebb}$ & -0.02 & 0.075 & -0.02 & 0.1 & -0.02 & 0.075 \\
\hline \multirow[t]{2}{*}{ Ilyanassa } & flood & -0.12 & 0.0125 & -0.14 & -0.0125 & -0.14 & 0.0125 \\
\hline & ebb & -0.16 & -0.0125 & -0.3 & -0.225 & -0.16 & -0.0125 \\
\hline \multirow[t]{2}{*}{ Crepidula } & flood & 0.2 & 0.125 & . & . & 0.2 & 0.125 \\
\hline & ebb & 0.06 & 0.1 & 0.2 & 0.25 & 0.06 & 0.1 \\
\hline \multirow[t]{2}{*}{ Anachis } & flood & -0.3 & -0.075 & 0.2 & 0.175 & -0.22 & -0.0375 \\
\hline & $\mathrm{ebb}$ & -0.02 & 0.1 & 0.2 & 0.2 & 0.02 & 0.125 \\
\hline
\end{tabular}


large confidence interval on the slope $b_{1}$ included both positive and negative values (Fig. 4-16).

Iyanassa larvae in the large size fraction were likely to be competent for metamorphosis, and were expected to behave similarly to competent mud snail larvae in laboratory turbulence. Field estimates of Myanassa behavior in turbulence are somewhat different than laboratory results (Fig. 4-16). Most of the laboratory data points are outside the confidence intervals for $b_{1}$ in both flood and ebb tide estimates. Maximum likelihood estimates of $w$ are below the laboratory values for all but the highest turbulence levels $\left(\varepsilon>10^{-0.3} \mathrm{~cm}^{2}\right.$ $\left.\mathrm{s}^{-3}\right)$.

Both Crepidula spp. and Anachis spp. showed a positive response to turbulence on ebb tides, swimming upward in strong turbulence. These larvae had strong responses to turbulence on flood tide too, but the confidence intervals for $b_{1}$ included both positive and negative values.

The goodness of fit tests indicated that the linear behavior model (4.6) was incorrect for all larval groups. The linear model could not be rejected for large Crepidula larvae, but the sample sizes were too small for the test to be valid. Although larvae had a strong response to turbulence, the shape of the true response curve is probably nonlinear and may depend on detection limits as well as viscosity and other physical factors.

\subsection{Discussion}

\subsubsection{Hydrodynamics}

Although Barnstable Harbor is a sheltered inlet, it is very turbulent, probably due to bottom friction over large- and small-scale roughness elements. The near-bottom dissipation rates of up to $\varepsilon=10^{1} \mathrm{~cm}^{2} \mathrm{~s}^{-3}$ are higher than normal for tidal channels $[14,23,43]$, and within the range of dissipation rates in the surf zone [13,42]. Near-bottom drag coefficients were also high at $C_{d}=0.01 . C_{d}$ is typically about $3 \times 10^{-3}$ for flow over smooth sandy substrates $[15,18]$, but the present estimates of $C_{d}$ are on the order of drag coefficients reported over mobile bed forms in a tidal inlet [46] and in the surf zone [31]. The high estimates of $C_{d}$ in Barnstable Harbor are probably due to form drag over large dunes $(\sim 2 \mathrm{~m}$ height, $\sim 6$ to $10 \mathrm{~m}$ wavelength). Additional bottom roughness features include smaller sand ripples $(\sim 1$ $\mathrm{cm})$ and dense aggregations of mud snails $(\sim 1 \mathrm{~cm})$. Near-bottom turbulence around these multi-scale roughness elements is probably an important issue for larval settlement, but is beyond the scope of this paper. 
Flows were tidally asymmetric, but whereas near-bottom current velocities were higher on flood tides, $u_{*}, C_{d}$, and $\varepsilon_{w}$ were higher on ebb tides. Tidal asymmetries in turbulence were damped with increasing height above the bottom, and could reflect the fact that form drag is greater on ebb tides when the current direction opposes the direction of the sand waves. Larvae are expected to attach to the bottom more successfully when shear velocity is low, and the fact that near-bottom shear velocities were higher on ebb tides suggests that flood tides would be a more opportune time for larval settlement.

Turbulence in the harbor was assumed to be laterally homogenous for the analysis of plankton distributions, but this assumption could be wrong given the presence of large bed forms. Sandwaves probably contribute to spatial variability in turbulence profiles over at least the wavelength of the sandwaves $(\sim 6$ to $10 \mathrm{~m})$. The current meters were located on the ridge of a sandwave, but the bottom conditions were unknown at the plankton mooring. Therefore there is some uncertainty in vertical turbulence profiles used in the plankton analysis. It is difficult to asses the potential errors in behavior estimates due to lateral inhomogeneity of turbulence, without a detailed sensitivity analysis. Both sites were located in a straight channel segment though, and the diffusivity and dissipation estimates used in the plankton analysis are probably correct to order of magnitude.

\subsubsection{Plankton Variability}

Larval concentrations were temporally variable over $10 \mathrm{~h}$ sampling periods, and this variability is attributed to the horizontal advection of larval patches past the sampling site. The maximum spatial extent of these patches can be estimated by integrating the surface current velocity over each sampling period. In this way, $22 \mathrm{July}$ samples represent $4.0 \mathrm{~km}$, 27 July samples represent $4.6 \mathrm{~km}$, and 29 July samples represent $6.5 \mathrm{~km}$. These estimates are on the order of patch sizes reported for blue crab larvae offshore [25] and fiddler crab larvae downstream of a spawning site [28]. Patches that were present for shorter time periods (e.g. 29 July crabs, Fig. 4-8c, and 29 July Ilyanassa, Fig. 4-9b) were almost certainly less extensive than the maximum spatial estimates. At low tide, a larva would have to travel about $4.6 \mathrm{~km}$ from the plankton mooring to reach the outlet to Cape Cod Bay or vice versa. Samples representing this spatial scale had order-of-magnitude variability in larval concentration, indicating that larvae are distributed heterogeneously across the harbor. The horizontal patchiness of planktonic larvae could contribute to patchy settlement.

The characteristics of the plankton-sample time-series allow some conjectures about whether larvae were spawned locally or dispersed to the harbor from elsewhere. Crab larva 
were most abundant on mid-ebb tides, and were mostly small, early stage zoea that probably originated within Barnstable Harbor. Ilyanassa larvae probably also originated within the harbor, given that they were most concentrated during late ebb tides and that the adult snails are extremely abundant at the study site. In contrast Anachis spp. and Crepidula spp. were most concentrated on late flood and early ebb tides. Adults of these species are more commonly found on sandy and gravelly beaches, and these larvae probably were spawned outside the harbor.

\subsubsection{Larval Behavior}

This analysis produced estimates of larval behavior that are reasonable for all physically realistic values of the dissipation rate, despite the fact that larval velocity is unbounded by the linear model (4.6). Larvae from coastal populations probably encounter dissipation rates ranging from $10^{-7} \mathrm{~cm}^{2} \mathrm{~s}^{-3}$ in the open ocean [6] to $10^{3} \mathrm{~cm}^{2} \mathrm{~s}^{-3}$ in the surf zone [13]. Using some of the most extreme MLE's $\left(\hat{b}_{0}=0.2 \mathrm{~cm} \mathrm{~s}^{-1}\right.$ and $\hat{b}_{1}=0.2 \mathrm{~s}^{2} \mathrm{~cm}^{-1}$ for small crab larvae on ebb tides, Table 4.1), the average larval velocity would span -1.2 to $0.8 \mathrm{~cm} \mathrm{~s}^{-1}$ over the entire range of potential turbulence conditions. These estimates are well within the range of swimming and sinking velocities for crab larvae [reviewed in 2], and within reported limits for veliger larvae [e.g., 9, 19].

Although the velocity estimates were reasonable, the linear response to turbulence (4.6) was an incorrect model for all larval groups. This result is not surprising. The linear model assumes that larvae are equally able to detect strong and weak turbulence, and that larval behavior depends only on turbulence. Larval detection of turbulence almost certainly depends on the length scale $\eta$ of the smallest eddies relative to larval size. The smallest eddies are smaller than larvae in strong turbulence (for $\varepsilon=10^{1} \mathrm{~cm}^{2} \mathrm{~s}^{-3}, \eta \approx 0.2 \mathrm{~mm}$ ) and larger than larvae in weak turbulence (for $\varepsilon=10^{-4} \mathrm{~cm}^{2} \mathrm{~s}^{-3}, \eta \approx 3 \mathrm{~mm}$ ). There is probably some turbulence threshold that is below larval detection limits. It is also very likely that larvae respond to additional environmental cues that vary non-linearly with turbulence (discussed below). Even though the linear model is incorrect, the behavior estimates confirm that turbulence is an important cue for behavior of crabs and gastropods in the field.

\section{Crab larvae}

Behavior estimates for crab larvae suggest that the response of zoea to turbulence enhances export of larvae to coastal areas. These results are consistent with other evidence for selective tidal stream transport (STST) of crab larvae. The distributions of Pachygrapsus 
crassipes larvae in San Diego Bay strongly suggest that these larvae sink on flood tides and swim upward on ebb tides, resulting in the export of larvae from the bay [5]. Likewise in this study, crab larvae swam upwards in strong turbulence during ebb tides and had a constant downward velocity during flood tides. The net result would be the export of larvae from the harbor to Cape Cod Bay. Tidally-dependent behaviors are species-specific, and not all species have larval behaviors that enhance export from natal estuaries $[3,5]$. In this study the behavior of crab larvae was analyzed at a high taxonomic level, yet zoea still showed a strong export-enhancing response to turbulence. The samples could have been dominated by a species with STST behaviors. Alternatively, it is possible that the most common crab species in the harbor share similar STST behavioral strategies.

The fact that crab larvae swim up on ebb tide turbulence but not on flood tide turbulence indicates that behavior is determined by multiple cues, as would be expected for STST. Blue crab (Callinectes sapidus) megalopae swim upwards in turbulence, but the response is stronger if accompanied by an increase in salinity mimicking flood tide [45]. In the present study the salinity range was very small over the sampling periods ( $<=1$ psu over 10 hours), but temperature changes were large $\left(\sim 6^{\circ} \mathrm{C}\right.$ over 10 hours $)$ and could also play a role in tidally-dependent behavior.

\section{Gastropod larvae}

The turbulence response of gastropod larvae was clearly species-dependent, and could indicate that larvae from different habitat types use turbulence differently. Iyanassa larvae were sinking under most conditions. This behavior would enhance larval retention in the harbor and nearshore zone [30], and could allow larvae to stay near natal habitats throughout the development period. Large Ilyanassa larvae had greater sinking velocities on strong ebb-tide turbulence, which would retard the export of potentially competent larvae to Cape Cod Bay. Large Iyanassa larvae were present in few plankton profiles though, and the behavior estimates are inconclusive based on the confidence intervals for $b_{1}$. Based on these few plankton profiles, mud snail larvae responded differently in the field than they did in laboratory turbulence, indicating that behavior depends on additional cues.

Crepidula and Anachis larvae behaved more like erab larvae, swimming upward on strong ebb tide turbulence. Behaviors were inconsistent on flood tides; Crepidula swam upward and Anachis sank on flood tide turbulence. Crepidula larvae apparently avoid the bottom in any turbulent conditions whereas Anachis behavior would favor export from

estuaries. Adult snails of these species inhabit sandy to gravelly beaches, rather than 
intertidal mud flats. The turbulence responses of these larvae could allow them to avoid settling in unfavorable estuarine habitats.

One unexpected result of the behavior estimates was that larvae were sinking under a broad range of conditions, even when there was no response to turbulence (Fig. 4-15a,c,e). This result has several possible explanations. As mentioned above, sinking could allow larval retention near favorable habitats. Sinking could also be a response to predators, as discussed in Ch. 2, but it's equally likely that sinking was due to negative phototaxis. All of the samples were collected on bright sunny days in shallow water, and widespread sinking could be a result of surface-avoidance.

\subsubsection{Summary}

On average, turbulence was an important behavioral cue for all larvae sampled, at least during ebb tides. Larvae of crabs and beach-dwelling gastropods swam upward on ebbtide turbulence, a behavior that would enhance larval transport out of the harbor. In contrast large mud snail larvae sank on ebb-tide turbulence, a behavior that would promote larval retention. No turbulence response was detectable for pooled gastropods and crab larvae on flood tides. This negative result could indicate the presence of multiple species whose turbulence responses cancelled out, or the suppression of a turbulence response by additional cues (e.g. increasing salinity [45]). These results support the hypothesis that larval behavior in turbulence contributes to the supply of larvae to benthic habitats. Genus-

specific responses to turbulence suggest that larvae could select habitats over relatively large spatial scales ( $\geq \mathrm{km})$. 

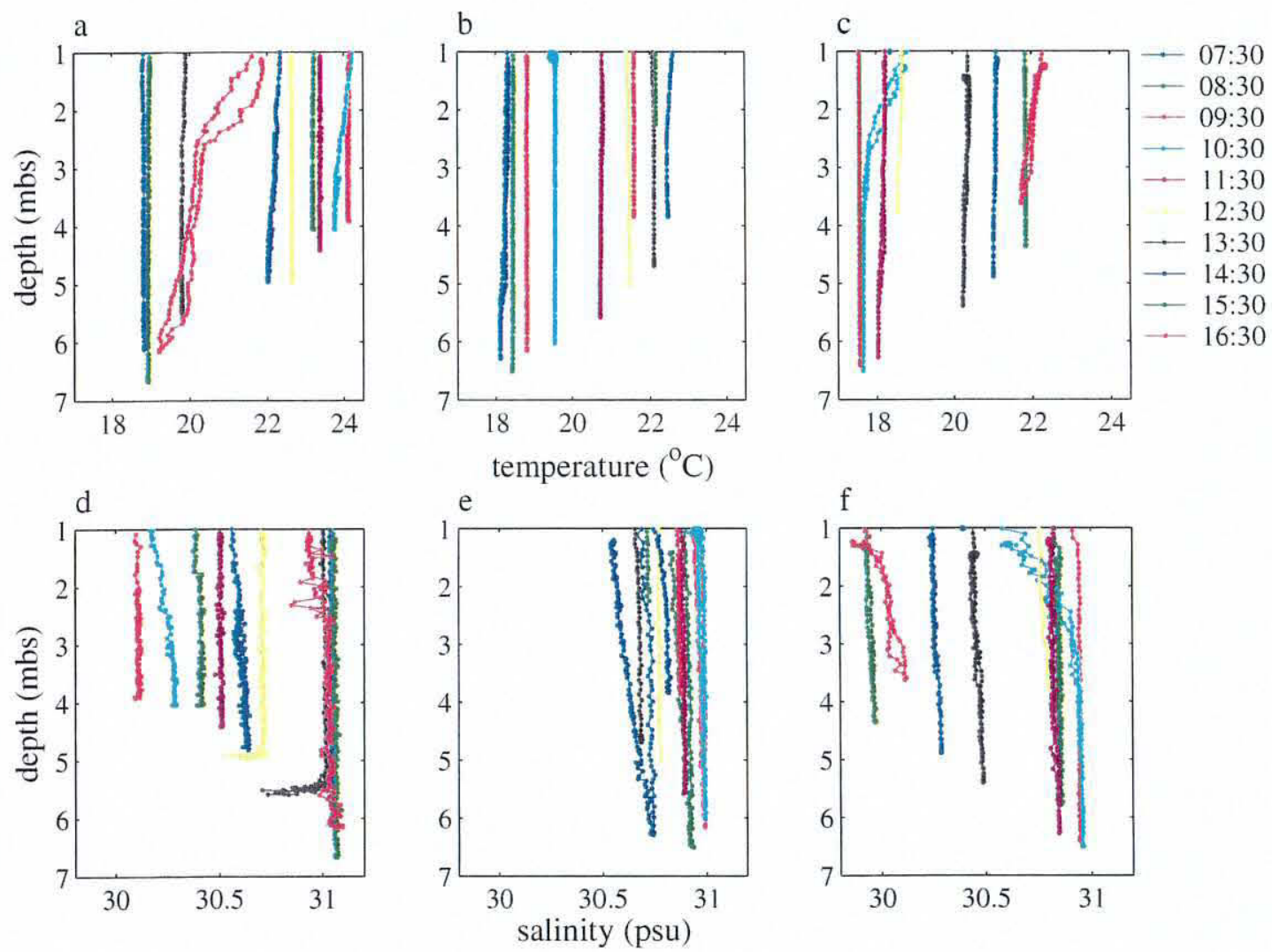

Figure 4-3: (a-c) Temperature and (d-f) salinity plots for plankton sampling periods on (a, d) 22 July, (b, e) 27 July, and (c, f) 29 July. Double lines represent down- and up-casts. 

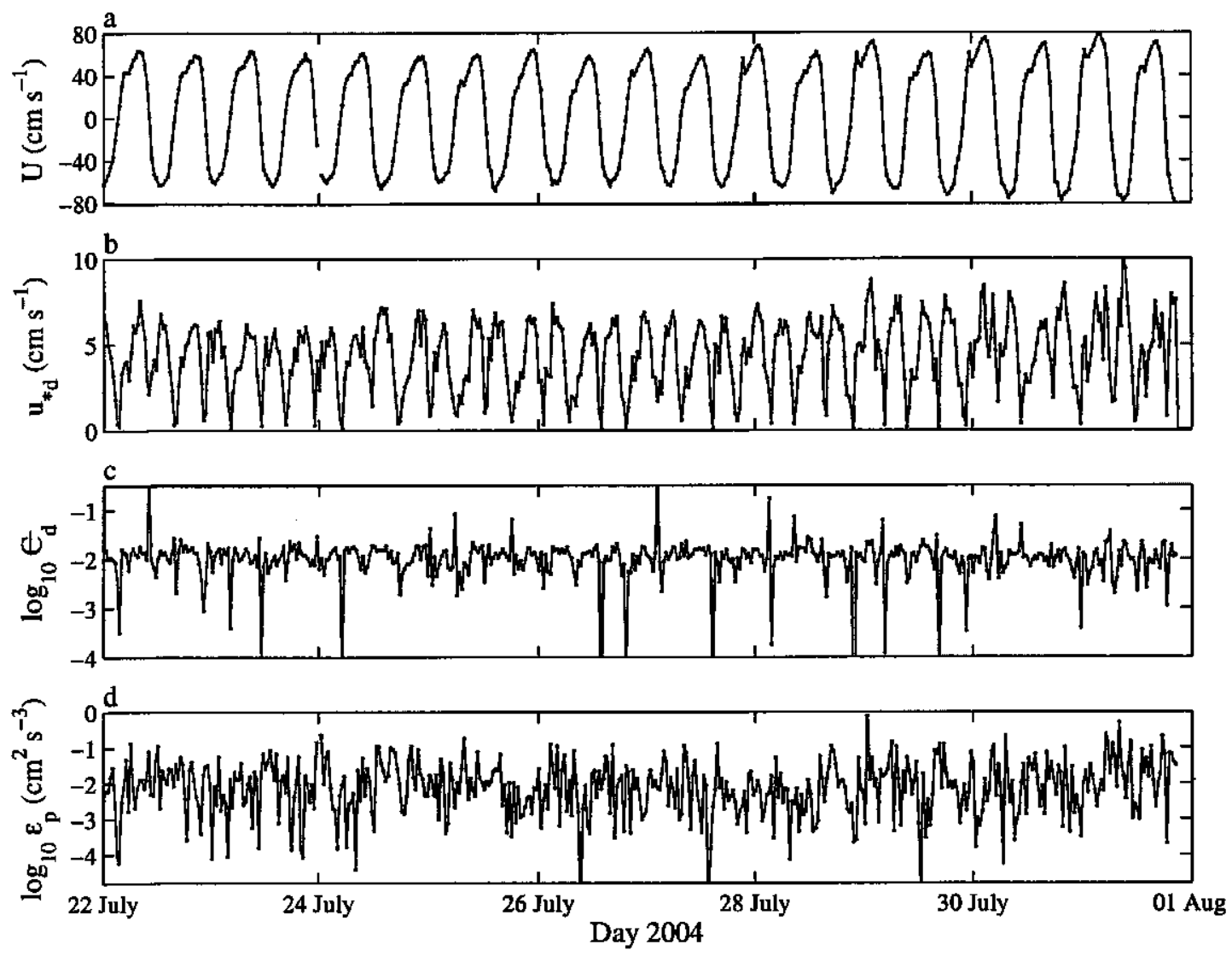

Figure 4-4: July measurements of (a) surface current velocity (positive on ebb tide, negative on flood tide), (b) depth-averaged shear velocity, (c) depth-averaged drag coefficient, and (d) surface dissipation rate from ADCP measurements ( $z=1.5 \mathrm{~m}$ to surface). 

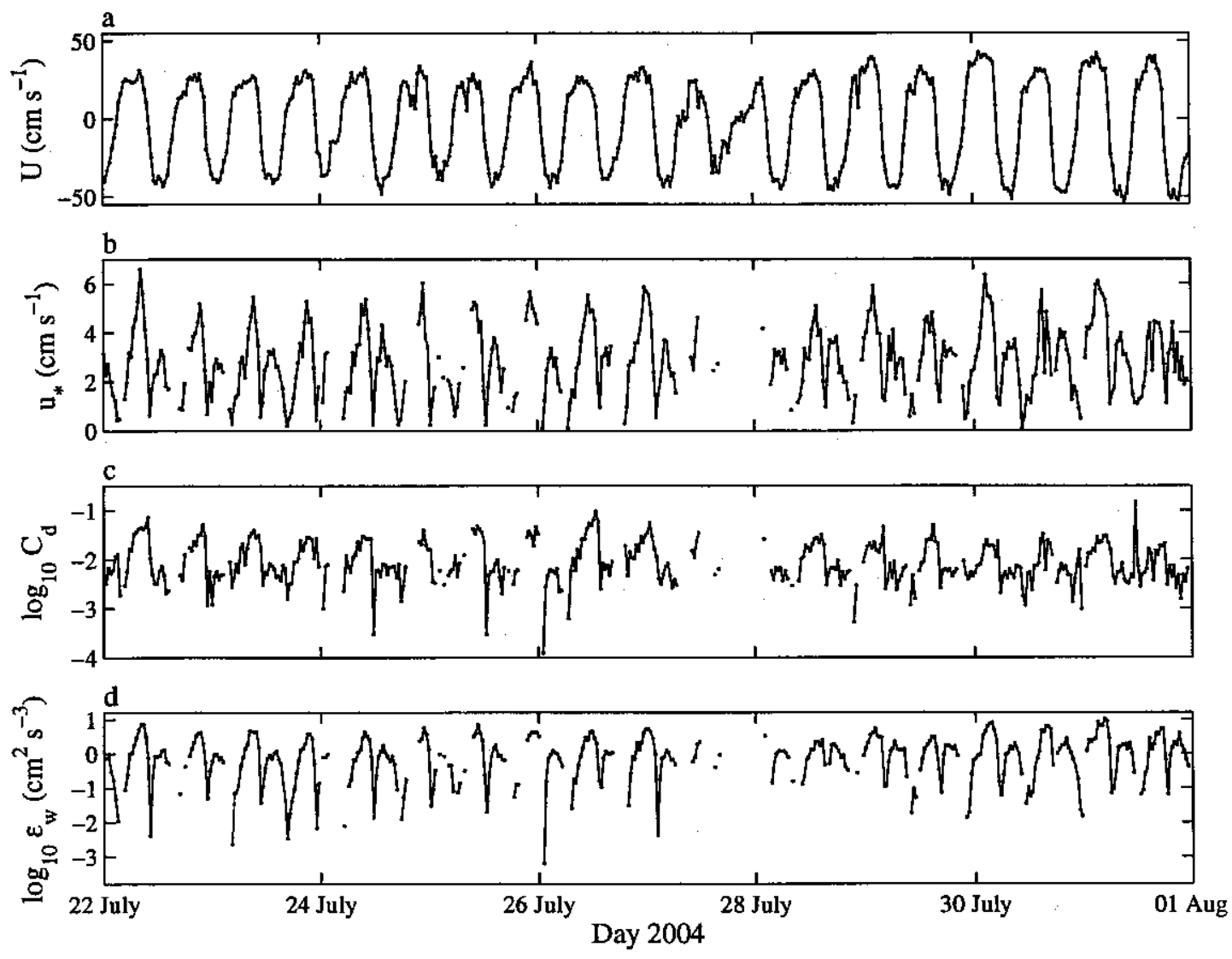

Figure 4-5: July measurements of (a) current velocity (positive on ebb tide, negative on flood tide), (b) shear velocity, (c) drag coefficient, and (d) dissipation rate from ADV measurements $(z=0.7 \mathrm{~m})$. Missing data points were discarded because of excessive noise due to sensor obstruction. 

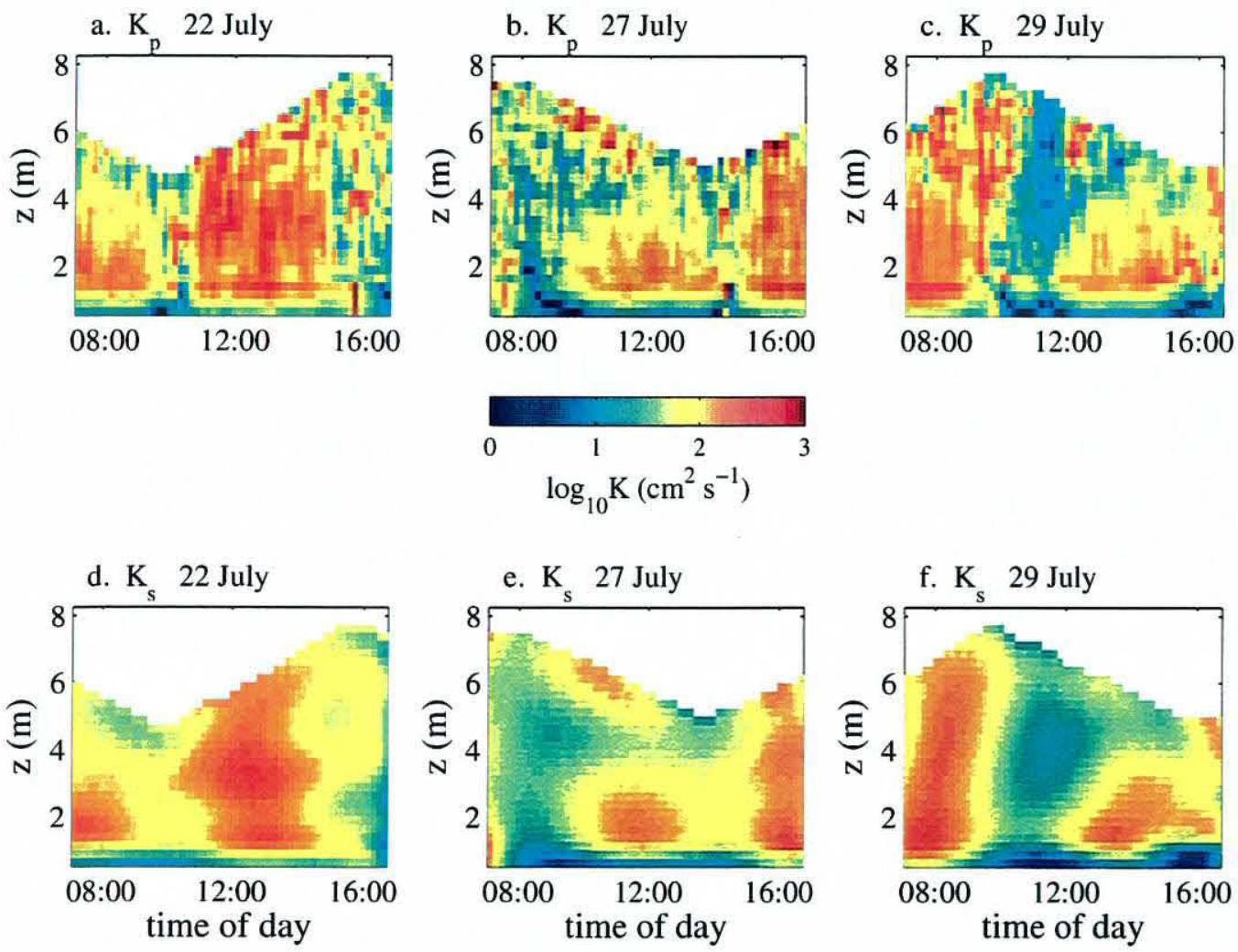

Figure 4-6: (a-c) Measured eddy diffusivity $K_{p}$ and (d-f) fitted eddy diffusivity $K_{s}$ for plankton-sampling periods of (a, d) 22 July, (b, e) 27 July, and (c, f) 29 July. 

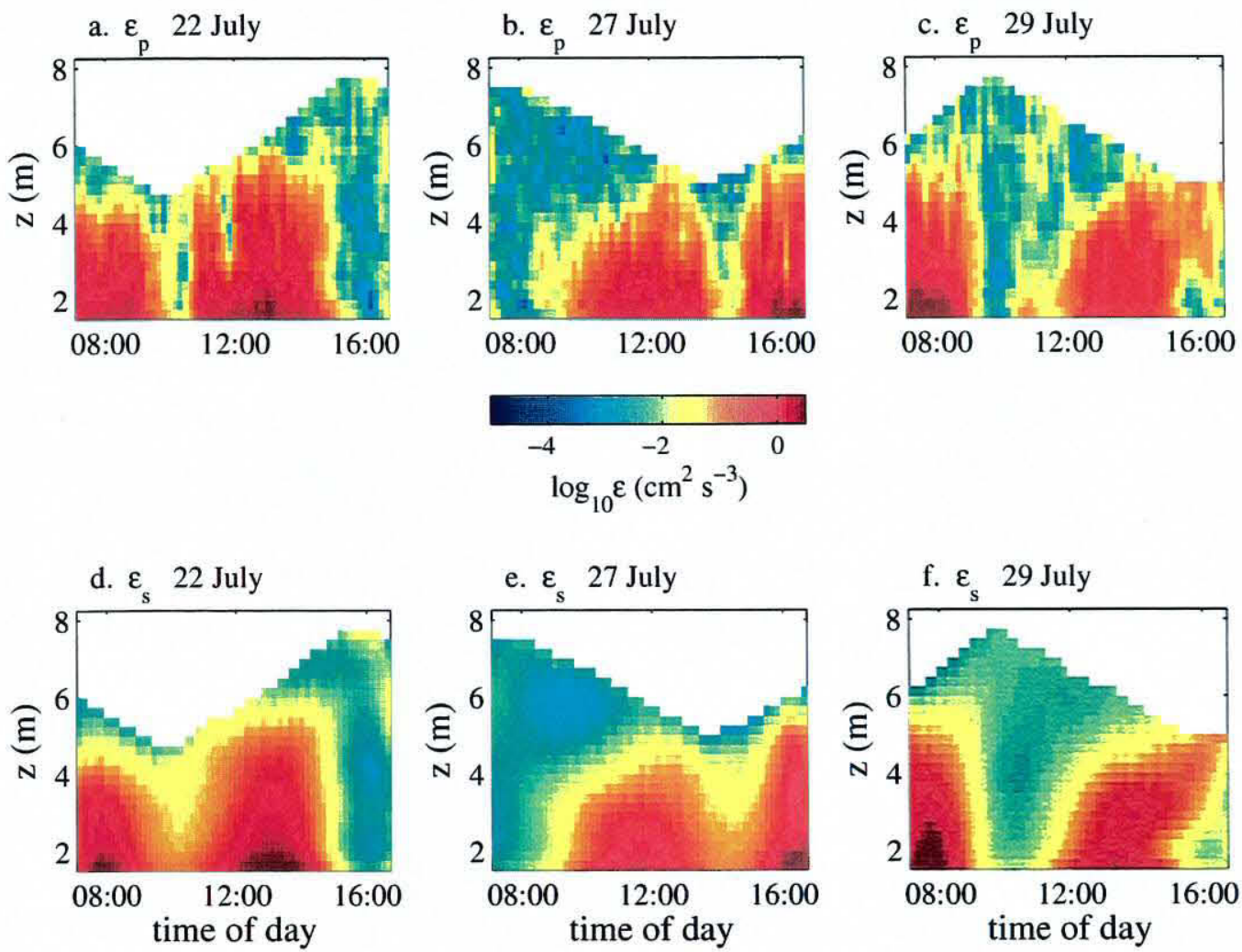

Figure 4-7: (a-c) Measured dissipation rate $\varepsilon_{p}$ and (d-f) fitted dissipation rate $\varepsilon_{s}$ for plankton-sampling periods of (a, d) 22 July, (b, e) 27 July, and (c, f) 29 July. 


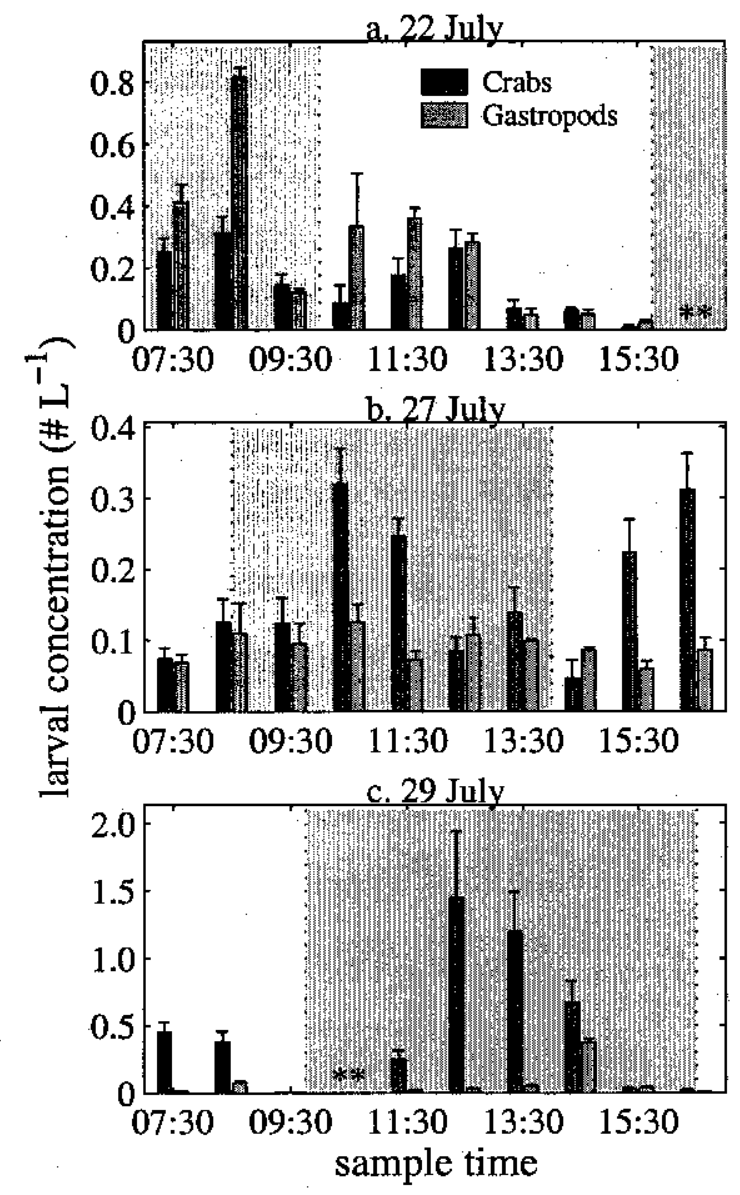

Figure 4-8: Time series of average total larval concentration $\left(\# L^{-1}\right)$ per profile for (a) 22 July, (b) 27 July, and (c) 29 July. Size classes are pooled and larvae are grouped by major taxa. Asterisks indicate excluded profiles. Background shading indicates ebb tides. Error bars are 1 standard error. 


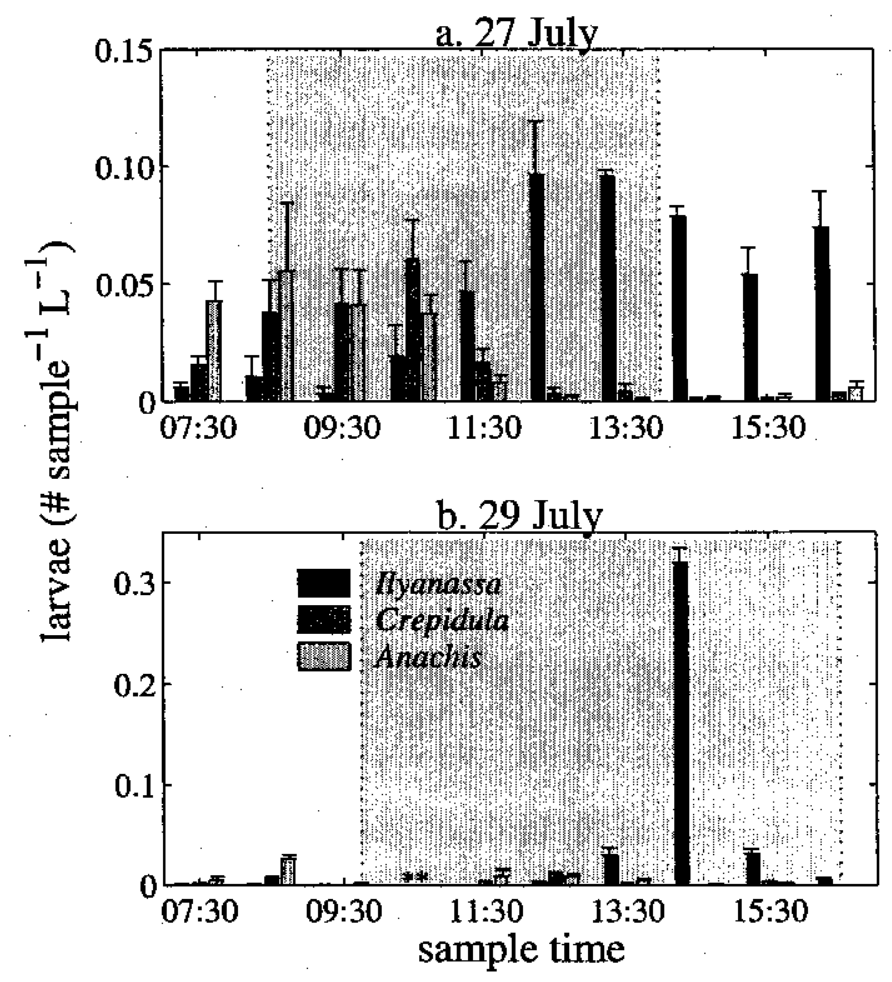

Figure 4-9: Time series of average total larval concentration $\left(\# L^{-1}\right)$ per profile of gastropods for (a) 27 July, and (b) 29 July (22 July gastropods were not identified to species). Size classes are pooled and larvae are grouped by genera. Asterisks indicate excluded profiles. Background shading indicates ebb tides. Error bars are 1 standard error. 

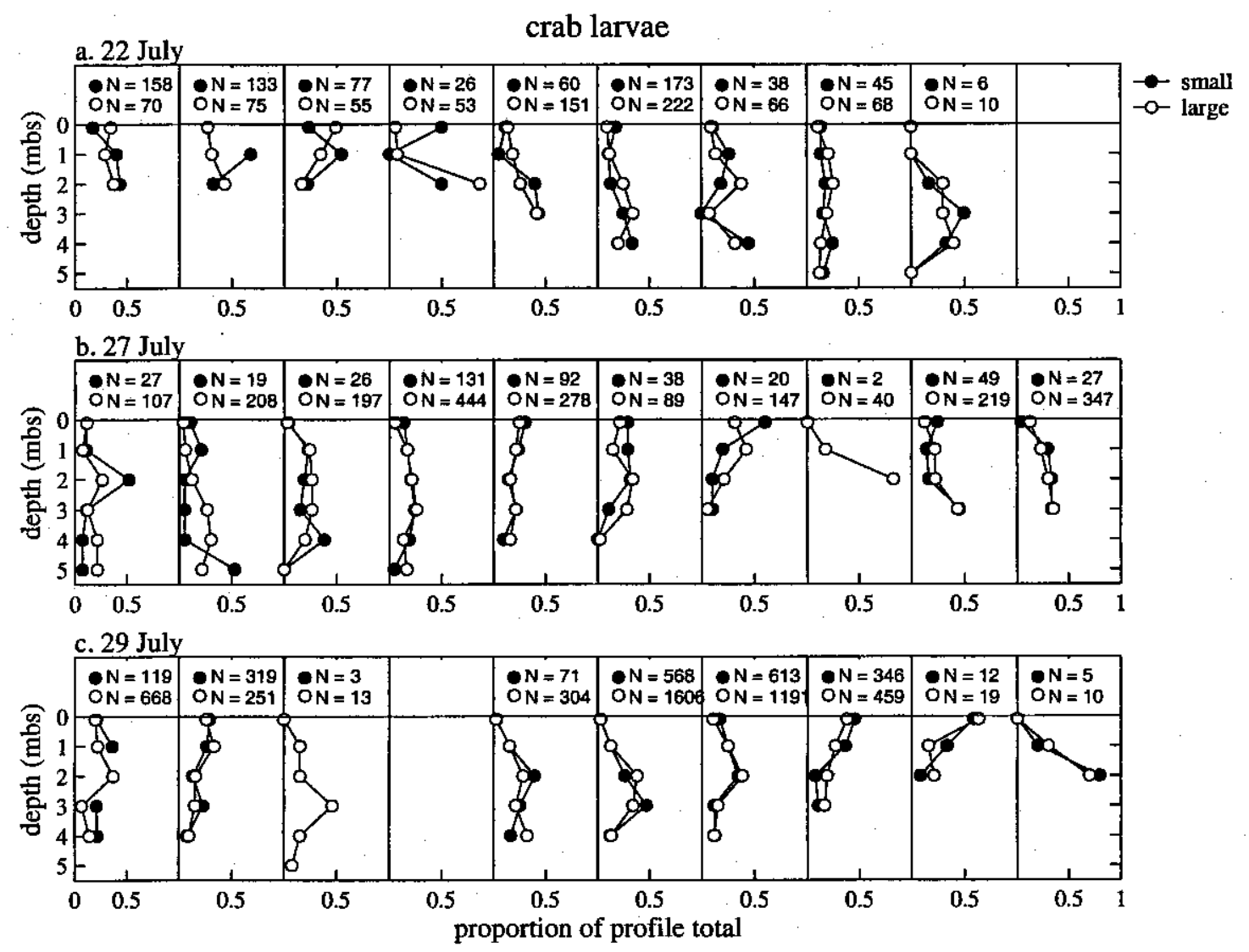

Figure 4-10: Ten-hour series of vertical plankton profiles of crab zoea in (o) large and (•) small size fractions for (a) 22 July, (b) 27 July, and (c) 29 July. Larval concentrations are shown as proportion of the profile total, which is indicated above each profile. Profiles with fewer larvae than samples are not plotted. 

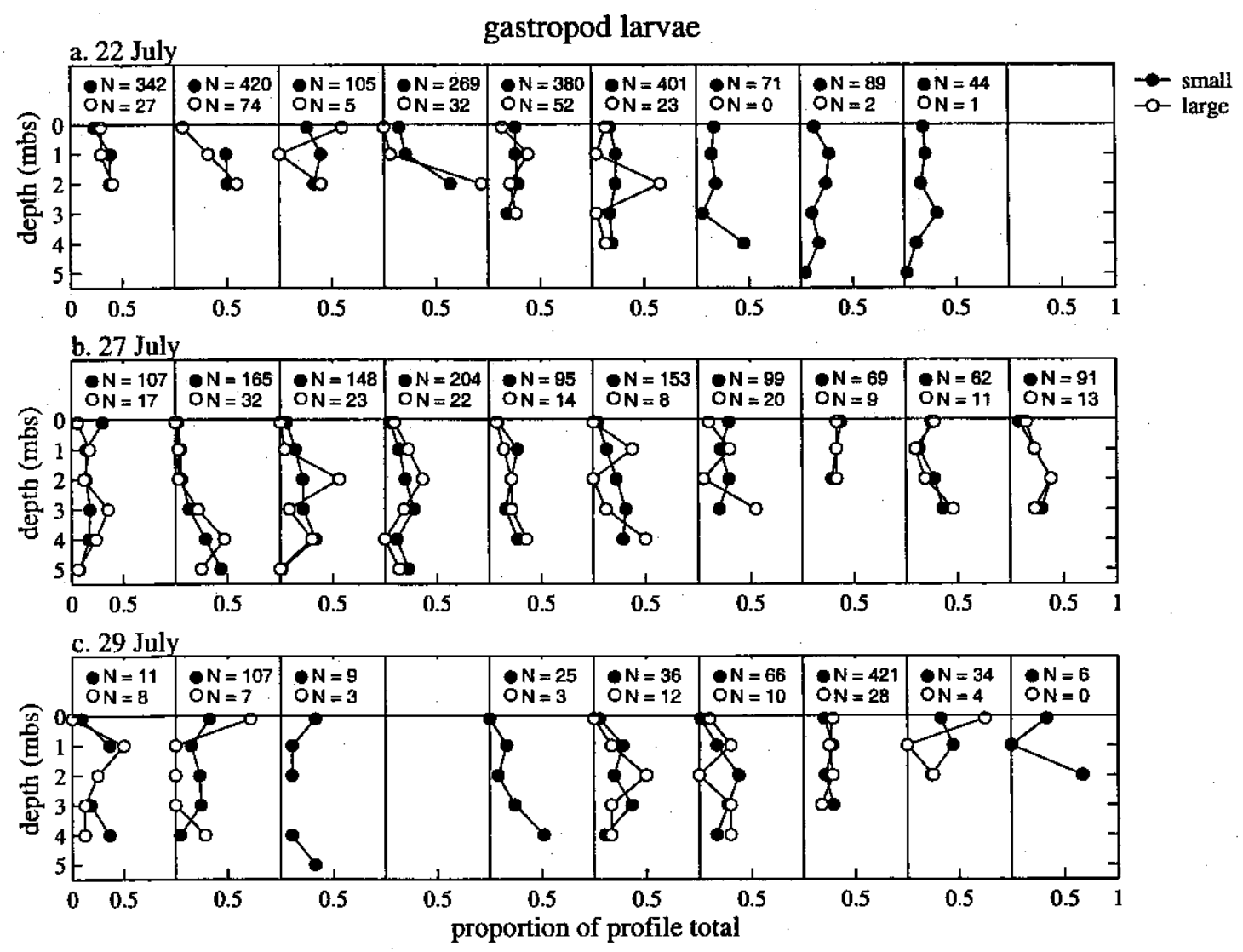

Figure 4-11: Ten-hour series of vertical plankton profiles of pooled gastropod larvae in (o) large and (•) small size fractions for (a) $22 \mathrm{July,} \mathrm{(b)} 27 \mathrm{July}$, and (c) 29 July. Larval concentrations are shown as proportion of the profile total, which is indicated above each profile. Profiles with fewer larvae than samples are not plotted. 

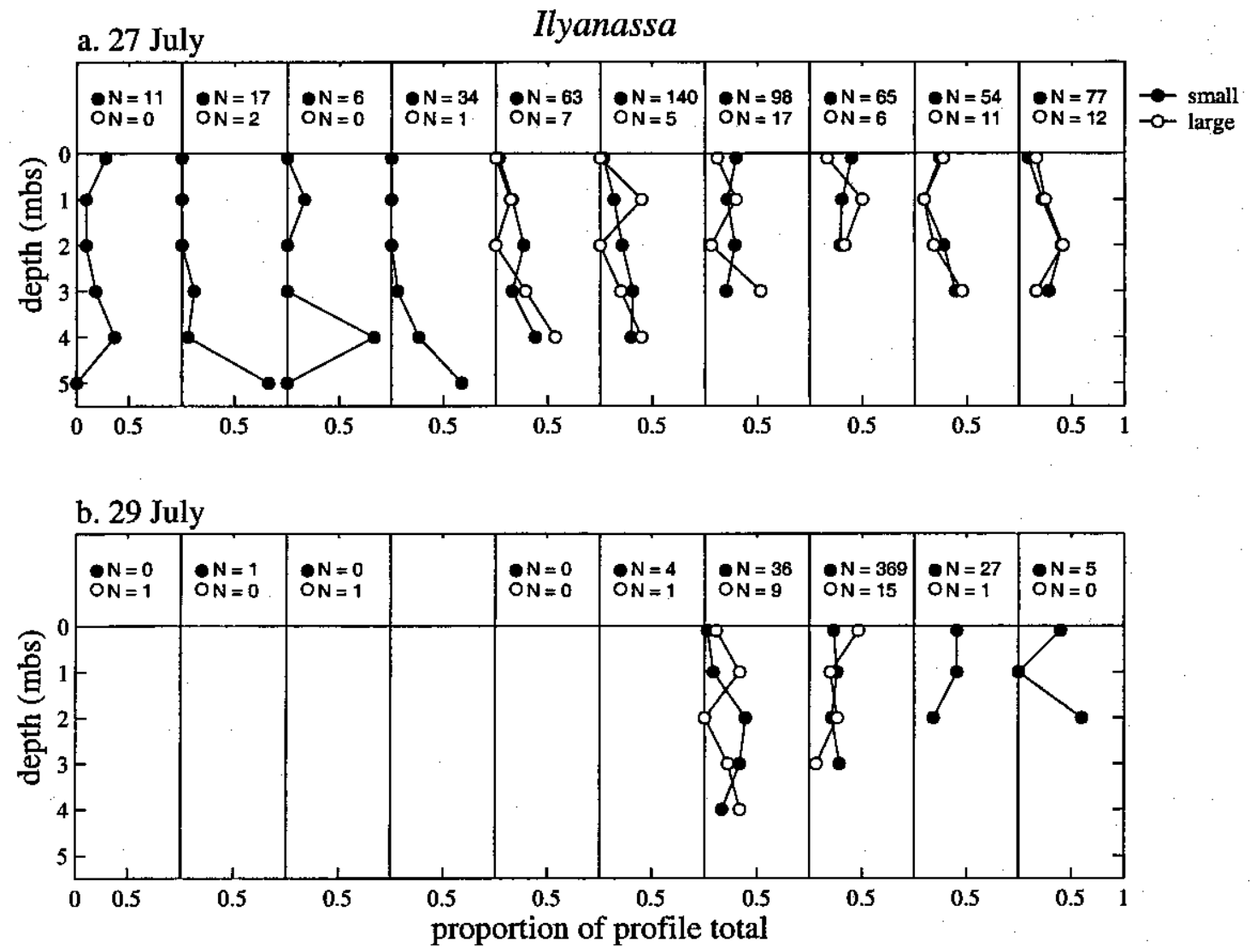

Figure 4-12: Ten-hour series of vertical plankton profiles of Ilyanassa obsoleta larvae in (०) large and (•) small size fractions for (a) $27 \mathrm{July}$, and (b) 29 July. Larval concentrations are shown as proportion of the profile total, which is indicated above each profile. Profiles with fewer larvae than samples are not plotted. 


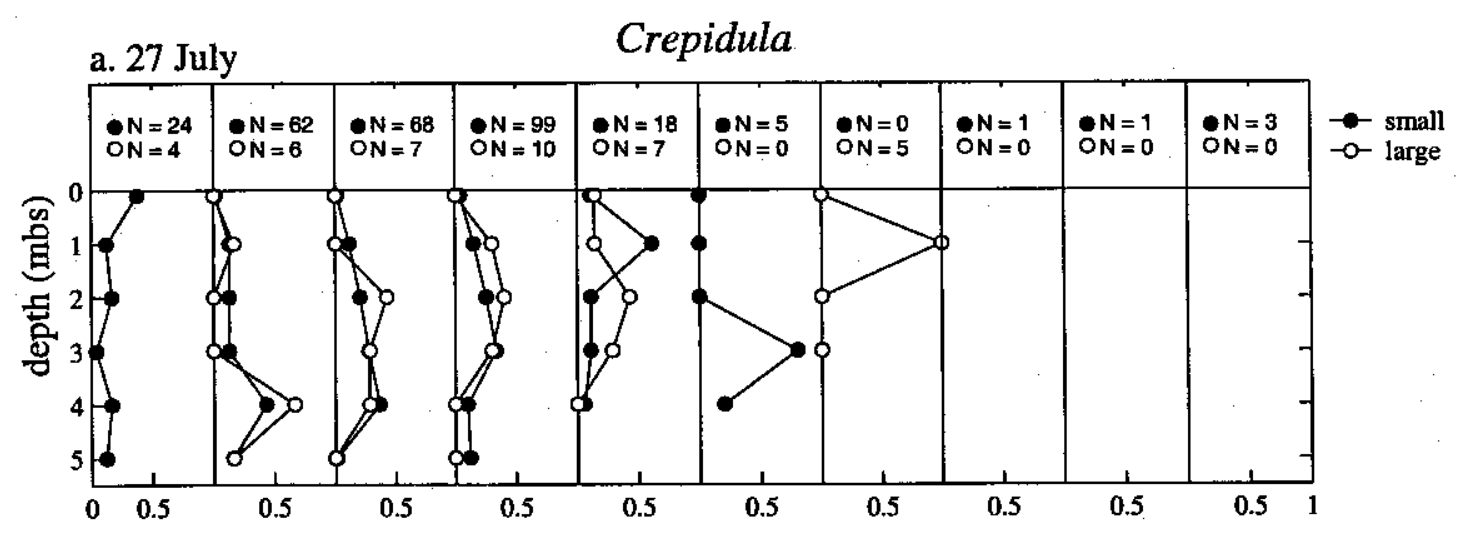

\section{b. 29 July}

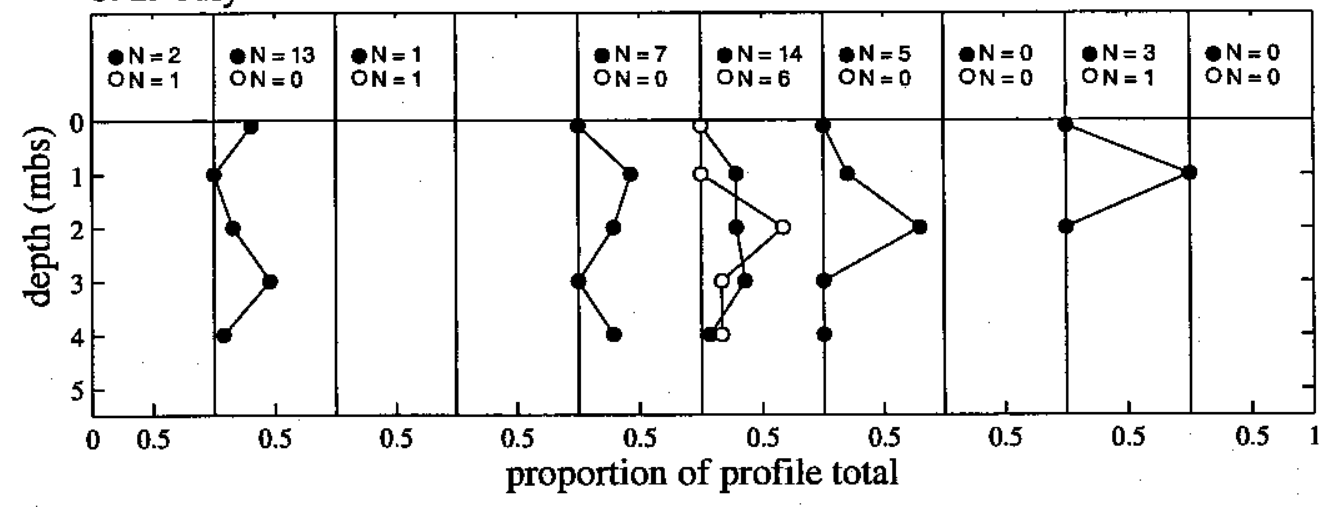

Figure 4-13: Ten-hour series of vertical plankton profiles of Crepidula spp. larvae in (o) large and (•) small size fractions for (a) $27 \mathrm{July}$, and (b) 29 July. Larval concentrations are shown as proportion of the profile total, which is indicated above each profile. Profiles with fewer larvae than samples are not plotted. 

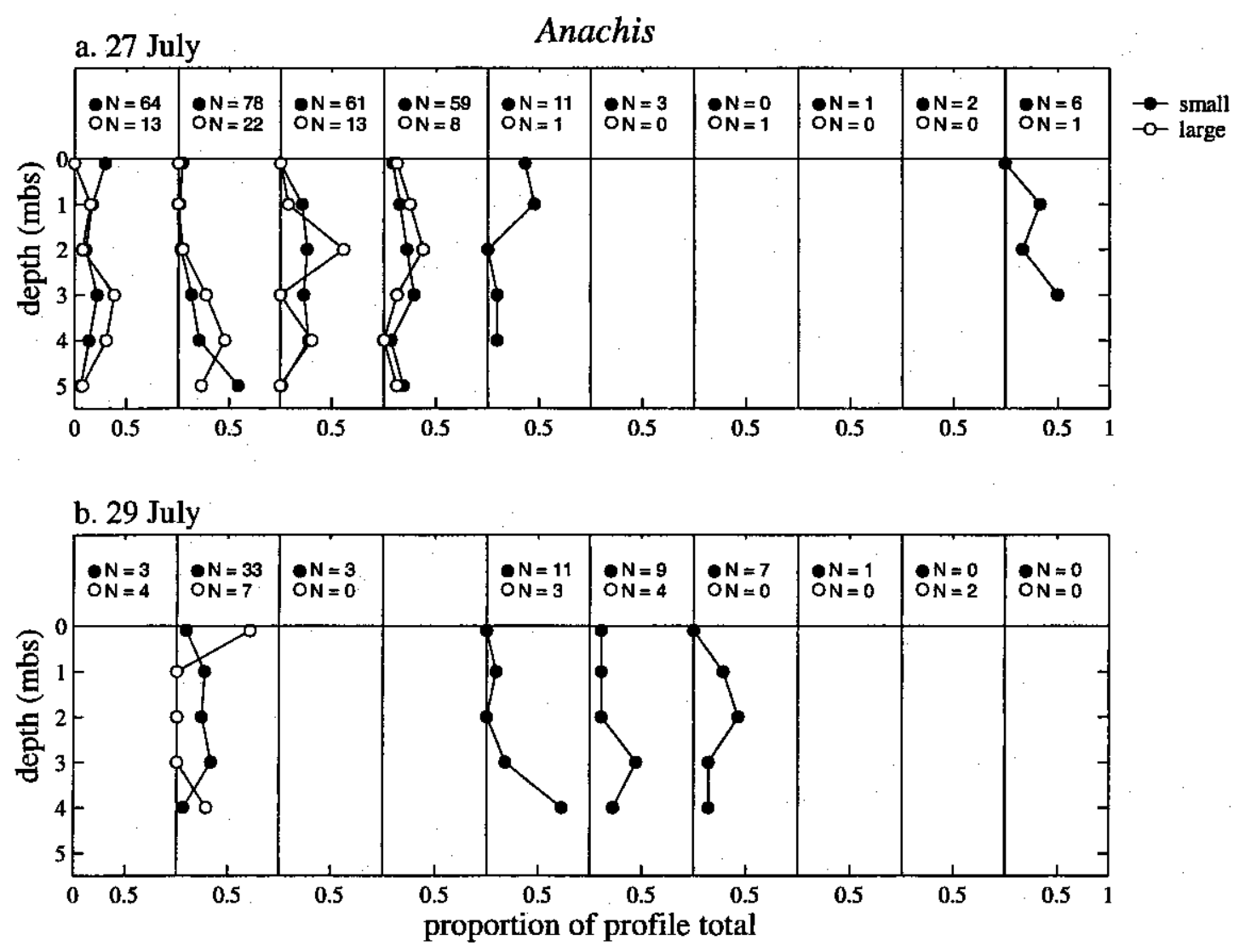

Figure 4-14: Ten-hour series of vertical plankton profiles of Anachis spp. larvae in (o) large and (•) small size fractions for (a) 27 July, and (b) 29 July. Larval concentrations are shown as proportion of the profile total, which is indicated above each profile. Profiles with fewer larvae than samples are not plotted. 

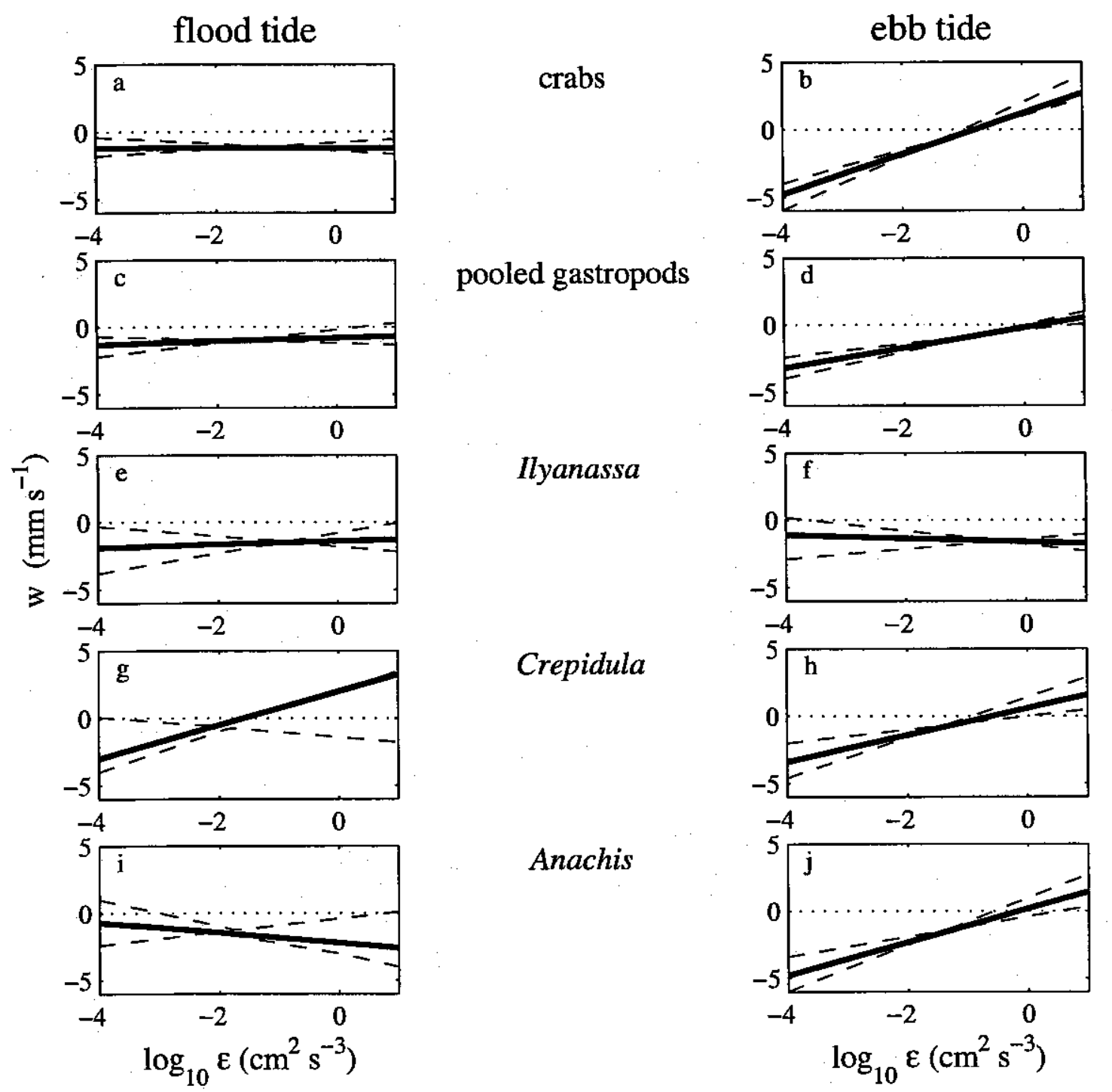

Figure 4-15: Maximum likelihood estimates of larval velocity $w=\hat{b}_{0}+\hat{b}_{1} \log _{10} \varepsilon$ vs. dissipation rate $\varepsilon$ (solid lines). Small and large size classes are combined. Separate estimates are shown for $(a, c, e, g, i)$ flood tide and $(b, d, f, h, j)$ ebb tide samples. Dotted lines indicate neutral buoyancy, dashed lines indicate a $95 \%$ confidence interval for the slope $b_{1}$. 

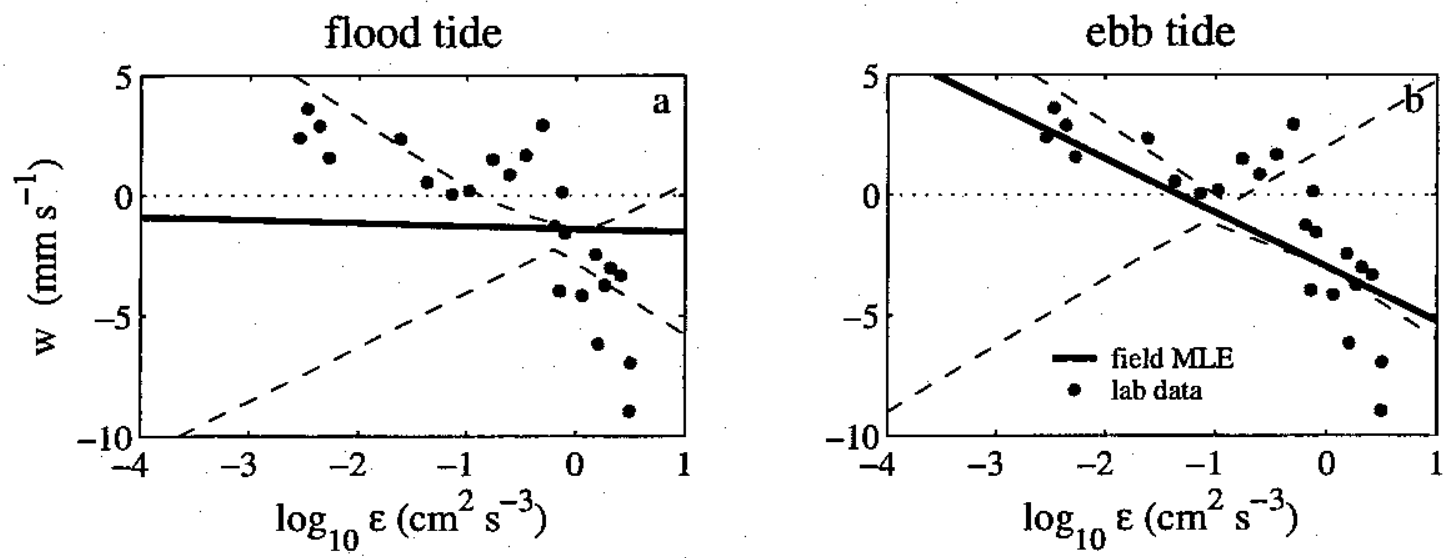

Figure 4-16: Maximum likelihood estimates of larval velocity $w=\hat{b}_{0}+\hat{b}_{1} \log _{10} \varepsilon$ vs. dissipation rate $\varepsilon$ for large Ilyanassa larvae, with laboratory data superimposed (redrawn from [9]). Separate estimates are shown for (a) flood tide and (b) ebb tide samples. Dotted lines indicate neutral buoyancy, dashed lines indicate a $95 \%$ confidence interval for the slope $b_{1}$. 


\section{Bibliography}

[1] J. C. Ayers. The hydrography of Barnstable Harbor, Massachusetts. Limnology and Oceanography, 4:448-462, 1959.

[2] F.-S. Chia, J. Buckland-Nicks, and C. M. Young. Locomotion of marine invertebrate larvae: A review. Canadian Journal of Zoology, 62:1205-1222, 1984.

[3] T.W. Cronin. Estuarine retention of larvae of the crab Rhithropanopeus harrisii. Estuarine, Coastal, and Shelf Science, 15:207-220, 1982.

[4] M.W. Denny. Biology and the Mechanics of the Wave-Swept Environment. Princeton University Press, Princeton, NJ, 1988.

[5] C. DiBacco, D. Sutton, and L. McConnico. Vertical migration behavior and horizontal distribution of brachyuran larvae in a low-inflow estuary: implications for bay-ocean exchange. Marine Ecology Progress Series, 217:191-206, 2001.

[6] T. M. Dillon and D. R. Caldwell. The Batchelor spectrum and dissipation in the upper ocean. Journal of Geophysical Research, 85:1910-1916, 1980.

[7] S. Elgar, B. Raubenheimer, and R. T. Guza. Current meter performance in the surf zone. Journal of Atmospheric and Oceanic Technology, 18:1735-1746, 2001.

[8] C.E. Epifanio, G. Perovich, A. I. Dittel, and S. C. Cary. Development and behavior of megalopa larvae and juveniles of the hydrothermal vent crab Bythograea thermydron. Marine Ecology Progress Series, 185:147-154, 1999.

[9] H. L. Fuchs, L. S. Mullineaux, and A. R. Solow. Sinking behavior of gastropod larvae (Ilyanassa obsoleta) in turbulence. Limnology and Oceanography, 49(6):1937-1948, 2004. 
[10] S.M. Gallager, C. S. Davis, A. W. Epstein, A. Solow, and R. C. Beardsley. Highresolution observations of plankton spatial distributions correlated with hydrography in the Great South Channel, Georges Bank. Deep-Sea Research II, 43:1627-1663, 1996.

[11] S.M. Gallager, H. Yamazaki, and C. S. Davis. Contribution of fine-scale structure and swimming behavior to formation of plankton layers on Georges Bank. Marine Ecology Progress Series, 267:27-43, 2004.

[12] A. Genin, J. S. Jaffe, R. Reef, C. Richter, and P. J. S. Franks. Swimming against the flow: a mechanism of zooplankton aggregation. Science, 308:860-862, 2005.

[13] R. George, R. E. Flick, and R. T. Guza. Observations of turbulence in the surf zone. Journal of Geophysical Research, 99:801-810, 1994.

[14] H. L. Grant, R. W. Stewart, and A. Moilliet. Turbulence spectra from a tidal channel. Journal of Fluid Mechanics, 12:241-263, 1962.

[15] W. D. Grant and O. S. Madsen. The continental-shelf bottom boundary layer. Ann. Rev. Fluid Mech., 18:265-305, 1986.

[16] T. F. Gross and A. R. M. Nowell. Spectral scaling in a tidal boundary layer. Journal of Physical Oceanography, 15:496-508, 1985.

[17] M.G. Hadfield and M. A. R. Koehl. Rapid behavioral responses of an invertebrate larva to dissolved settlement cue. Biological Bulletin, 207(28-43), 2004.

[18] A.D. Heathershaw. The turbulent structure of the bottom boundary layer in a tidal current. Geophys. J. R. Astr. Soc., 58:395-430, 1979.

[19] H. Hidu and H. H. Haskin. Swimming speeds of oyster larvae Crassostrea virginica in different salinities and temperatures. Estuaries, 1:252-255, 1978.

[20] H. L. Hunt, D. A. McLean, and L. S. Mullineaux. Post-settlement alteration of spatial patterns of soft shell clam (Mya arenaria) recruits. Estuaries, 26:72-81, 2003.

[21] Y. Lu and R. G. Lueck. Using a broadband ADCP in a tidal channel. Part I: Mean flow and shear. Journal of Atmospheric and Oceanic Technology, 16:1556-1567, 1999.

[22] Y. Lu and R. G. Lueck. Using a broadband ADCP in a tidal channel. Part II: Turbulence. Journal of Atmospheric and Oceanic Technology, 17(1568-1579), 1999. 
[23] R.G. Lueck and D. Huang. Dissipation measurement with a moored instrument in a swift tidal channel. Journal of Atmospheric and Oceanic Technology, 16:1499-1505, 1999.

[24] H. Ma. Spatial and temporal variation in surfclam (Spisula solidissima) larval supply and settlement on the New Jersey inner shelf during summer upwelling and downwelling. Estuarine, Coastal and Shelf Science, 62:41-53, 2005.

[25] C.C. Natunewicz and Charles E. Epifanio. Spatial and temporal scales of patches of crab larvae in coastal waters. Marine Ecology Progress Series, 212:217-222, 2001.

[26] J. P. Pawlik. Chemical ecology of the settlement of benthic marine invertebrates. Oceanography and Marine Biology Annual Review, 30:273-335, 1992.

[27] J. P. Pawlik and C. A. Butman. Settlement of a marine tube worm as a function of current velocity: Interacting effects of hydrodynamics and behavior. Limnology and Oceanography, 38:1730-1740, 1993.

[28] C. Petrone, L. B. Jancaitis, M. B. Jones, C. C. Natunewicz, C. E. Tilburg, and C. E. Epifanio. Dynamics of larval patches: spatial distribution of fiddler crab larvae in Delaware Bay and adjacent waters. Marine Ecology Progress Series, 293:177-190, 2005 .

[29] J. Pineda. Circulation and larval distribution in internal tidal bore warm fronts. Limnology and Oceanography, 44(6):1400-1414, 1999.

[30] J. M. Pringle and P. J. S. Franks. Asymmetric mixing transport: A horizontal transport mechanism for sinking plankton. Limnology and Oceanography, 46:381-391, 2001.

[31] B. Raubenheimer, S. Elgar, and T. R. Guza. Observations of swash zone velocities: A note on friction coefficients. Journal of Geophysical Research - Oceans, 109:C01027, 2004:

[32] O.N. Ross and J. Sharples. Recipe for 1-D Lagrangian particle tracking models in space-varying diffusivity. Limnology and Oceanography: Methods, 2:289-302, 2004.

[33] H. L. Sanders, E. M. Gousdmit, E. L. Mills, and G. E. Hampson. A study of the intertidal fauna of Barnstable Harbor, Massachusetts. Limnology and Oceanography, $7: 63-79,1962$. 
[34] A. Scheltema. Pelagic larvae of New England gastropods: IV. Anachis translirata and Anachis avara (Columbellidae, Prosobranchia). Vie et Milieu Serie A: Biologie Marine, 1-A:94-104, 1969.

[35] R. S. Scheltema. Metamorphosis of the veliger larvae of Nassarius obsoletus (Gastropoda) in response to bottom sediment. Biological Bulletin, 120:92-109, 1961.

[36] R.S. Scheltema. Pelagic larvae of New England intertidal gastropods. I. Nassarius obsoletus Say and Nassarius vibex Say. Transactions of the American Microscopical Society, 81(1):1-11, 1962.

[37] P.V.R. Snelgrove, J. P. Grassle, J. F. Grassle, R. F. Petrecca, and H. Ma. In situ habitat selection by settling larvae of marine soft-sediment invertebrates. Limnology and Oceanography, 44(5):1341-1347, 1999.

[38] M.T. Stacey, S. G. Monismith, and J. R. Burau. Measurements of Reynolds stress profiles in unstratified tidal flow. Journal of Geophysical Research, 104:10933-10949, 1999.

[39] J.L. Stake and P. W. Sammarco. Effects of pressure on swimming behavior in planula larvae of the coral Porites astreoides (Cnidaria, Scleractinia). Journal of Experimental Marine Biology and Ecology, 288:181-201, 2003.

[40] M. N. Tamburri, C. M. Finelli, D. S. Wethey, and R. K. Zimmer-Faust. Chemical induction of larval settlement behavior in flow. Biological Bulletin, 191:367-373, 1996.

[41] C. Thiriot-Quievreux and R. S. Scheltema. Planktonic larvae of New England gastropods. V. Bittium alternatum, Triphora nigrocincta, Cerethiopsis emersoni, Lunatia heros, and Crepidula plana. Malacologia, 23(1):37-46, 1982.

[42] J. Trowbridge and S. Elgar. Turbulence measurements in the surf zone. Journal of Physical Oceanography, 31:2403-2417, 2001.

[43] J. H. Trowbridge, W. R. Geyer, M. M. Bowen, and A. J. Williams, III. Near-bottom turbulence measurements in a partially mixed estuary: Turbulent energy balance, velocity structure, and along-channel momentum balance. Journal of Physical Oceanography, 29:3056-3072, 1999.

[44] L.-P. Wang and D. E. Stock. Dispersion of heavy particles by turbulent motion. Journal of the Atmospheric Sciences, 50:1897-1913, 1993. 
[45] J. M. Welch and R. B. Forward, Jr. Flood tide transport of blue crab, Callinectes sapidus, postlarvae: Behavioral responses to salinity and turbulence. Marine Biology, 139:911-918, 2001.

[46] J.J. Williams, P. S. Bell, and P. D. Thorne. Field measurements of flow fields and sediment transport above mobile bed forms. Journal of Geophysical Research - Oceans, 108:3109, 2003. 


\section{Chapter 5}

\section{Summary and Conclusions}

\subsection{Summary of Results}

The goals of this thesis were to quantify the behavior of gastropod larvae (mud snails Ilyanassa obsoleta) in turbulence, and to investigate how that behavior affects larval supply in a turbulent coastal inlet. I used several approaches, including laboratory, modeling, and field studies, to explore this problem. The laboratory study was necessary to quantitatively describe the response of larvae to turbulence. The model provided insights on the theoretical effects of this behavior on larval supply and settlement. The field study produced some discoveries about larval responses to turbulence that would have been very difficult to obtain in the laboratory. My results suggest that larval responses to turbulence significantly affect larval supply to benthic habitats, and that larvae from multiple habitats could use turbulence as a cue for habitat selection.

In Chapter 2, I quantified the behavior of competent mud snail larvae in laboratory turbulence. The larvae had three behavioral modes: swimming, hovering, and sinking. The proportion of larvae in the sinking mode increased exponentially with the turbulence dissipation rate. As a result, the average larval velocity shifted from positive (upward) to negative (downward) at a dissipation rate of about $\varepsilon \approx 10^{-1} \mathrm{~cm}^{2} \mathrm{~s}^{-3}$. This turbulence threshold occurs when the Kolmogorov-scale eddies are about the size of the larvae, supporting the notion that larvae detect turbulence by interacting with the smallest eddies. The shift in behavior occurred at a turbulence level found only in coastal areas, and the response to turbulence is expected to influence the supply of larvae to benthic habitats.

In Chapter 3, I used a model to characterize how turbulence-induced sinking affects 
larval supply and settlement in tidal channels or inlets. Behaving larvae (those that sink in turbulence) had higher larval supply than passive larvae (those with constant buoyancy) during flood and ebb tides, but not during slack tides. Higher larval supply gave behaving larvae a settlement advantage over passive larvae under some hydrodynamic conditions. In strong currents, behaving larvae settled more successfully than passive larvae if the settlement velocity was non-zero during flood/ebb tides. Behaving larvae settled more successfully in stronger currents than in weaker ones. These results suggest that sinking in turbulence makes larvae more likely to settle in turbulent inlets such as Barnstable Harbor.

In Chapter 4, I used data from Barnstable Harbor to estimate how larvae respond to turbulence in the field. When larval velocity was estimated as a linear function of the dissipation rate, larvae showed a strong response to turbulence. For all larval groups (crabs, gastropods, mud snails, slipper shells, and dove shells) behavior differed on flood and ebb tides, indicating that other environmental cues are also important determinants of behavior. Gastropod larvae had genus-specific behaviors, suggesting that turbulence provides a cue for large-scale habitat selection by species from multiple habitat types.

\subsection{Evolutionary Context}

There are two main hypotheses for why larvae sink in turbulence. Until recently it was generally assumed that larvae sank to avoid predators.[e.g., 9]. In this thesis I propose that larvae of coastal species use turbulence as an indicator of potentially favorable habitats, and that sinking allows larvae to get to the bottom and explore for settlement sites in coastal areas. The predator-avoidance hypothesis and settlement hypothesis are not contradictory, making it difficult to test or reject either hypothesis.

Sinking in turbulence probably increases larval fitness in multiple ways. Larvae that sink in turbulence may escape being eaten by predators [but see 4], and could have lower mortality rates during dispersal. As shown in Chapter 3, larvae that sink in turbulence are also more likely to settle into favorable habitats than into unfavorable ones, and should have lower mortality rates at or after settlement. The combined reductions in mortality rate probably reinforce the adaptive benefits of sinking in turbulence.

Some larvae may sink "mistakenly," for example in storm-generated turbulence at sea, and it is unknown whether the costs outweigh the benefits for larvae that sink in storms. Mud snail larvae sink at a turbulence threshold that is higher than the dissipation rates measured during mild offshore storms (up to $\varepsilon=10^{-2} \mathrm{~cm}^{2} \mathrm{~s}^{-3}$ in winds up to $16 \mathrm{~m} \mathrm{~s}^{-1}$ $[3,5])$. Dissipation rates in stronger storms would probably reach levels well above the 
threshold for larval sinking. It is expected that larvae would sink to calmer depths during storms [e.g., 1], but this sinking might be costly if sinking slows the return transport of larvae to coastal habitats and prevents larvae from settling. Although sinking in storms might be counterproductive for settlement, it could be beneficial for avoiding predators. Stormgenerated turbulence would increase contact rates between larvae and predators [e.g., 6, 7], and sinking would still allow larvae to reach calmer depths where contact rates with predators are lower. Any costs of sinking in storm-related turbulence are probably outweighed overall by the benefits of avoiding predators and settling more successfully.

\subsection{Unanswered Questions and Future Work}

\subsubsection{Laboratory vs. field estimates of behavior}

Responses of mud snail larvae to turbulence were estimated both in the laboratory and in the field. In the laboratory, average larval vertical velocities switched from upward to downward at $\varepsilon=10^{-1} \mathrm{~cm}^{2} \mathrm{~s}^{-3}$. In the field, larvae responded differently to turbulence on $\mathrm{ebb}$ and flood tides, and only the ebb-tide behavior estimates were similar to laboratory estimates. For both tidal stages, field estimates of larval velocity were lower than laboratory estimates except at the highest turbulence levels $\left(\varepsilon>1 \mathrm{~cm}^{2} \mathrm{~s}^{-3}\right)$.

There are several potential reasons for differences between field and laboratory estimates of larval velocity: 1 . Other physical factors (e.g. salinity, temperature) besides turbulence varied in the field, and larval behavior could depend on additional cues. 2. Temperature changes in the field could have affected larval swimming abilities by altering viscosity and by altering larval biochemical rates. 3 . Laboratory estimates of larval velocity decreased exponentially with turbulence; the linear response model used in the field study was incapable of capturing non-linear responses to turbulence. 4. Field data for large mud snail larvae were sparse, resulting in wide confidence intervals on behavior estimates. The differences between laboratory and field estimates could be due partly to differences in larval behavior under artificial vs. natural conditions, and due partly to the difficulty in obtaining good behavior estimates from field data. This uncertainty could be resolved partially by using more plankton data and by fitting non-linear behavior models to the field plankton distributions. 


\subsubsection{Omissions of the model}

The model in Chapter 3 is a simplification of boundary-layer hydrodynamics and of larval behavior. This simplified model provides insights into the effects of turbulence-induced sinking on larval supply and settlement, but many questions remain about larval settlement in the real world. For example, mud snail larvae have sediment-selection behaviors in still water [8] - are these behaviors effective in turbulent tidal inlets? If so what are the combined effects of turbulence-induced sinking and sediment selection behavior on larval settlement? In the field, larval behavior differs on flood and ebb tides - how does tidalstage dependent behavior affect temporal patterns of larval supply? Other questions relate to the characteristics of the tidal boundary layer. What happens to larvae that approach the bottom and become entrained in mobile sediments? What about larvae settling at the water's edge? How do turbulence intermittency and calm eddies around roughness elements affect the ability of larvae to settle during peak flood and ebb tides? These questions were beyond the scope of this thesis but could be answered with additional laboratory, field, and modeling studies.

\subsubsection{Future work}

Many questions remain about the ecological benefits of larval sinking in turbulence, and some of these questions could be answered with future modeling efforts. For example, how does the response to turbulence affect settlement success in patchy environments? And do larvae benefit more from settlement responses to cues in the water column or very near the bottom (i.e. substrate-selection behavior)? I hope to address these questions with a 2-dimensional model that incorporates substrate patchiness and larval substrate-selection behavior.

Thus far, horizontal larval dispersal has been treated generally as a passive process. Larval behavior in turbulence appears to influence vertical distributions and large-scale (> $\mathrm{km}$ ) settlement patterns, and probably also affects patterns of dispersal. It is now possible to predict patterns of passive larval dispersal using sophisticated physical oceanographic models (e.g. FVCOM [2]). However, physical transport models typically ignore larval behavior and contain large biological uncertainties. Uncertainties in dispersal estimates could be reduced by incorporating quantitative descriptions of larval behavior in physical transport models. 


\subsection{Significance}

In this thesis I use two new approaches for estimating larval behaviors in turbulence. The mixture model (Chapter 2) makes it possible to untangle larval behavior from fluid motion in laboratory flows. With some further development of the model and parameter-estimation algorithm, this approach could be used to estimate plankton behaviors from field-collected data including video archives from marine observatories. The maximum-likelihood analysis of larval distributions in the field (Chapter 4) provides another means of untangling larval behavior from turbulent flows. Drawbacks to this approach are the sparseness of biological data and the necessary separation distance between sites of biological and physical data collection. Despite these difficulties, this method of analysis provides quantitative behavior estimates that are an improvement over the more speculative inferences of the past.

This research supports the hypothesis that larvae use turbulence as a cue to sink to the bottom in potentially-favorable coastal habitats. It is still impossible to reject the hypothesis that larvae sink to avoid predators, but there is no reason to believe that the two hypotheses are contradictory. Modeling results (Chapter 3 ) show clearly that sinking in turbulence will increase the supply of larvae to benthic habitats in turbulent tidal inlets. Larvae that sink in turbulence are more likely to settle in favorable habitats such as Barnstable Harbor than in unfavorable, calmer areas. Genus-specific responses to turbulence (Chapter 4) suggest that the use of turbulence for habitat selection could be widespread among coastal gastropods. These results demonstrate that larval behavior is important and should no longer be ignored in models of dispersal and settlement. 


\section{Bibliography}

[1] P. J. Barile, A. W. Stoner, and C. M. Young. Phototaxis and vertical migration of the queen conch (Strombus gigas linne) veliger larvae. Journal of Experimental Marine Biology and Ecology, 183:147-162, 1994.

[2] C. S. Chen, H. D. Liu, and R. C. Beardsley. An unstructured grid, finite-volume, three-dimensional, primitive equations ocean model: Application to coastal ocean and estuaries. Journal of Atmospheric and Oceanic Technology, 20:159-186, 2003.

[3] T. M. Dillon and D. R. Caldwell. The Batchelor spectrum and dissipation in the upper ocean. Journal of Geophysical Research, 85:1910-1916, 1980.

[4] P. J. S. Franks. Turbulence avoidance: An alternate explanation of turbulence-enhanced ingestion rates in the field. Limnology and Oceanography, 46:959-963, 2001.

[5] A. E. Gargett, T. B. Sanford, and T. R. Osborn. Surface mixing layers in the Sargasso Sea. Journal of Physical Oceanography, 9:1090-1111, 1979.

[6] T. Kiorboe and B. MacKenzie. Turbulence-enhanced prey encounter rates in larval fish: Effects of spatial scale, larval behaviour and size. Journal of Plankton Research, 17:2319-2331, 1995.

[7] B. J. Rothschild and T. R. Osborn. Small-scale turbulence and plankton contact rates. Journal of Plankton Research, 10:465-474, 1988.

[8] R. S. Scheltema. Metamorphosis of the veliger larvae of Nassarius obsoletus (Gastropoda) in response to bottom sediment. Biological Bulletin, 120:92-109, 1961.

[9] C. M. Young. Behavior and locomotion during the dispersal phase of larval life. In L. McEdward, editor, Ecology of Marine Invertebrate Larvae, pages 249-278. CRC Press, 1995. 


\section{Appendix A}

\section{Web appendix (Chapter 2)}

From H. L. Fuchs, L. S. Mullineaux, and A. R. Solow. 2004. Limnology and Oceanography 49(6):1937-1948 
Linnel, Ocemongr., 4996), 2004, 1937-1948

Sinking behavior of gastropod larvae (llyanassa obsoleta) in turbulence

Heidi L. Fuchs, Lauren S. Mullineaux, and Andrew R. Solow

Web appendix 1. Modified expectation-maximization algorithm

For behavioral experiments in turbulence, the mixing proportions $\alpha_{T^{t}}$ and the fluid velocity variance $\sigma_{o}^{2}$ were estimated by the expectation-maximization (EM) algorithm below. We used measured values for the mean flow velocity $\mu_{s}$ and maximum likelihood estimates (from still-water data) for the behavioral velocity means $\mu_{i}$ and variances $\sigma_{f}^{2}$ of larvae in each mode. The relative mean velocity $\mu_{T}$ for each mode was known $\left(\mu_{T^{i}}=\mu_{o}+\mu_{7}\right)$. Here, $i=(1: g)$ is the mixture component index for $g=3$ modes, $j=(1: n)$ is the data value index for $n$ measurements, and $k$ is the iteration index. The probability density of a measured velocity $w_{1 /}$ given that it was drawn from a normal distribution with parameters $\theta_{T^{i}}^{k_{i}}=\left(\mu_{T^{i}} ; \sigma_{T^{k}}^{z^{k}}\right)$, is $f_{i}\left(w_{\mathrm{L} j} ; \theta_{T^{i}}^{k^{i}}\right)$. The probability that data value $j$ came from component $i$, given the parameters at step $k_{\text {, is }} \tau_{i j}^{k}$. The expected value of the log-likelihood function, given the parameters at step $k$, is $L\left(\theta_{T} ; \theta_{T}^{*}\right)$. The algorithm was repeated until the value of $L$ increased by $<10^{-4}$ per iteration. Only Eqs. 4 and 5 differ from the standard algorithm described in McLachlan and Peel (2000).

E-Step

$$
\tau_{i j}^{k}=\frac{\alpha_{T^{\prime}}^{k} f_{i}\left(w_{L j} ; \theta_{T^{i}}^{k}\right)}{\sum_{h=1}^{g} \alpha_{T^{h}}^{k} f_{h}\left(w_{L^{\prime} j} ; \theta_{T^{k}}^{k}\right)}
$$

Reference

MCL.aChlan, G., AND D. PEEL. 2000. Finite mixture models. John Wiley \& Sons. 


\section{Appendix B}

\section{Diffusivity and Dissipation Estimates for Maximum Likelihood Analysis (Chapter 4)}

For maximum likelihood analysis of plankton profiles, the diffusivity and dissipation terms in $(4.5,4.6)$ had to be accurate, to minimize bias in the estimates of larval vertical velocity, as well as continuous, to allow numerical solution of (4.5). Simple models of eddy diffusivity and dissipation rate were poor predictors of measured values, particularly on ebb tides. Measured diffusivity and dissipation rates were calculated at 10-minute intervals and were discontinuous. Therefore, high-order polynomial functions were fitted to field data to produce diffusivity and dissipation functions that were both accurate and continuous for use in (4.5).

Smooth diffusivity functions $K_{s}=f(z / H, t)$ were fitted to measured diffusivity $K_{p}$ for each plankton sampling period. No near-bottom diffusivity measurements were available because ADCP measurement bins began at $z_{b}=1.5 \mathrm{~m}$. In order to fit $K_{s}$ over the entire water column, the diffusivity was extrapolated from $z_{b}=1.5$ down to $z=0$. The diffusivity between the lowest bin and the bottom was estimated in $25 \mathrm{~cm}$ increments by

$$
K_{p}(z, t)=\overline{u^{\prime} w^{\prime}} / \frac{\partial U^{*}}{\partial z}
$$

where the Reynolds stress was extrapolated to the bottom using

$$
\overline{u^{\prime} w^{\prime}}=\left.\overline{u^{\prime} w^{\prime}}\right|_{z_{b}}\left(1-\frac{z}{H}\right)
$$


The along-channel velocity shear was extrapolated to the bottom by assuming that $U(z)$ decreases linearly vs. $\ln z$ to $U(0)=0$ (the no-slip condition), so

$$
\frac{\partial U^{*}}{\partial z}=\frac{U\left(z_{b}\right)}{\ln z_{b}} \frac{1}{z}
$$

A polynomial response surface was fitted to $K_{p}(z / H, t)$ on a $\log _{10}$ scale to produce a continuous-time diffusivity function $K_{s}$. The polynomial orders of $z$ and $t$ were selected as those that provided the best fit to the data for each sampling period (Table B.1).

Smoothed field data were used likewise for the turbulence dissipation rate in (4.6). The dissipation rate between the lowest bin $\left(z_{b}=1.5 \mathrm{~m}\right)$ and the bottom was estimated in 25 cm increments by

$$
\varepsilon_{p}=\frac{u_{*}^{3}}{\kappa z}\left(1-\frac{z}{H}\right)
$$

where $\kappa$ is von Karmann's constant $(=0.4)$. A response surface $\varepsilon_{s}=f(z / H, t)$ was fitted to the measured dissipation rate $\varepsilon_{p}$ on a $\log _{10}$ scale for each plankton sampling period, using the orders of $z$ and $t$ that provided the best fit (Table B.1).

Table B.1: Orders of $z$ and $t$ that provided the best fits of $K_{s}$ and $\varepsilon_{s}$ to measured diffusivity $K_{p}$ and dissipation rate $\varepsilon_{p}$ for plankton sampling periods (Ch. 4). Also given are $R^{2}$ for regressions of $K_{s}$ vs. $K_{p}$ and $\varepsilon_{s}$ vs. $\varepsilon_{p}$.

\begin{tabular}{c|ccc|ccc}
\hline & \multicolumn{3}{|c|}{$\bar{K}_{s}$} & \multicolumn{3}{|c}{$\varepsilon_{s}$} \\
\hline sampling period & $z$ order & $t$ order & $R^{2}$ & $z$ order & $t$ order & $R^{2}$ \\
\hline 22 July & 20 & 9 & 0.62 & 20 & 7 & 0.68 \\
27 July & 19 & 6 & 0.57 & 20 & 9 & 0.70 \\
29 July & 20 & 10 & 0.59 & 19 & 6 & 0.64 \\
\hline
\end{tabular}

